LA W RENCE LIVERMORE N A TIO NAL LABORATORY

\section{Recent Developments in X-ray Imaging Technology}

R. G. Lanier

October 3, 2012 
This document was prepared as an account of work sponsored by an agency of the United States government. Neither the United States government nor Lawrence Livermore National Security, LLC, nor any of their employees makes any warranty, expressed or implied, or assumes any legal liability or responsibility for the accuracy, completeness, or usefulness of any information, apparatus, product, or process disclosed, or represents that its use would not infringe privately owned rights. Reference herein to any specific commercial product, process, or service by trade name, trademark, manufacturer, or otherwise does not necessarily constitute or imply its endorsement, recommendation, or favoring by the United States government or Lawrence Livermore National Security, LLC. The views and opinions of authors expressed herein do not necessarily state or reflect those of the United States government or Lawrence Livermore National Security, LLC, and shall not be used for advertising or product endorsement purposes.

This work performed under the auspices of the U.S. Department of Energy by Lawrence Livermore National Laboratory under Contract DE-AC52-07NA27344. 


\title{
Recent Developments in X-ray Imaging Technology
}

\author{
Robert G. Lanier \\ ${ }^{1}$ Lawrence Livermore National Laboratory \\ Livermore, CA
}

June 12, 2012

(IM \# 658363)

LLNL-TR-587512

This work performed under the auspices of the U.S. Department of Energy by Lawrence Livermore National Laboratory under Contract DE-AC52-07NA27344.

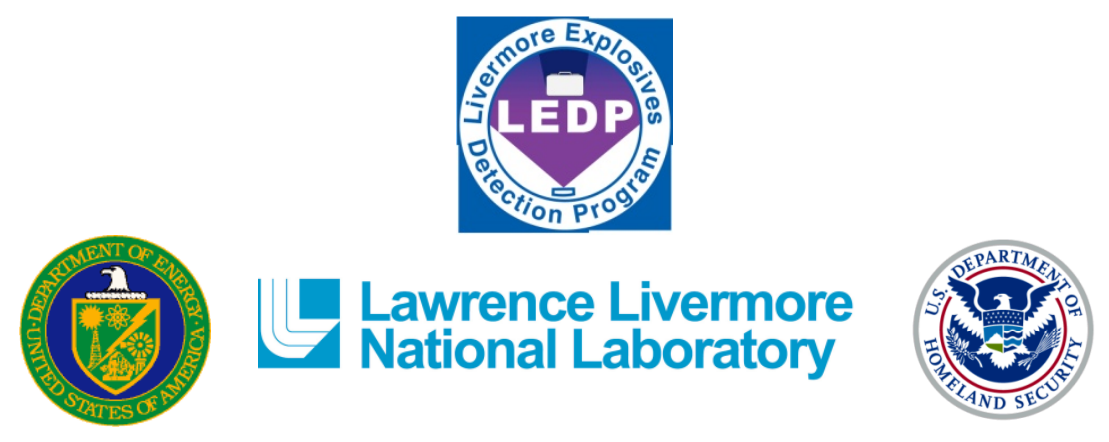




\section{Specific Recommendations:}

\section{Executive Summary}

A review of recent developments in the technology of x-ray imaging hardware has been completed. Based on this review, we believe that the following items merit more detailed scrutiny in regards to their applications to US Homeland Security interests:

- Fujifilm's 17" x 17" flat panel detectors which are part of the company's FDR AcSelerate x-ray imaging systems

- GE Healthcare's Gemstone ${ }^{\mathrm{TM}}$ scintillators for their use in CT units

- CZT baggage scanning units under development by either Endicott Interconnect Technologies or Redlen Technologies and which employ a new "XENA" TM" IC with NEXISTM protocols.

- Dual Energy Line- Scanning devices from either Hamamatsu Photonics (C10800 series) or from the X-Scan Imaging Corporation (XD8800 and XDR8800 Series Line-Scan Camera).

The bases for these recommendations, as well as other not highlighted above, are noted below. The footnotes document company contact information. Beyond the text highlighting the recommendations, a number of appendices have been added which document the research conducted for this review.

\section{Introductory Comments}

A review of recent developments in the technology of x-ray imaging hardware has been completed. The topics reviewed are presented in detail in the appendices. In most cases, either a short report was written to summarize developments in a particular area (Appendices i - iv) or tables have been assembled which provide a snapshot compilation of hardware items currently available from reputable vendors (Appendices v - vii). Finally, Appendix viii is a selected list of titles that speak to various aspects of $\mathrm{x}$-ray imaging technology.

In product information provided by vendors, it is often the case that a vendor will indicate his willingness to partner with $\mathrm{R} \& \mathrm{D}$ centers to develop technologies which may not be available as market items but which could be developed given current state-of-the art knowledge. Reference to these vendors is made in the body of the text or in the footnotes. 
Looking into the near future, we offer suggestions of new technology developments which are only now finding their way into the commercial arena or which are shortly expected to make their way there. Most new innovations appear in medical imaging where the emphasis is on maximizing image quality and minimizing patient dose. For industrial applications and for applications directed to US Homeland Security interests, radiation dose is less of a concern unless human subjects are involved.

Acknowledging a short-term perspective and accepting the caveat that medical and industrial
Figure 1: Fujifilm's ISS Technology. By reading data from the incident side of the detector, light is collected before it can be attenuated or diffused, thereby significantly improving MTF and DQE.

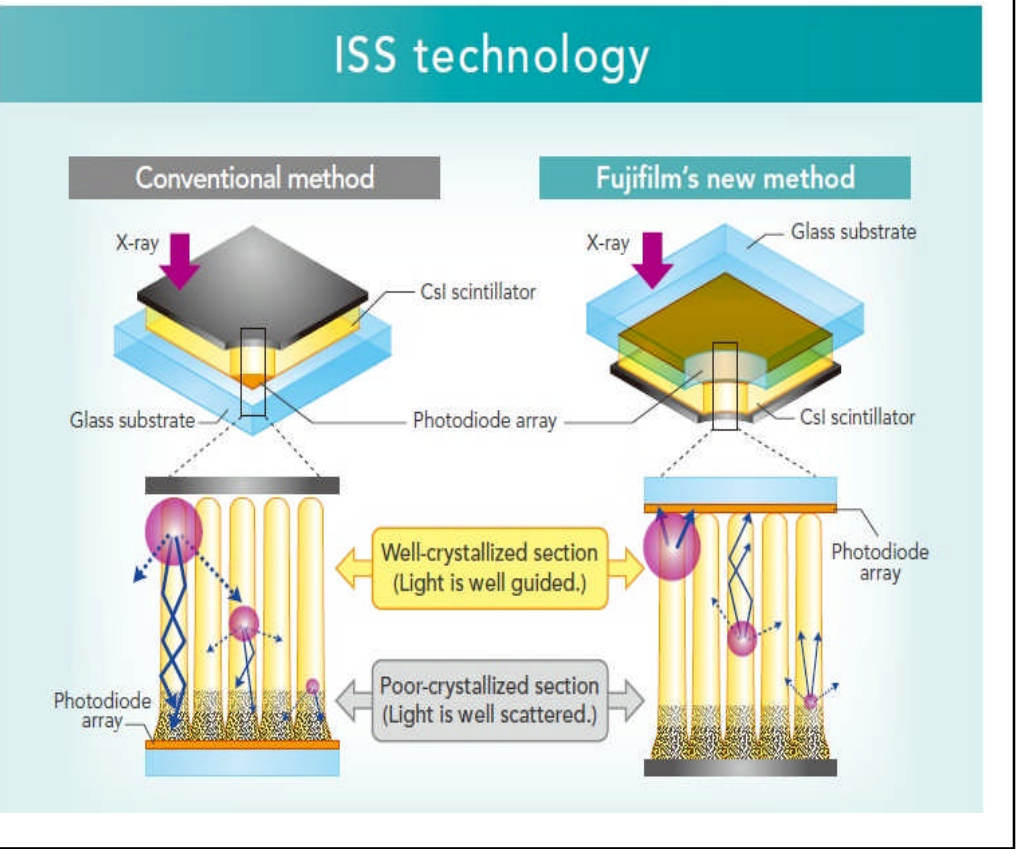
imaging applications some time have competing concerns, we note below the following specific areas of developing x-ray imaging hardware:

- Amorphous Selenium (a-Se) flat panel technology with active pixel technology.

- Structured CsI (Cesium Iodide) scintillators

- TFT (thin-film transistor) and CMOS (complementary metal-oxidesemiconductor) technology

- CZT (cadmium-zinc telluride) arrays and their associated electronics.

- Ceramic scintillators

These areas continue to be the subject of a great deal of research and development and none can be considered a "mature technology". Nevertheless, they are sufficiently developed that vendors have incorporated them into their future business models. This is a clear expression of confidence that the technology improvements will have utility and durability under real-world conditions. Moreover, the fact that industry has made investments in these areas virtually 
guarantees that continued improvements are expected in order to protect capital investments.

Finally, throughout the information presented in the appendices we touch on and reference items that would be arguably considered more "next generation technologies". These include, for example, new scintillators such as $\mathrm{HgI}_{2}, \mathrm{PbI}_{2}$, $\mathrm{PbO}_{2}, \mathrm{GaAs}$, lutetium-doped crystals, highpressure gas sensors, large CZT arrays currently built for and used for astronomical research applications, indirect flat-panel imagers with avalanche gain, etc.
Figure 2: Fujifilm flat-panel detector.

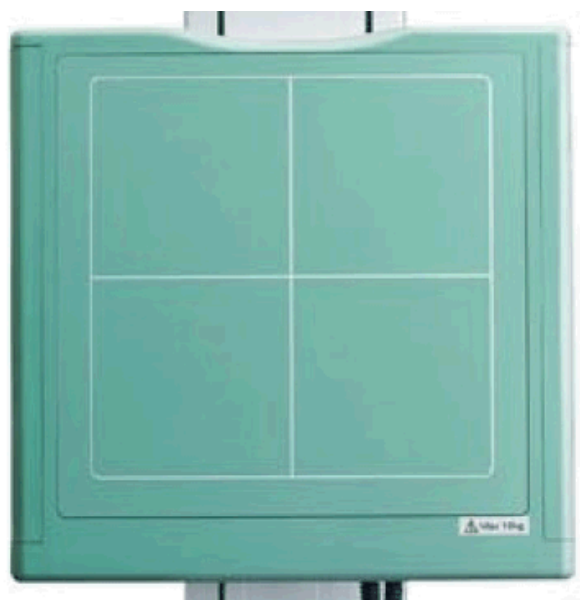

\section{Flat panel Imagers}

\section{Fujifilm Units}

There are at least two commercial flat panel units that appear at the forefront of imaging technology. Both are developed by Fujifilm $^{\mathbf{1}}$ and are the primary imaging devices incorporated into the company's "FDR AcSelerate System". In summary, the technology associated with the two units is noted below. Both are rated for x-ray energies up to a maximum of $150 \mathrm{kVp}$ and each displays an active pixel area of $2880 \times 2880$ with a pixel pitch of $150 \mu \mathrm{m}$ :

(1) A CsI 17" x 17" wireless panel (7.9 lbs) that employs what the vendor calls ISS (Irradiated Side Sample, see Figure 1) technology which allows the detector to capture radiation signals on the same side of the irradiated subject and closest to the area where the signals are strongest. The vendor claims enhanced MTF and DQE relative to other flat panel units ${ }^{2}$.

(2) an amorphous selenium (a-Se) direct-conversion flat panel unit (17" x 17 “). The vendor claims reduced radiation dose lifespan and enhanced MTF and DQE relative to other flat panel units.

In publicly available company sales brochures, the Fujifilm's FDR AcSelerate system is advertised with either panel (1) or panel (2) packaged in the same

\footnotetext{
${ }^{1}$ Medical Technical Support:; (888) FUJI-MED (385-4633); (800) 272-8465; (203) 602-3580

${ }^{2}$ A Fujifilm representative noted that a Gadox scintillator can be substituted for Csl, with the unit still incorporating the ISS technology.
} 
external housing (see Figure 2). This information is available in individual brochures without any cross referencing leading to confusion as to which flat panel is actually used in the FDR AcSelerate system. In discussion with a representative from $\mathbf{F u j i f i l m}$, the company has apparently decided that the CsI alternative is technologically superior to the a-Se unit and cheaper to manufacture. Therefore, since the precise imaging technology is generally transparent to most users, the company is quietly making the transition to the CsI unit. The Fujifilm representative expressed his willingness to work with US Homeland Security technical experts on either technology for baggage screening applications.

\section{The Dexela Flat Panel Units}

The Dexela ${ }^{3}$ flat panel CMOS $\mathrm{X}$-ray detector is a good alternative flat-panel detector. Dexela units use a crystalline silicon CMOS sensor which the vendor claims is superior to units created with TFT technology in flexibility, stability, speed and low noise and which results in higher resolution images. A unit available for non-destructive testing is shown in Figure 3. The panel offers active pixel sensors with a pixel pitch of $74.8 \mu \mathrm{m}$ and a $3888 \times 3072$ active pixel area.

\section{Figure 3: Dexela 2923 Flat Panel 12" x 9" Imager for Non- destructive testing.}

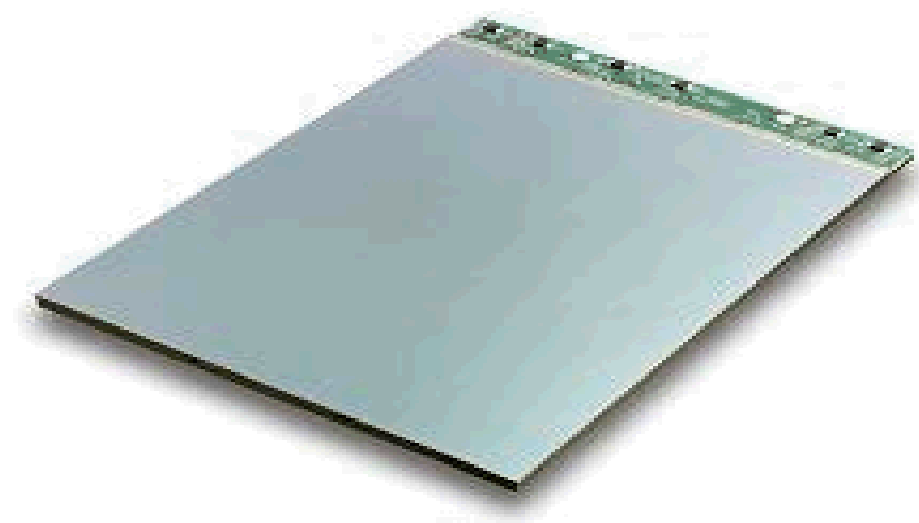

${ }^{3}$ Dexela Limited (UK Office) Wenlock Business Centre 50-52 Wharf Road London N1 7EU; PHONE: +44 (0)20

7148 3107; FAX: +44 (0)20 71483107 
Flat panels from other Vendors

As noted in Appendix vii companies such as Perkin-Elmer ${ }^{4}$, General Electric ${ }^{5}$, Teledyne $^{6}$, Hamamatsu ${ }^{7}$, Varian Medical Systems ${ }^{8}$, Allied Vision ${ }^{9}$, KonicaMinolta $^{10}$, etc., offer what appear to be reasonably comparable units based on $\mathbf{a - S i}$ technology, using Gadox or CsI scintillators and supported with various electronic designs.

Scintillators for CT (Computed Tomography) Applications

An important issue within the medical community is to obtain quality CT scans at the lowest possible patient dose. This concern has spurred the development of efficient scintillators that provide high light output with minimum

Figure 4: GE Gemstone scintillator. Displays show the unit mounted in a CT array and an individual unit with its associated electronics.
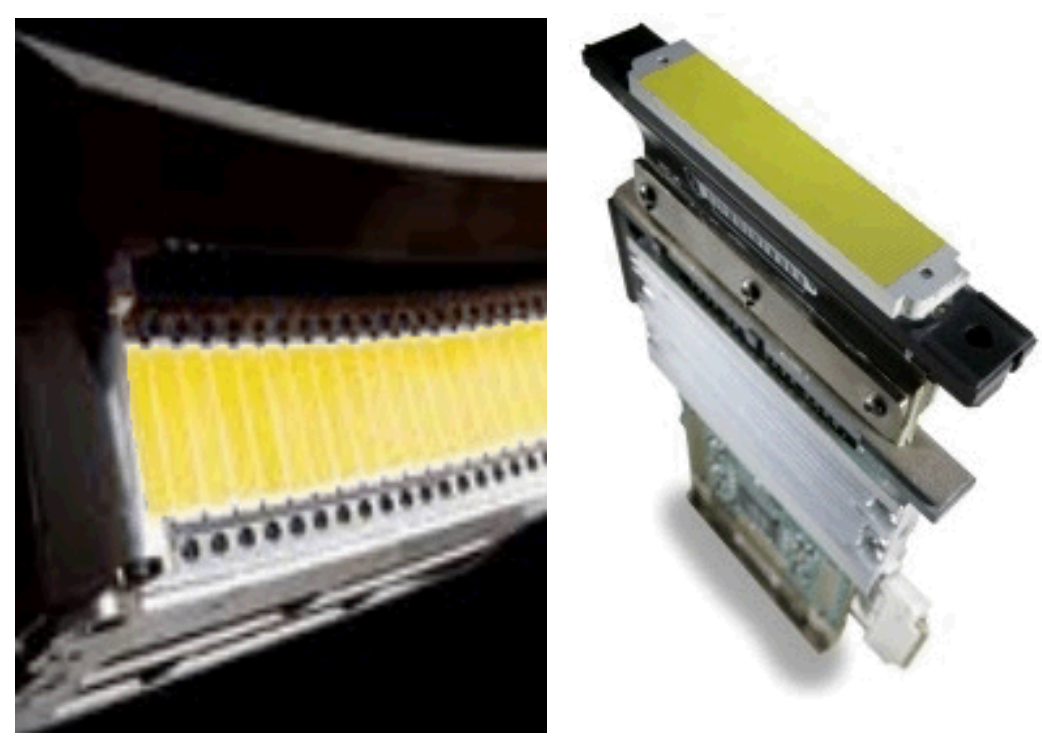
after-glow along with radiation stability, chemical stability, and mechanical strength.

Gemstone $^{\text {TM }}$ (see Figure 4) is a transparent polycrystalline scintillator for CT from GE Healthcare. Competing products are HiLight ${ }^{\mathrm{TM}}$ (also from GE Healthcare)

\footnotetext{
${ }^{4}$ Customer Care USA Telephone : 800-762-4000 or +1 203-925-4602 FAX : +1 203-944-4904 CustomerCareUS@perkinelmer.com ; Corporate Headquarters 940 Winter Street Waltham Massachusetts 02451 USA ${ }^{5}$ GE Healthcare Worldwide - gehealthcare.com; 930 East Arques Avenue Sunnyvale, CA 94085; (408) 737-3000

$6 \frac{\text { Teledyne Microelectronics }}{}$ 12964 Panama Street, Los Angeles, CA 90066 310.822.8229 • 800.518.1015 | microelectronics@teledyne.com

${ }^{7}$ Hamamatsu City Building7F, Tenma 312-32, Naka-ku,Hamamatsu, Japan Zip code:430-0935 Tel (+81)53-4564960 Fax (+81)53-459-3915

${ }^{8}$ Varian Medical Systems, Inc., 3100 Hansen Way Palo Alto, CA 94304-1038

${ }^{9}$ (Head Office, Manufacturing, Customer Care, Technical Support) Allied Vision Technologies GmbH

;Taschenweg 2a; 07646 Stadtroda, Germany Tel.: +49.36428.677-0 Fax.: +49.36428.677-28

${ }^{10}$ Konica-MinoltaKonica Minolta Medical Imaging USA, Inc; http://www.konicaminolta.com/medicalusa/about/index.html
} 
and $\operatorname{GOS}^{11}$ (from Hitachi ${ }^{12}$, Toshiba ${ }^{13}$, Siemens ${ }^{14}$, and Philips ${ }^{15}$ ). GE claims that Gemstone $^{\mathbf{T M}}$ is the only new CT scintillator developed in the past two decades and further claims that it delivers the best performance characteristics compared to other competing units. It has a primary decay time of $\sim 30 \mathrm{~ns}$, or 100 times faster than GOS $(2-3.4 \mu \mathrm{s})$. Gemstone ${ }^{\mathbf{T M}}$ has very low afterglow (about $20 \%$ of GOS at $40 \mathrm{~ms})$, extremely low radiation damage $(0.03 \%$ vs. $0.65 \%$ for GOS $)$, and very good chemical durability, mechanical properties, uniformity, and manufacturability. Gemstone ${ }^{\text {TM }}$ has a cubic garnet crystal structure and is based on a rare earth composition system that was invented by GE. It is made into a transparent polycrystalline material with processes developed by GE's scientists.

Appendix vii lists some scintillator providers and Appendix iii describes some developments in scintillator research along with collections of new scintillators and their associated properties.

\section{Cadmium-Zinc-Telluride (CZT) Imaging Devices}

Over the last two decades, the semiconductor CdZnTe (CZT) has emerged as the material of choice for room temperature detection of hard $\mathrm{X}$-rays and soft $\gamma$-rays ${ }^{16}$. The techniques for growing the
Figure 5: CZT Cardiac Imager from GE

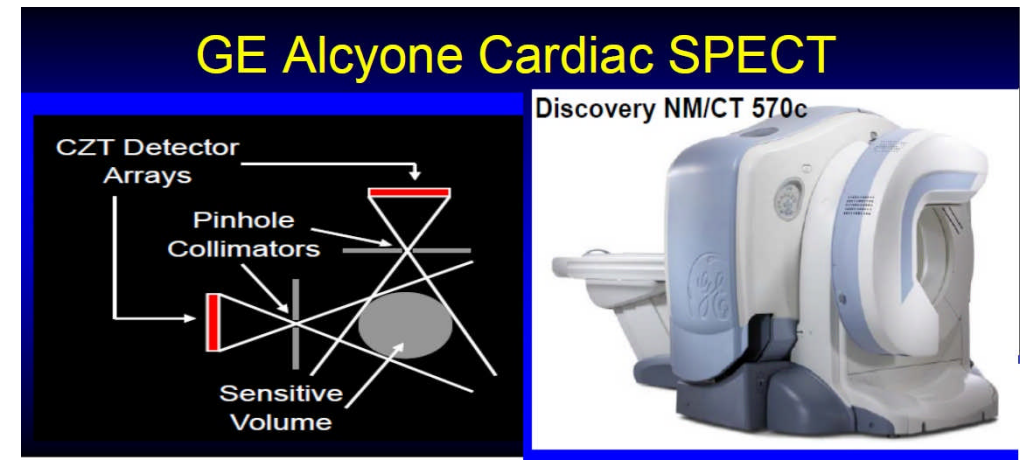

crystals, the design of the detectors, and the electronics used for reading data from the detectors have been considerably improved over the last few years ${ }^{17}$. The commercialization of this technology is currently focused on cardiac imaging with devices such as D-SPECT (Spectrum Dynamics ${ }^{18}$ ), GE Healthcare's Alcyone

\footnotetext{
${ }^{11}$ The GOS or Gadox scintillators are made of polycrystalline Gadolinium Oxysulfide crystals with dopants of either Praseodymium (Pr), Terbium ( $\mathrm{Tb}$ ) or Europium (Eu) determined by the requirements of the application.

12 Hitachi HQ; Marunouchi 1-6-1, Chiyoda-ku, Tokyo 100-8220, JAPAN Tel: +81-(0)3-3258-1111 (Switchboard)

${ }^{13}$ Toshiba America Medical Systems, Inc. 2441 Michelle Drive Tustin, CA 92780 (800) 421-1968

${ }^{14}$ United States Headquarters Siemens Medical Solutions USA, Inc. 51 Valley Stream Parkway Malvern, PA 19355

${ }^{15}$ Philips Healthcare 3000 Minuteman Road Andover, MA 01810-1099

${ }^{16}$ The items described in this section are from approximately 2009 or later.

${ }^{17}$ See for example H. Krawczynski, I. Jung, J. Perkins, A. Burger, M. Groza, Proc. SPIE 5540 (2004) 1. astroph/0410077; H. Chen, S.A. Awadalla, F. Harris, et al., IEEE Trans. Nucl. Sci. 55 (2008) 1567 and Q. Li, A. Garson, P. Dowkontt, J. Martin, et al., in: Proc. NSS/MIC conference, 484, 2008. Available from: arXiv:0811.3201.

${ }^{18}$ Spectrum Dynamics (Israel) Ltd. 22 Bareket Street North Industrial Park POB 3033 Caesarea 30889, Israel Tel: (+972) 737374500 Fax: (+972) 737374501
} 
technology family of SPECT detectors (see Figure 5), Cardius X-ACT (Digirad ${ }^{19}$ ) and IQSPECT (Siemens). CZT has a marked advantage in the clinical setting because quality images can be obtained with significantly reduced radiation doses.

Research continues emphasizing the use of CZT detector arrays for baggage screening. Endicott Interconnect Technologies ${ }^{20}$ claims that it has commercialized a prototype automated linear baggage inspection unit (ABIS) using a linear array of CZT detectors (see Figure 6) with a throughput of 1200 bags/hour.

Additionally, Redlen Technologies ${ }^{21}$ provides highresolution CZT detectors for medical and commercial applications. From information provided by a company representative, Redlen expects to field its first commercial screening unit in 2014. The company further claims to be working with others who are developing baggage scanning systems to use CZT technology to address the removal of the European Union (EU) ban on liquid carry ons.

\section{Figure 6: ABIS (Automated Baggage Inspection System)} Prototype CZT linear baggage scanning system.

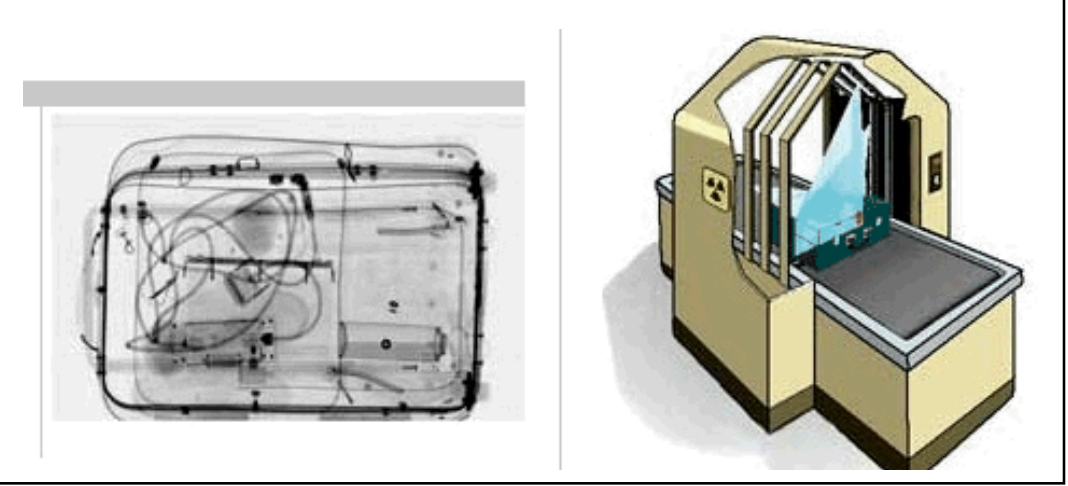


The enabling technology for the ABIS (Automated Baggage Inspection System) is provided by a modular detector system ${ }^{22}$. This is built around custom linear CZTdetector pixel arrays which are read out by a proprietary signal processing integrated circuit (IC) embodying fast, multiple energy-band output functions. The design of the CZT arrays was modified during subsequent efforts to achieve improved photon-counting performance under high-flux conditions.

More recently ${ }^{23}$, a redesign of the readout integrated circuit was undertaken to enhance energy-binning and rate capabilities and address the more practical issue of process longevity. To bring together the benefits of the optimized CZT detector and a new "XENA ${ }^{\text {TM" }}$ IC (X-ray ENergy-binning Applications), the NEXIS $^{\text {TM }}$ (N-Energy $\mathbf{X}$-ray Image Scanning) detector system was developed. NEXIS supersedes the original ABIS design (Figure 7

shows an image taken with the new system) and incorporates features that favor product manufacturability and commercial viability.

In Appendix i and ii, we describe other activities focused on the development of CZT detector arrays for a variety of applications.

\section{$\underline{\text { Linear x-ray Scanning Devices }}$}

An alternate approach to conventional digital cone-beam radiography is to synchronize the scan of a linear x-ray sensor with a narrow

Figure 7: Depiction of a collimated stationary $x$-ray beam preparing to image a moving object with a stationary sensor.

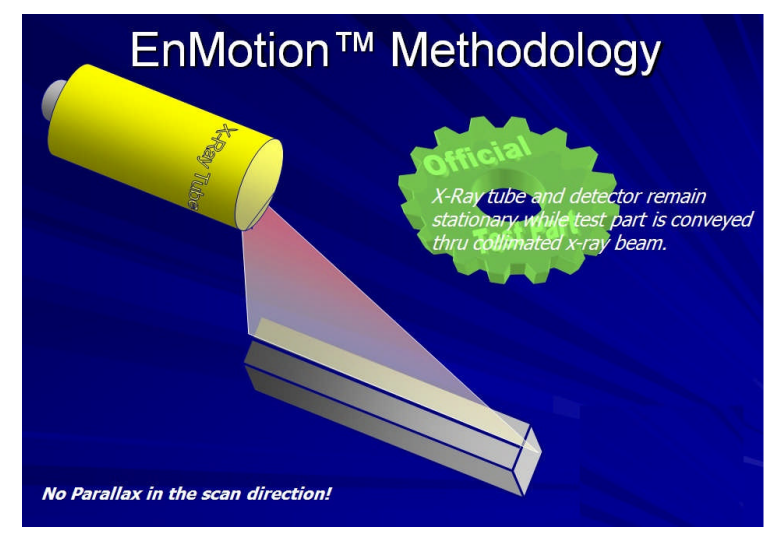

Figure 8: Sens-Tech supplies a range of linear $X$-ray sensors which use the XDAS detector head and signal processing boards to provide an array of any required length.

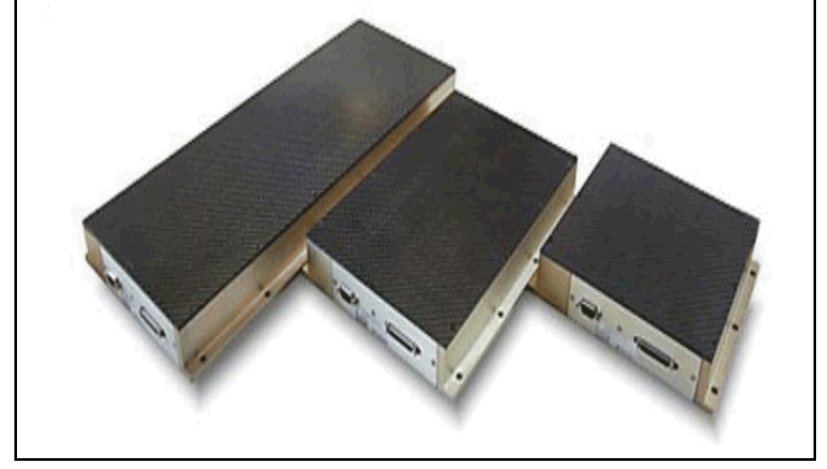
fan-beam x-ray source along the imaging field. The advantage of this technique is that allows the scan of large fields while minimizing the sensor area and also minimizing the amount of scattered radiation reaching the detector. The main disadvantages are the need for precise motion control of the source and sensor and

\footnotetext{
${ }^{22}$ Developed by NOVA R \& D NOVA R\&D, Inc., 833 Marlborough Avenue, Suite 200, Riverside, CA $92507-$ 2133, USA

${ }^{23} \mathrm{http} / / / \mathrm{s} 3$.amazonaws.com/zanran_storage/www.novarad.com/ContentPages/16825031.pdf
} 
the need to maintain stable $\mathrm{x}$-ray output over the duration of the scan. However, fixing the detector source ${ }^{24}$ and sensor (Figure 7) can eliminate the potential synchronization problems.

Hamamatsu Photonics has introduced the $\mathbf{C 1 0 8 0 0}$ series of "Dual Energy" X-ray Line Scan Cameras specifically designed for imaging materials and objects requiring improved detection and composition classification. The technology allows for combining two radiographs acquired at two distinct energies (high energy and low energy) which allows density as well as other material characteristics to be determined. The vendor offers a variety of combinations of scintillator, filters and gain factor in order to optimize object and X-ray conditions for a users applications The vendor further suggests contacting the company for information regarding interest in specific or unique applications.

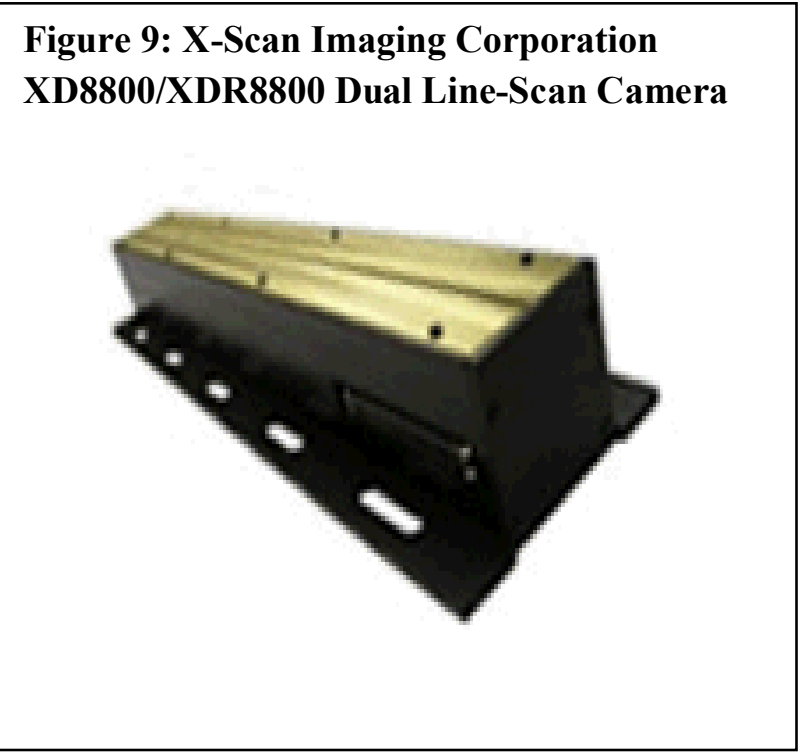

Sens-Tech Ltd (STL) is a UK company which describes itself as "specializing in the supply of X-ray detection and data acquisition systems which are designed for industrial and security applications." It claims the development of a flexible detection system architecture that enables systems to be customized for specific linescan and CT imaging applications. Descriptions provided by the company show examples of the use of this imaging technology in wood mills, particle board manufacture and steel thickness measurement. The company describes an "XDAS solution" which is alleged to provide a flexible approach for building customized detector configurations. The company supplies a range of linear X-ray sensors which uses an XDAS detector head and signal processing boards to provide an array of any required length. Detector pitch can be $2.5 \mathrm{~mm}, 1.6 \mathrm{~mm}, 0.8 \mathrm{~mm}$ or $0.4 \mathrm{~mm}$. X-rays are detected using silicon photodiodes, with a range of scintillation materials. Gadox $\left(\mathrm{Gd}_{2} \mathrm{~S}_{2} \mathrm{O}\right), \mathrm{CsI}(\mathrm{Tl})$ and $\mathrm{CdWO}_{4}$ are used to cover the X-ray energy range of $20 \mathrm{keV}$ to $300 \mathrm{keV}$.

\footnotetext{
24 "EnMotion" is a trademark of the Envision CmosXray LLC, 7800 King Street Anchorage, Alaska 99518. The company also provides an array of imaging devices for service to petroleum interests.
} 
The X-Scan Imaging Corporation XD8800 and XDR8800 Series Line-Scan Camera offers dual energy imaging capability to differentiate materials in a variety of inspection applications by simultaneously capturing high-energy and lowenergy images. The XDR8800 Series is a more compact version of the earlier XD8800 Series. Specific features include; X-ray energy range options for low (25$100 \mathrm{keV}$ ) and high (45-160 KeV) energy imaging, 16-bit A/D conversion, low noise, high sensitivity, variable scan speed with position synchronization.

\section{Appendices}

i. Cadmium Zinc Telluride (CZT) Detectors: Imaging Applications

ii. The HEXITEC Project

iii. Scintillators

iv. Comparison of CMOS Detectors for Mammography

v. A Collection of Recent Imaging Technology Developments

vi. Data Sheets for Commercial Medical Imaging Devices (2002 - 2008)

vii. Detectors and Scintillator Materials; A Survey of Market Availability (Parts 1 and 2)

viii. Titles 


\title{
Appendix i: Cadmium Zinc Telluride (CZT) Detectors: Imaging Applications
}

\author{
Robert G. Lanier
}

December 12, 2011

\section{Executive Summary}

Over the last two decades, the semiconductor CdZnTe (CZT) has emerged as the material of choice for room temperature detection of hard X-rays and soft $\gamma$-rays ${ }^{25}$. The techniques for growing the crystals, the design of the detectors, and the electronics used for reading data from the detectors have been considerably improved over the last few years $^{26}$. Moreover, the development of direct deposition methods for polycrystalline materials offers a promising route to large area imaging devices in the future. In what follows, a snapshot of the current state of the technology is presented. The discussion includes selected examples of both practical applications and results of forward-looking research.

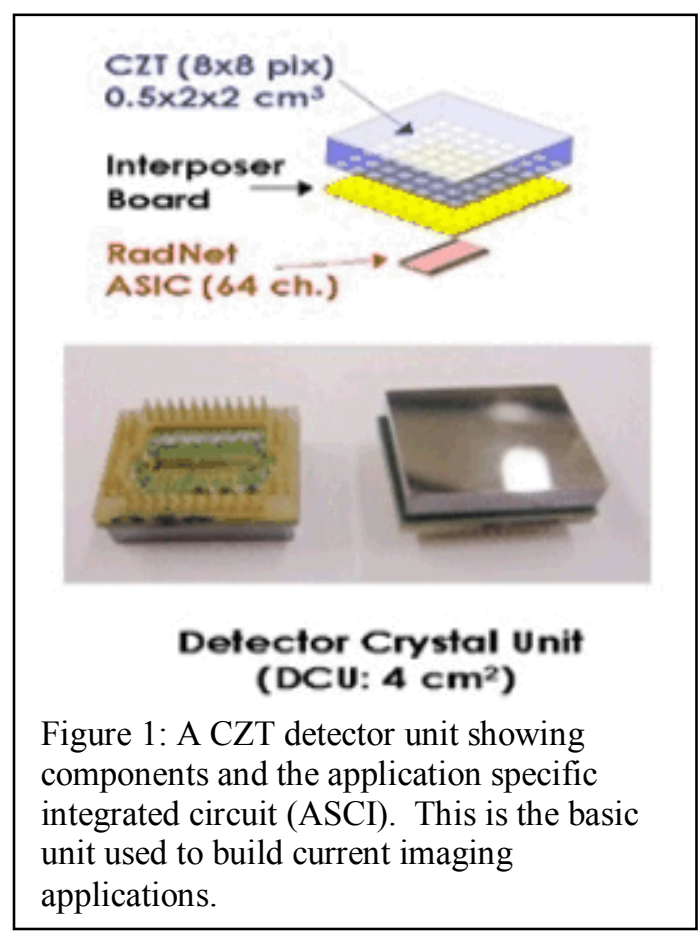

While a variety of devices have been made for commercial imaging applications and tagged with a variety of brand names, their basic CZT detector element is similar to the one shown in Figure 1. That is, non-pixilated crystals larger than $4 \mathrm{~cm}^{2}$ and thicker than about $7.5-10 \mathrm{~mm}$ have generally not been reported. The applications encountered use arrays of these crystal elements in various collimated and non-collimated configurations.

\footnotetext{
${ }^{25}$ The items described in this report are from approximately 2009 or later.

${ }^{26}$ See for example H. Krawczynski, I. Jung, J. Perkins, A. Burger, M. Groza, Proc. SPIE 5540 (2004) 1. astroph/0410077; H. Chen, S.A. Awadalla, F. Harris, et al., IEEE Trans. Nucl. Sci. 55 (2008) 1567 and Q. Li, A. Garson, P. Dowkontt, J. Martin, et al., in: Proc. NSS/MIC conference, 484, 2008. Available from: arXiv:0811.3201.
} 

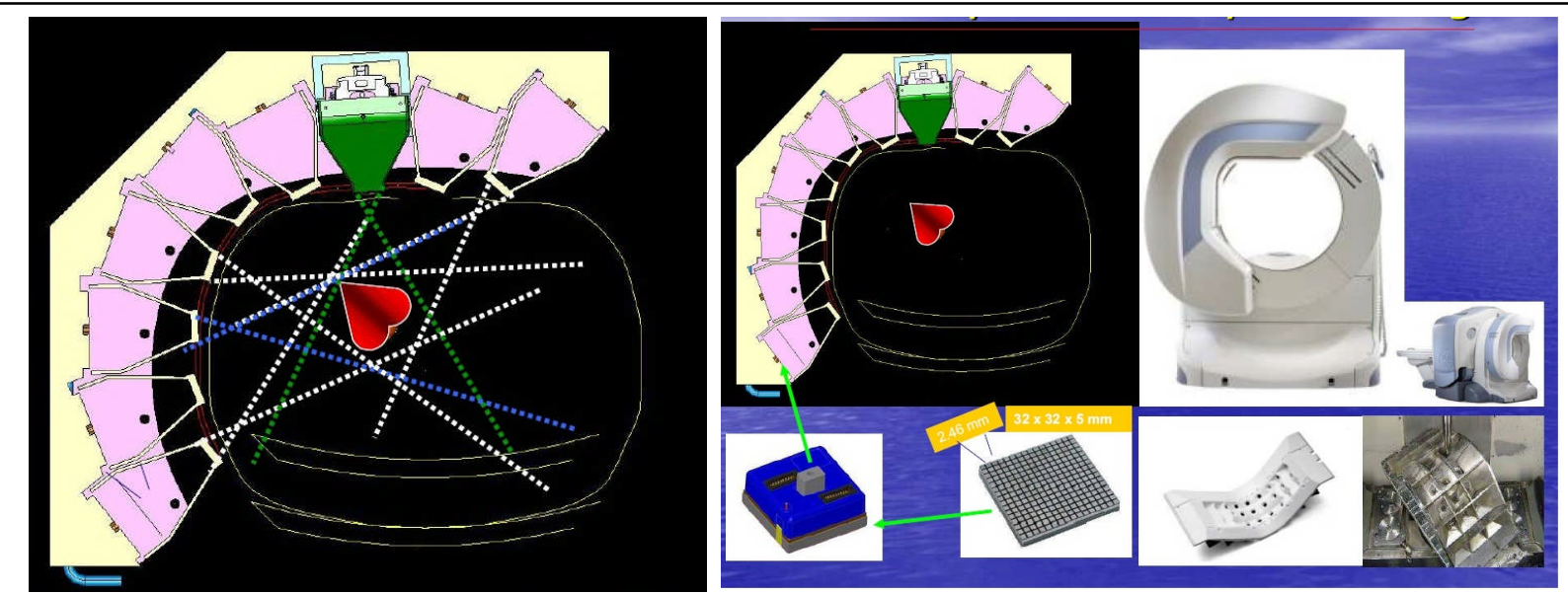

Figure 2: GE’s Discovery NM 530C CZT-based cardio-scanning unit. Scanning configuration (left); system components (right)

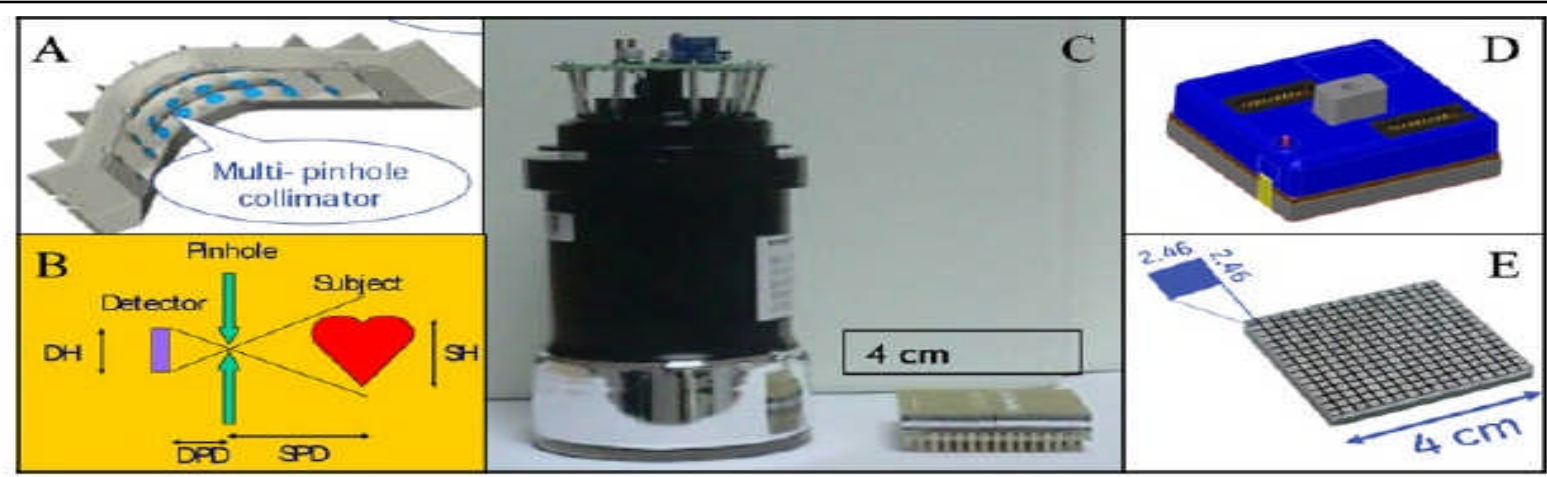

Figure3: Details of the 530C Detector Arrangement. (A) Multi-pinhole collimator covering the heart volume. (B) Pinhole collimation and miniaturization of the detector enable proximity to the heart with minification of the heart image, utilizing most of the detector surface to cover the heart projection. (C) A $4 \times 4 \mathrm{~cm}$ CZT detector size as compared to a classic photomultiplier tube of a conventional SPECT camera. (D)The detector box with its rear electronic connections. (E) The CZT is pixelated featuring intrinsic resolution of about $2.5 \mathrm{~mm}$ irrespective of photon energy.

In the field of medical applications, CZT detectors present viable options for Positron Emission Tomography (PET) and Single Photon Emission Computed Tomography (SPECT). Space borne applications and those anticipated to be useful for US Homeland Security purposes include the development of coded mask and Compton imaging detectors for detection, localization, and identification of radiation sources ${ }^{27}$.

\footnotetext{
${ }^{27}$ A. Zoglauer, M. Galloway, M. Amman, S.E. Boggs, J.S. Lee, P.N. Luke, L. Mihailescu, K. Vetter, C.B. Wunderer, 2009, IEEE Nuclear Science Symposium Conf. Rec. (NSS/MIC), 887Available from: doi:10.1109/NSSMIC.2009.5402475 and J.M. Mitchell, C.E. Seifert, IEEE Trans. Nucl. Sci. 55 (2008) 769
} 
Other compound semiconductor materials, notably GaAs, InP, $\mathrm{TlB}$ and $\mathrm{HgI}_{2}$ continue to develop as material quality improves. However, for these materials the best spectroscopic results are limited to a very small number of limited applications and research devices ${ }^{28}$.

As anecdotal evidence of present and future commercial interest in CZT materials, in February 2011, GE completed the acquisition of the assets of Orbotech Medical Solutions

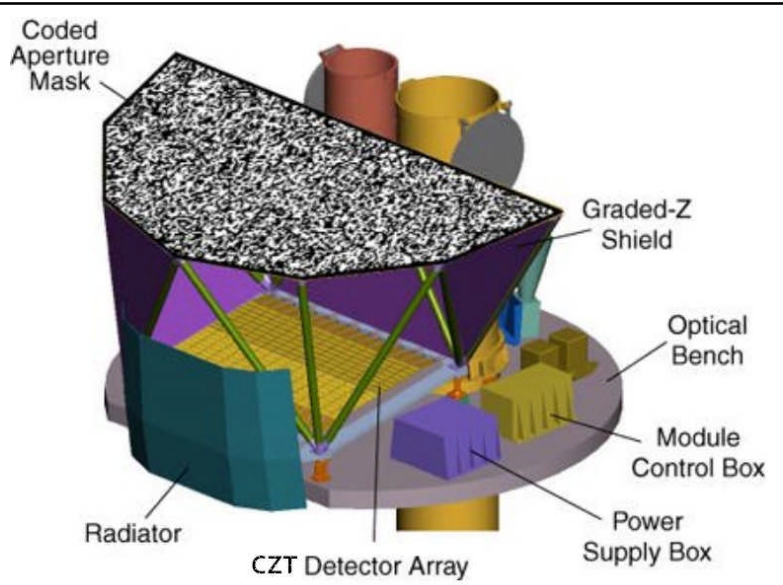

Figure 6: Telescope Array Ltd. (OMS), a subsidiary of Orbotech $\operatorname{Ltd}^{29}$. The company manufacturers the CZT detectors used in its "Alcyone" technology applications.

\section{Selected Applications, Research Reports and Fabrication Options}

\section{The GE Discovery NM530C Imaging System}

CZT technology ${ }^{30}$ has been implemented in GE's nuclear cardiology platform, the Discovery NM 530C imaging system, where the radiation detectors are combined with a total of 19 detector heads appropriately arranged for cardiac scanning applications. The detector heads are directed towards the heart and the region around it. The target volume is a sphere of approximately $19 \mathrm{~cm}$ in diameter. Figure 2 shows more details of the components; Figure 3 expands on the details of the detector arrangement and compares it to standard PM technology units; and, finally, Figure 4 shows more detail of the collimator design. The D-SPECT imaging system from Spectrum Dynamics uses identical technology.

(2) Thick CZT

\section{Detectors}

Multiple-Pinhole Collimator Design

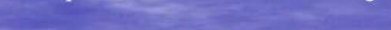

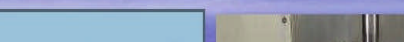
\begin{tabular}{l}
${ }^{28}$ Recent Advances in Compound Semiconductor Radiation Detectors, Paûl J Sellin, \\
Methods in Physics Research Section A: Accelerators, Spectrometers, Detectors aly As. \\
\hline Vol 513, Issues 1-2, 1 November 2003, Pages 332-339
\end{tabular}

${ }^{29} \mathrm{http}: / /$ www.genewscenter.com/content/detail.aspx?ReleaseID=11944\&News AreaID $=2$

${ }^{30}$ Referred to by GE as "Alcyone" technology.
Back

Tungsten $5 \mathrm{~mm}$ pinhole inserts

provide high energy collimation

(I-123) and limits $\mathrm{Pb}$ x-rays (Tl-201)

Thick $\mathrm{Pb}$ septa

prevents crosstal

between detectors

Figure4: NM 530C Collimator Design 
Recent research reports ${ }^{31}$ on the systematic tests of thick $(\geq 0.5 \mathrm{~cm})$ CZT detectors with volumes between $2 \mathrm{~cm}^{3}$ and $4 \mathrm{~cm}^{3}$. The detectors studied achieved Full Width Half Maximum (FWHM) energy resolutions of $2.7 \mathrm{keV}(4.5 \%)$ at $59 \mathrm{keV}, 3 \mathrm{keV}(2.5 \%)$ at $122 \mathrm{keV}$ and $4 \mathrm{keV}(0.6 \%)$ at 662 $\mathrm{keV}$. The $59 \mathrm{keV}$ and $122 \mathrm{keV}$ energy resolutions are claimed to be among the world-best results for $\geq 0.5 \mathrm{~cm}$ thick CZT detectors. The data set is further used to study trends of how the energy resolution depends on the detector thickness and on the pixelpitch. The research reports no clear trends, indicating that achievable energy resolutions are largely determined by the properties of individual crystals. Finally, the researchers note that the results are achieved without applying corrections to the anode signals for the depth of the interaction. This implies that knowing and correcting for the interaction depth does not seem to be a pre-requisite for achieving sub-1\% energy resolutions at $662 \mathrm{keV}$. Figure 5 shows some samples of thick, pixilated CZT detectors.

\section{(3) The CZR Burst Alert Telescope}

The Burst Alert Telescope (BAT) is a highly sensitive, large field of view instrument designed to provide critical data on gamma ray bursts (Figure 6). It is a coded aperture imaging instrument with a 1.4 steradian field-of-view with x-ray sensitivity in the energy range of $15-150 \mathrm{keV}$ for coded imaging and a non-coded response up to $500 \mathrm{keV}$. The instrument uses a two-dimensional coded aperture mask (see Figure 6) and a large area solid state detector array (Figure 7) to detect weak bursts, and has a large field of view. The table shows the telescope parameters.

\footnotetext{
${ }^{31}$ Study of Thick CZT Detectors for X-ray and Gamma-Ray Astronomy; Qiang Li1,, M. Beilicke, Kuen Lee, Alfred Garson III, Q. Guo, Jerrad Martin, Y. Yin, P.Dowkontt, G. De Geronimo, I. Jung, H. Krawczynski, Astroparticle Physics, 34, 769 - 777 (2011)
} 


\section{(4) A modular high- resolution photon-counting $\mathrm{x}$-ray detector}

Researchers ${ }^{32}$ at Radiation Monitoring Devices $\operatorname{Inc}^{33}$ claim to be developing a family of modular, highly configurable photon-counting, energy-discriminating, high-resolution imaging devices based on a novel combination of cadmium zinc telluride (CdZnTe) semiconductor radiation

Digital Pixel Sensor

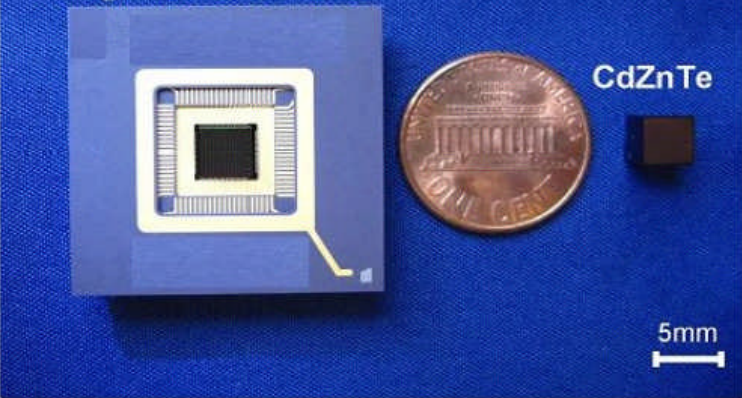

Figure 9: CMOS APCD (mounted for testing) and CdZnTe pixel array prototypes, each consisting of $19 \times 19$ pixels of $250 \times 250 \mu \mathrm{m}^{2}$ per pixel on a $5.5 \times 5.5 \mathrm{~mm}^{2}$ footprint. sensors and high-resolution custom application-specific integrated circuits. The concept, identified as an "Advanced Photon Counting Detector" ${ }^{\mathrm{TM}}$ (APCD) module, is to combine these two high-performance components into small (e.g., $1 \times 1 \mathrm{~cm}^{2}$ and $2 \times 2 \mathrm{~cm}^{2} /$ modules that tile seamlessly, forming detectors of arbitrary size and 2- or 3D shape (see Figure 8). It is expected that APCD components and APCDbased detectors will be designed for applications such as medical x-ray CT and munitions inspection, as well as for medical and nonmedical x-ray CT and radiography in general. APCD devices are also intended to be used to read out other solid-state sensors in addition to CdZnTe. Finally, the APCD design is also being upgraded to read out scintillators.

Each APCD module consists of a monolithic sensor (e.g., CdZnTe) of appropriate thickness to absorb X-rays, coupled to a CMOS APCD chip, incorporating at least 40 $\mathrm{x} 40$ pixels of $250 \times 250 \mu \mathrm{m}$ per pixel or smaller (Figure 9). Each individual pixel will independently support a data rate high enough

${ }^{32}$ See for example S. Kleinfelder, S. Lim, X. Liu, A. El Gam pixel sensor, IEEE J. Solid-State Circuits 36, pp. 2049, 2001. Kleinfelder, Fast high-resolution and multi-energy x-ray imas CZT arrays, SPIE Opt. Photon. Conf., 2010. Presentation 780 Solid-state photon-counting hybrid detector array for high-res Symp. Radiat. Meas. Appl. (SORMA XII), 2010. Paper 0126

${ }^{33}$ Radiation Monitoring Devices, Inc; 44 Hunt Street; Watert LEAD-RMD (800-532-3763); Fax: 617-926-9980; Email: inf

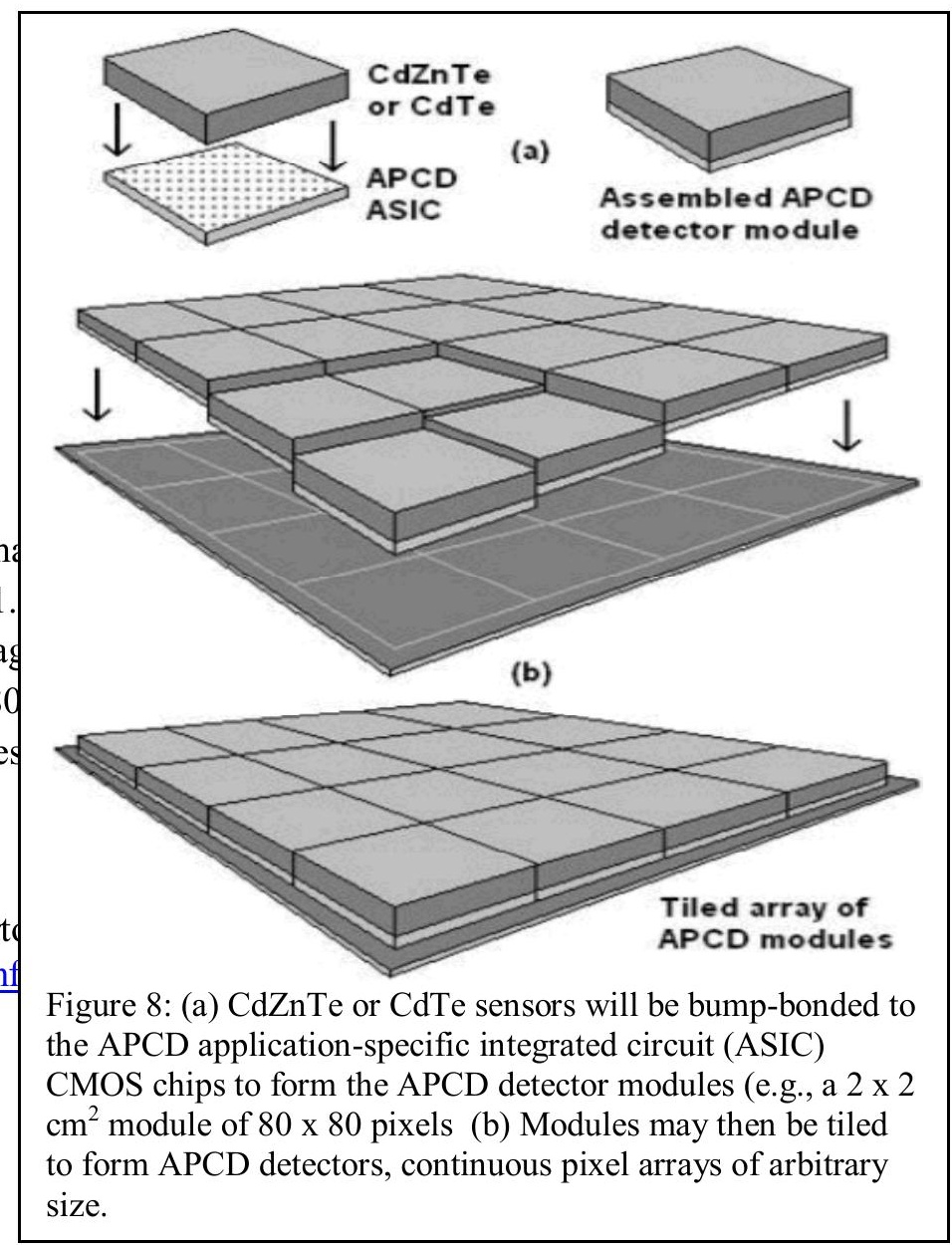


to effectively measure individual source X-rays, even at high flux. APCD modules will mount mechanically on a motherboard containing the necessary power, ground, control, and readout electronics, and can be individually removed and replaced for service. 


\title{
Appendix ii: The HEXITEC Project
}

\author{
Robert G. Lanier \\ January 10, 2012
}

In 2006 English researchers began a collaborative program to develop CZT detector technology for various applications. The program was identified as the HEXITEC project ( High Energy $\underline{X}$-ray Imaging Technology) and involved five principle investigators at various English institutes with focused responsibility on the various elements of the research. The following view graphs describe the overall scope of the four-year, wellfunded ( $£ 3$ million) project.

Subsequent work in the intervening years has led to a color 3D X-ray system that allows material at each

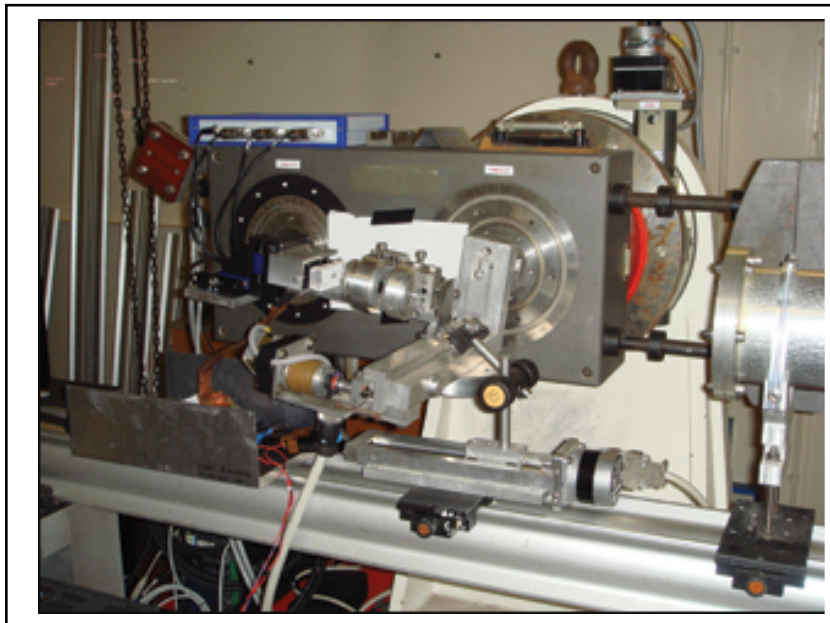

University of Manchester researchers use this experimental setup as they work to develop a "color" Xray scanner that uses additional wavelengths of light to detect the object's chemical structure. The technique is called tomographic energy dispersive diffraction imaging (TEDDI)

point of an image to be clearly identified. The technique is termed TEDDI (Tomographic Energy Dispersive Diffraction Imaging). The researchers claim that the technique has applications across a wide range of disciplines including medicine, security scanning and aerospace engineering.

The TEDDI method is claimed to be highly applicable to biomaterials, with the possibility of specific tissue identification in humans or identifying explosives, cocaine or heroin in freight. It could also be used in aerospace engineering, to establish whether the alloys in a weld have too much strain.

In the development of this technology two major challenges were overcome, which would be expected to have a positive impact on the overall future development of the technology: 
- The first was to produce pixellated spectroscopy grade energy-sensitive detectors. This was carried out in collaboration with Rutherford Appleton Laboratory, Oxford and Daresbury Laboratory, Cheshire.

- The second challenge was to build a device known as a 2D collimator, which filters and directs streams of scattered X-rays. The collimator device needed to have a high aspect ratio of $6000: 1$, meaning that it its width to its length is more than that of the channel tunnel.

This collimator was built using a laser drilling method in collaboration with The University of Cambridge.

Further details on the HEXITEC project development have been reported. Three individual collections of related information on HEXITEC are appended to this report. These include:

- Vewgraphs outlining the original scope of the project

- A refereed publication document describing the development of the electronic interface (ASIC). The ASIC (application specific integrated circuit) provides charge preamp, shaping and peak detect on each pixel above a programmable threshold.

- Viewgraphs showing a general overview of related developments from the research 


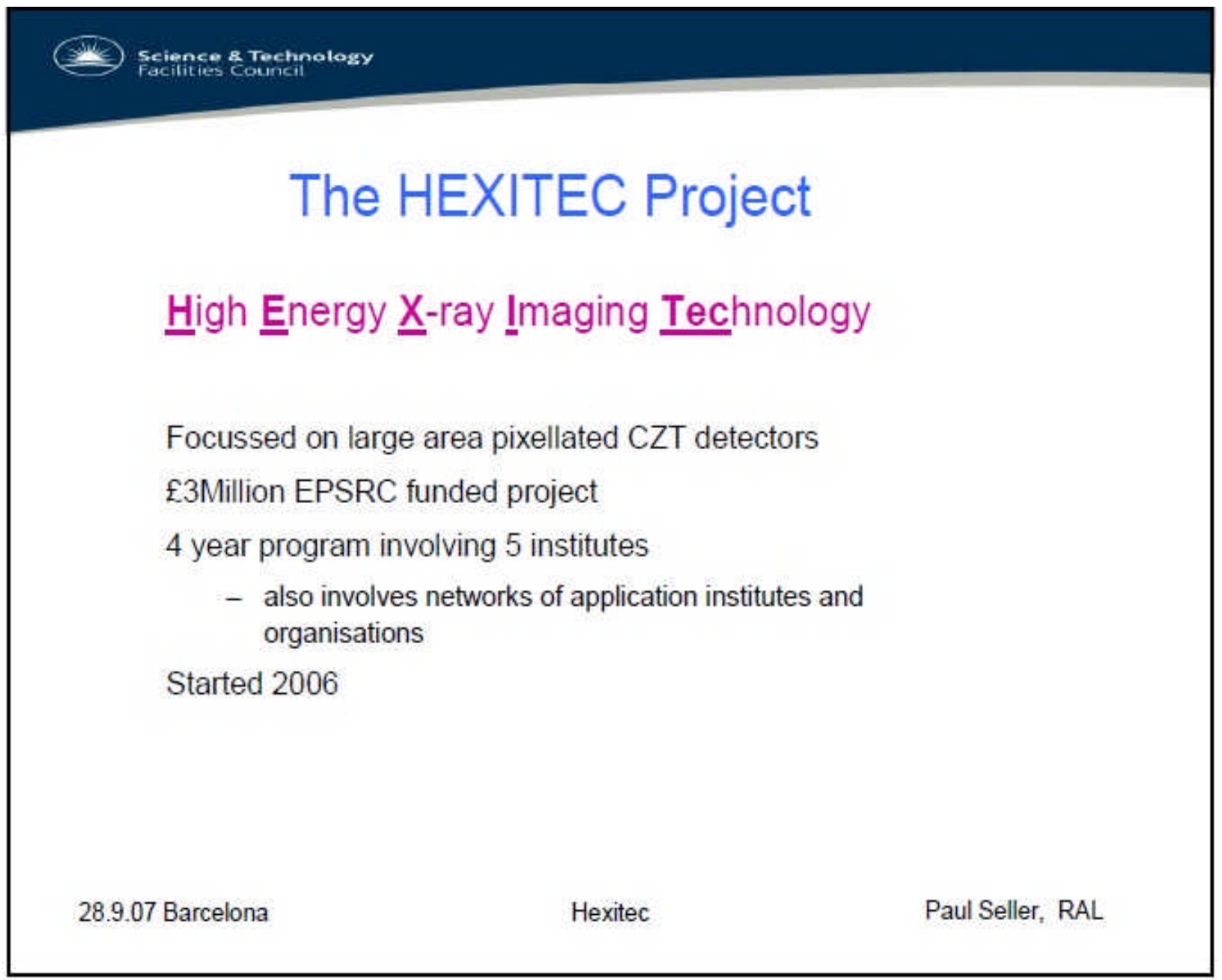




\section{Science sf Technology}

\section{HEXITEC Project objectives}

fabricate large area CZT detector material for X-ray imaging

characterise to improvement material performance

develop cutting/polishing/contact-deposition and passivation techniques

develop bump-bonding techniques for $\mathrm{CZT}$

develop pixellated spectroscopy ASIC for CZT

insert this technology into a diverse network of scientific users

create a sustainable base for continued CZT detector production

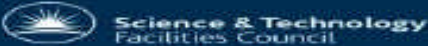

\section{HEXITEC Investigators (In order of functions)}

Dr Andrew Brinkman, Durham University

- growth of 3 inch CZT by fast PVD (commercialised for CdTe PVD)

Dr Paul Sellin, Surrey University

- CZT characterisation (PL mapping, PICTS, IBIC, Alpha TOF, NCR mapping)

- development of contacts and passivation

Paul Seller, CCLRC

- detector fabrication from raw material

- detector characterisation (Spectroscopy, noise/temperature, small-pixel effect)

- large area ASIC development

Prof Bob Cernik, The University of Manchester Principle Investigator

- lead of Application Networks

- Imaging + tomography for engineering

- Space Science

- Synchrotrons

- Security

- Medical and biological

Prof Paul Barnes, Birkbeck College London Materials Imaging Network

- TEDDI 


\section{Science se Technology}

\section{CZT room-temp semiconductor detector}

CZT has been proposed as good stopping power material and gives radiationhard detectors in proton environments (HEP and space)

There is good reason believe it is good in low energy $\mathrm{X}$-ray systems

- do not have oxide interfaces

- heavier atom than Si so low bulk damage
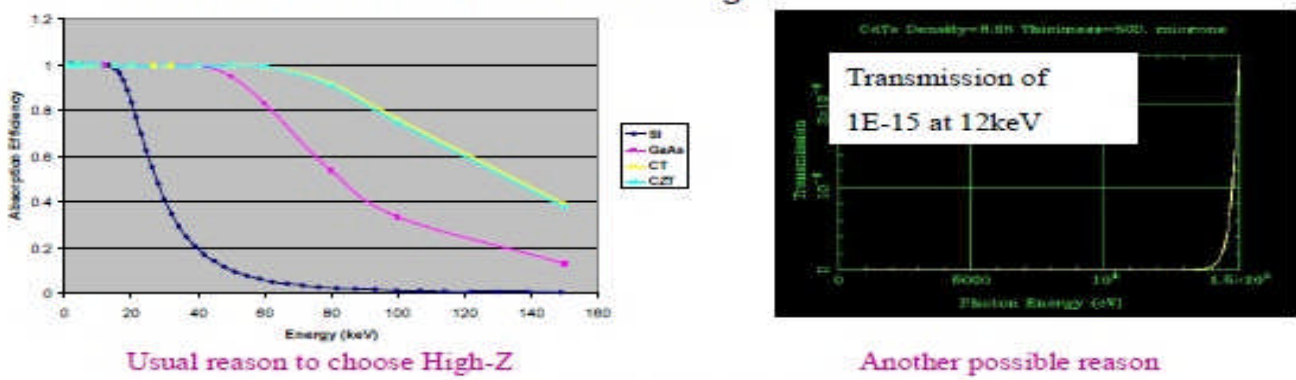

Another possible reason

- stop most of the X-rays so shield ASICs and bonding interface

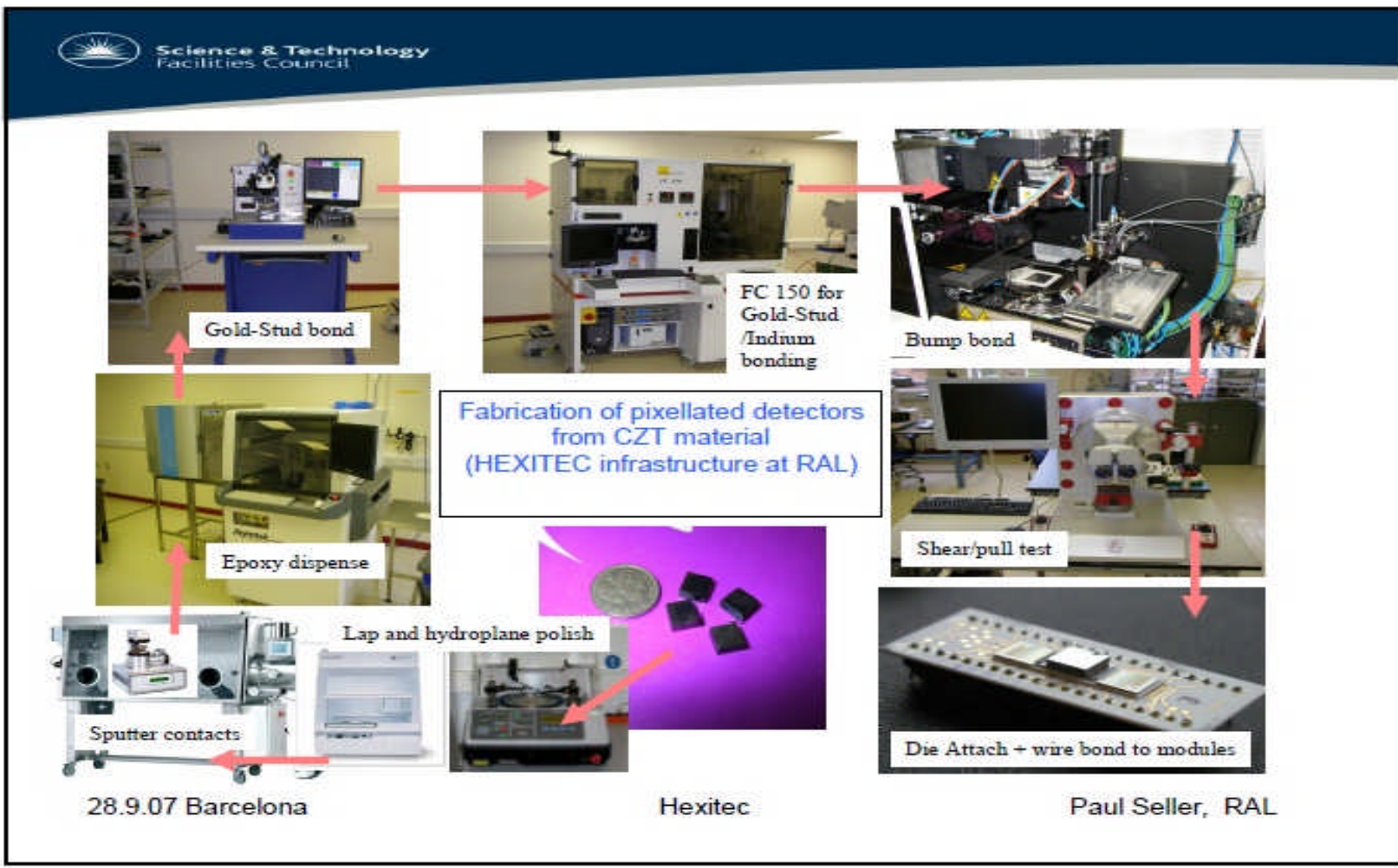




\section{(3ix) Science se Technology}

\section{HEXITEC ASIC OVERVIEW}

-Bump bonded readout chip for CZT

- $80 * 80$ pixels each $250 u^{*} 250 u m$

- $1 \mathrm{keV}$ to $150 \mathrm{keV}$ dynamic range (x10 option)

-200eV FWHM noise

- Sequential Rolling shutter readout (not data driven)

-Intended for $2 \mathrm{~mm}$ thick CZT material

-1000 frames a second (variable) readout rate

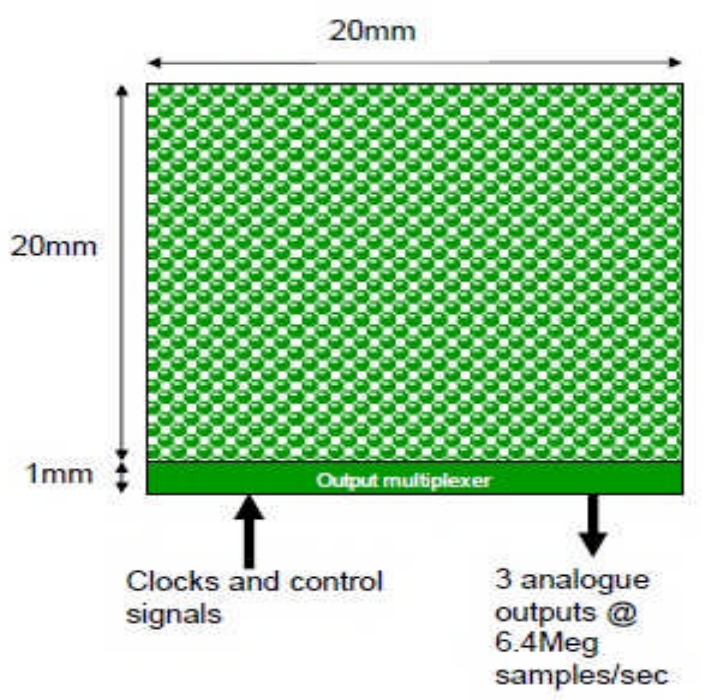

\section{(20) Science so Tachnology}

HEXITEC ASIC: Simulations and measurements

-With 250 um pixels and $2 \mathrm{~mm}$ thick detectors the small-pixel effect is quite strong

- See $<<1$ us rise-time signals due to the electrons moving when close to the anode contact. Do not see the several microsecond electron and hole transit times through bulk

-Can chose a faster shaping time without significant ballistic deficit

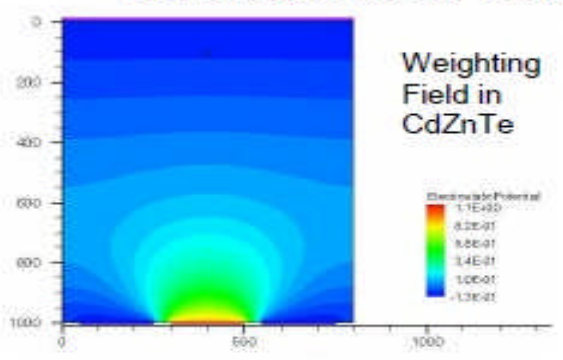

28.9.07 Barcelona

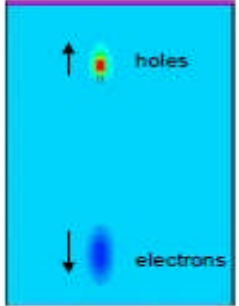

Hexitec

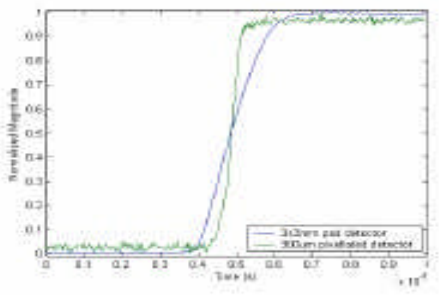

Paul Seller, RAL 


\section{Science R Technology}

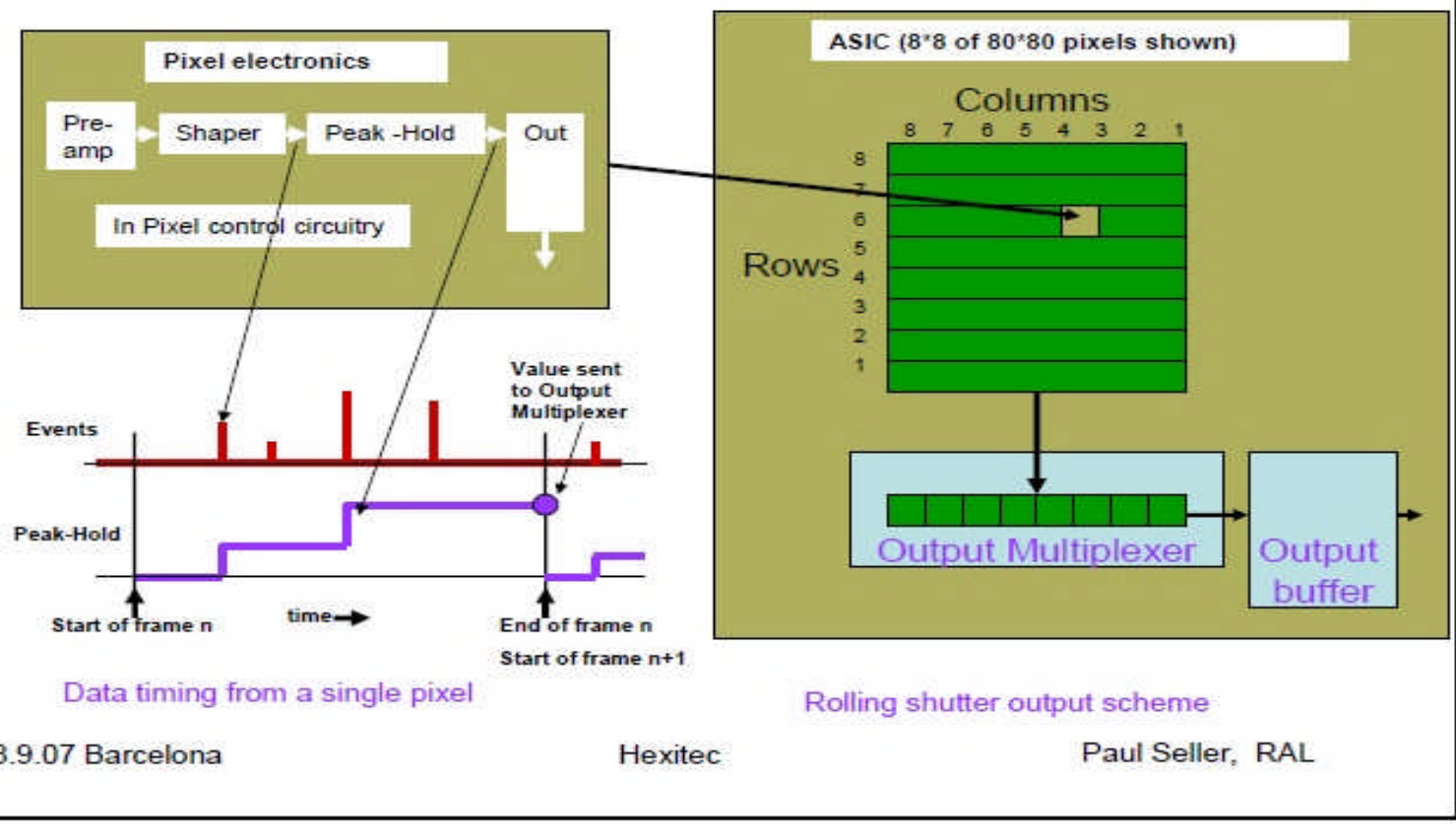

\section{Science Rै Technology}

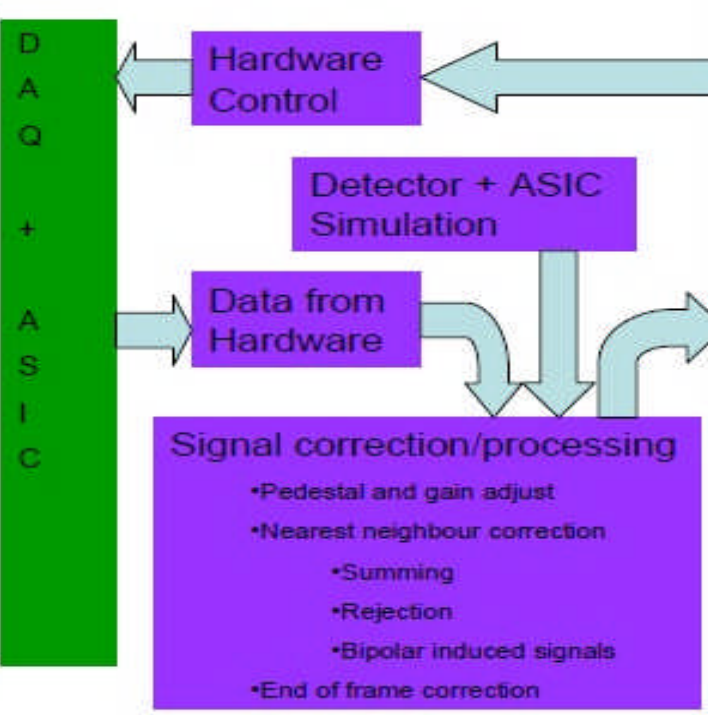

Software

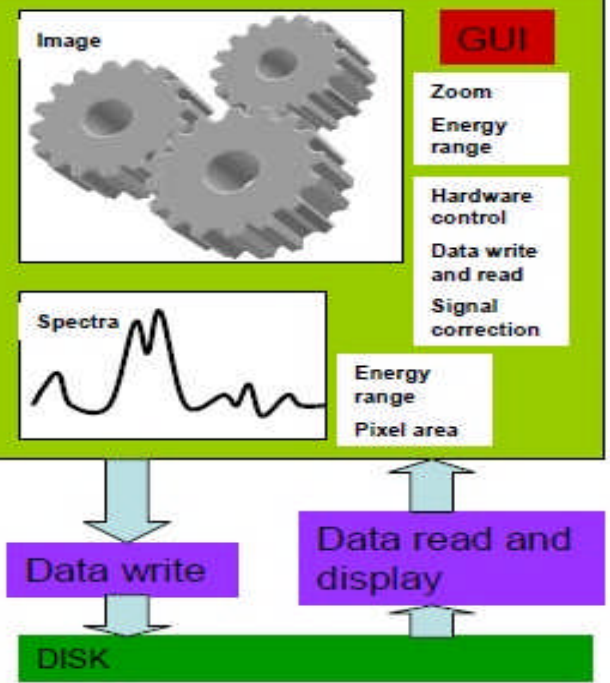

Paul Seller, RAL 


\begin{tabular}{cc|}
\hline & Contents lists avsilable at ScienceDirect \\
Nuclear Instruments and Methods in \\
Physics Research A
\end{tabular}

\title{
HEXITEC ASIC - a pixellated readout chip for CZT detectors
}

\author{
Lawrence Jones *, Paul Seller, Matthew Wilson, Alec Hardie

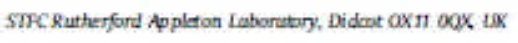

\begin{tabular}{l} 
A R T I C L E I N F O \\
\hline Available online 11 february 2009 \\
\hline Keywords: \\
X-ray \\
CdR nile \\
Readout ASIC \\
Clock driven \\
Gold stud bonded
\end{tabular}

Gold stud bonded

\section{Overview}

Cadmium Zinc Telluride (CZT) is a particularly attractive material for dimect conversion semiconductor X-ray detectors. It has been demonstrated that pixellated devices down to $55 \mu \mathrm{m}$ geometry can function with acceptable spectroscopic (colour X-ray) performance [1]. The HEXITEC ASIC has been designed specifically to provide very good spectroscopy for every incident photon at the expense of speed of acquisition. Our target applications (induding synchrotron diffraction and tomography experiments as well as space science imaging) require very good energy resolution, and as a secondary requirement want speed. This later requirement is handled by the region of interest features, which allow fast readout in specified areas. Also this architecture which reads out all pixels, allows detector charge sharing and other correction algorithms to be investigated off-line,

The HEXITEC ASIC consists of $20 \times 20$ pixel on a pitch of $250 \mu \mathrm{m}$. Each pixel contains a $52 \mu \mathrm{m}$ bond pad which can be gold stud-bonded to a CZT detector. Fig. 1 shows a block diagram of the electronics contained in each HEXITEC ASIC pixel. Charge is read out from each of the CZT detector pixels using a charge amplifier. which has a selectable range and a feedback circuit which compensates for detector leakage currents up to $50 \mathrm{pA}$.

The output from the each charge amplifier is filtered by a $2 \mu 5$ peaking circuit comprising a $C R-R C$ shaper followed by a secondorder bw-pass filter, A peak hold circuit maintains the voltage at the peak of the shaped signal until it can be read out.

Three track-and-hold buffers are used to sample the shaper and peak hold voltages sequentially prior to the pixel being read

\footnotetext{
- Correnponding suthot 'Vel ; +441235446508; fac; +441235 448008.

I-mail address: 11.janeasstif $x$ uik (L- janes)

$0168-9002 / 5$-see front matter o 2009 Elevier H.V. All rights rexerved. dai:1010 vifjnima200901.046
}

out. When readout occurs, the output from the pixel comprises the two samples from the shaper output and the one sample of the peak hold output. These three signals are used to vetoincormect peak hold data due to partly developed signals or incorrect peak hold reset levels. Switches are enabled which connect 1 pixel in each column of the pixel array to shared column outputs. A calibration circuit is included for characterizing the pixel electronics

Readout logic controls the sequencing of data from the HEXTIEC ASIC pixel array. Fig. 2 shows a block diagram of the top level of the ASIC For simplicity the chip uses a completely clock-driven architecture.

Three programmable registers can be used to define regions of interest within the pixel array. The first register defines the regions that will be read out, the second defines regions which will be powered down, and the third defines regions where the calibrate circuit is enabled.

The HEXITEC ASIC pixel array is read out using a rolling shutter technique, A row select register is used to select the row which is to be read out. The data from each pixel becomes available on all column outputs at the same time, and at this point the peak hold circuits in that row can be reset to accept new data. The data being held on the column output is read out through a column multiplexer. The column readout rate is up to $25 \mathrm{MHz}$ and the total frame rate depends on the number of pixels being read out.

\section{Functional description}

\subsection{Preamplifier}

The preamplifier employs a single-ended folded-cascode architecture and has selectable input range of either 40000 or 


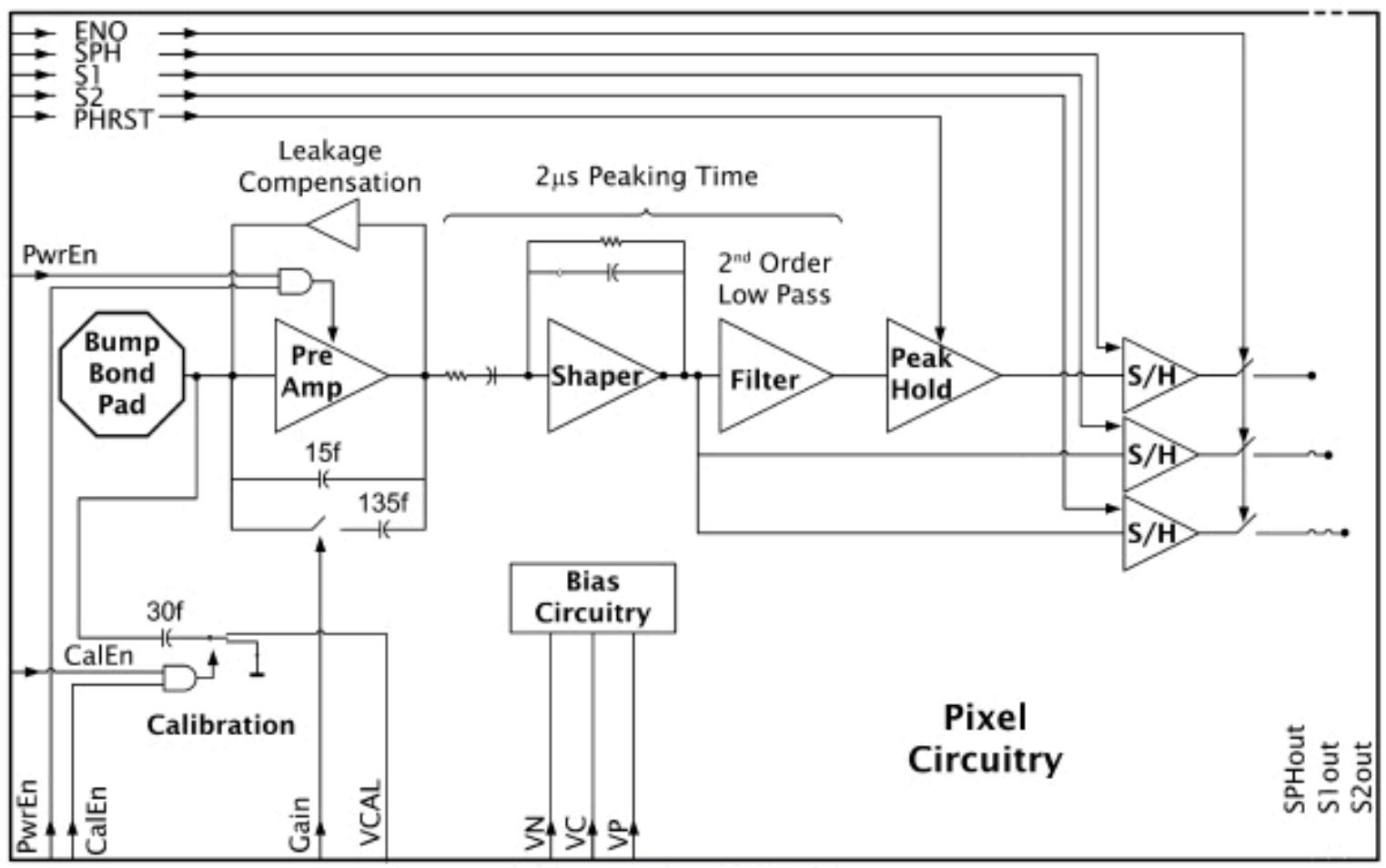

Fig 1. Hlock diagram of pivel electronics.

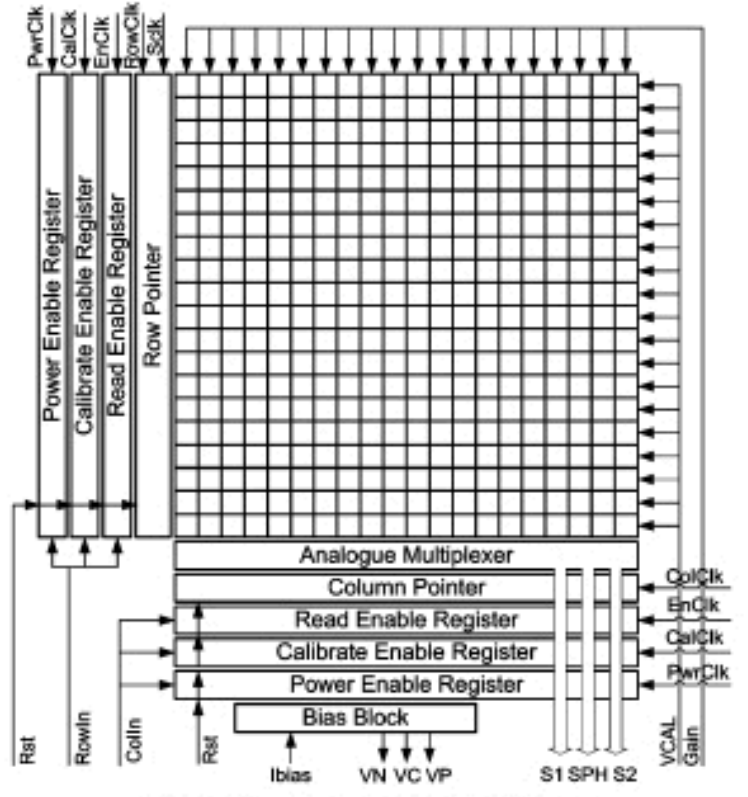

Fig. 2. Blodk diagram of the top level of the chip.

400000 electrons, A feedback circuit [2] provides DC stability and can source up to $250 \mathrm{pA}$ of detector leakage current. The preamplifier input FET is biased at $1.65 \mathrm{~V}$ to reduce power consumption and can be powered down further by selecting a lower bias current through the FET. At this lower bias level the preamplifier remains operational but has higher electronic noise.

There are two main noise contributors within the preamplifier. The thermal noise of the input FET has been minimized by matching the size of this device to that of the detector capacitance and applying the maximum possible bias current within specification. The second major contribution is the current noise of the feedback circuit at the input to the preamplifier. In addition, there is an external noise contribution from the shot noise of the detector leakage current [4]. The noise specification for the ASIC has been defined at $5 \mathrm{pA}$ detector leakage current.

\subsection{Nois filtering}

A band pass is used to filter noise and to improve double pulse resolution. A CR-RC type configuration is used employing a single-ended folded-cascode architecture as with the preamplifier.

Normally, shaping time is optimised to equalize the contributions of the major noise sources within a circuit. Longer shaping times reduce the thermal noise of the preamplifier input FET and shorter shaping times reduce the current noise of the preamplifier feedback circuit and the detector leakage. It was not possible to optimise the circuit in this way since the optimum shaping time was found to be too short for applications involving CZT detector signals, where charge collection times can be in the region of $1 \mu s$. A compromise was reached, and the shaping time is set to $1.25 \mu \mathrm{s}$. However, the CR-RC circuit alone cannot filter out enough of the noise to meet the specification. 
A second low-pass filter is used to attenuate the highfrequency noise at the output of the CR-RC shaper. The filter employs a second-order low-pass architecture and is required to filter excessive noise in the $1-10 \mathrm{MHz}$ region. The effect on the pulse peaking time is to increase it to $2 \mu s$ at the output of the low-pass filter (Figs. 3).

\subsection{Data sampling}

The peak amplitude of the filter output needs to be held long enough for it to be sampled prior to readout. This time will vary depending on when the signal occurs within a readout frame, and how many pixels have been selected for readout. This function is performed by the peak hold circuit [3]. A signal peak is held until its voltage can be sampled by a sample and hold circuit prior to readout, after which time the peak hold circuit is reset (Figs. 4).

However, there are two problems with the operation of the peak hold circuit which have to be addressed. Firstly, if peak hold

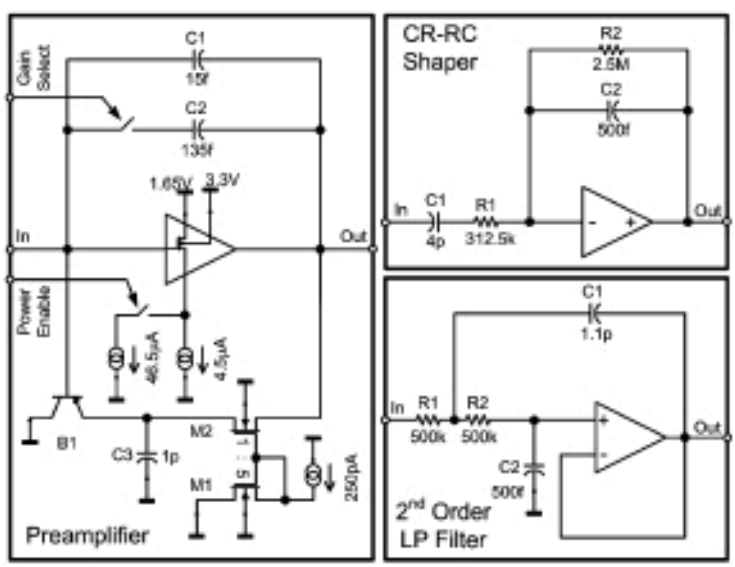

Fig 3 Schematics of the preamplifier shaper, and the second-or der low-pass filter in the pivel electronics

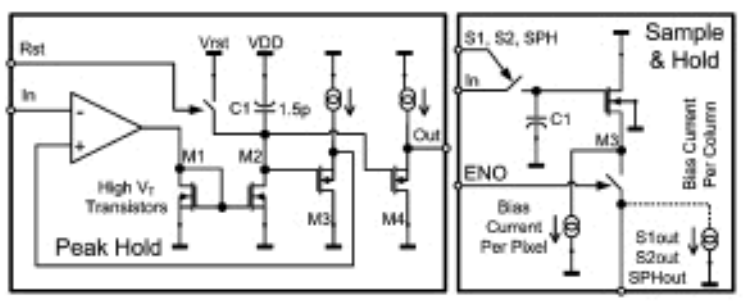

Fig 4. Schematics of the peak hold circuit and the sample and hold circuit in the pibel electronics. circuit reset occurs during the tail end of a filter signal, the circuit will not reset to the correct voltage level If this happens, the peak hold circuit will not be able to see further signals whose magnitude is less than this voltage. Secondly, the peak hold circuit may be read out before a filter signal has fully formed. In this case the value read from the peak hold circuit will be incorrect.

It is necessary to determine when the peak hold signal has been sampled with respect to active signals on the filter output. This is to be done by sampling the filter output twice, one sample occurring before and the other occurring after the peak hold are sampled. A simple algorithm can then reject corrupt data.

\subsection{Readout}

A full-frame readout only requires three external control signals. Rowak, Scik, and CoiClk Fig. 5 shows a full-frame readout for a 5 rows and 5 column array of pixels. Prior to the readout cycle, the Read Enable Register should be programmed with the required rows and columns to be read out.

The Row Pointer is a shift register which controls the row which is being read out. It is clocked by the signal RowClk and shifts through only those rows which are programmed into the Read Enable Register, skipping over all those rows which are not. The signal Sclk is global to the chip but is used to generate the control signals internal to the row being read out. These control the peak hold circuit, sample and hold circuits, and the column output.

Like the Row Pointer, the Column Pointer controls which columns are to be read out through the analogue multiplexer. The Column Pointer reads only those columns programmed into the Read Enable Register. It is controlled using the signal ColClk, and the maximum clock period at which this can run is limited by the column-to-column readout speed which is about $40 \mathrm{~ns}$. Data on each of the columns to be read out are multiplexed and buffered off the chip.

At the start of a frame readout, the row pointer and column pointer are both in a parked position. The first clock pulses on RowClk and Colak move them to the first row and column to be read out. This means that at the end of a row readout cycle, an extra clock pulse is required on ColClk to return the column pointer to its parked position. Similarly, at the end of a full-frame readout, the Row Pointer must be returned to its parked position by Row $a k$.

Data appear on the outputs synchronized with Colak. The dynamic output rangs is $1 \mathrm{~V}$.

\section{Status}

The present status of the project is that a $20 \times 20$ pixel prototype has been designed and manufactured but not yet tested. However, a smaller 1 pixel test structure has been tested to verify the design of the preamplifier, shaper, filter, and peak hold circuit.

Due to the low-bias currents in the preamplifier feedback circuit there was uncertainty in the accuracy of the transistor

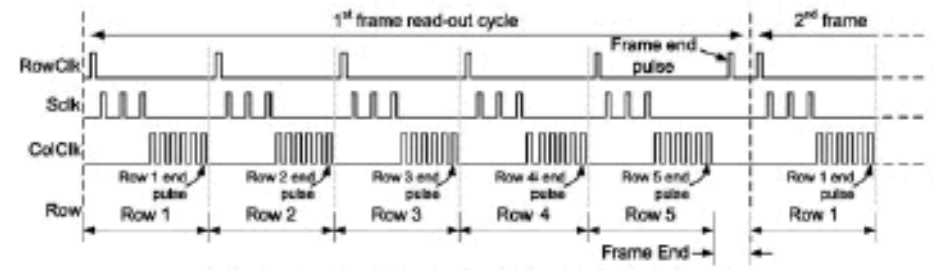

Fig 5. External control signals for a $5 \times 5$ array of pixek 


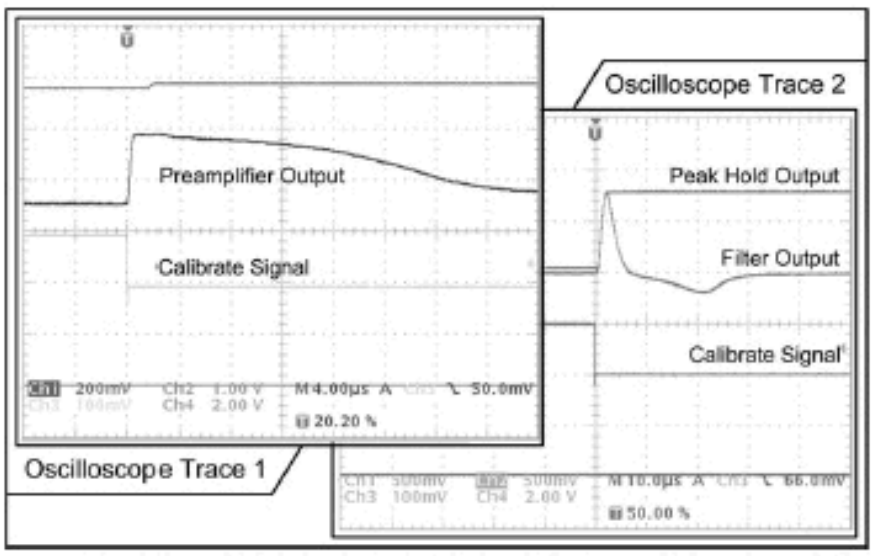

Fig 6. Test results from a single-pixel test structure, showing output from the preamplifier filter, and peak hold circuit

simulation models. In addition, it was found during simulation that for certain process corners and temperatures the peak hold circuit suffered from droop due to sub-threshold currents in the transistors. It was decided to manufacture a test structure to verify the design of the pixel electronics. Fig. 6 shows some results which confirm this.

\section{Conchusions}

A prototype ASIC has been designed and manufactured for readout of pixellated CZT detectors. For simplicity, it has a completely dock-driven architecture. Following testing, an $80 \times 80$ pixel version of this will be manufactured.

\section{Acknowledgements}

HEXITEC is a collaboration between the universities of Manchester, Durham, Surrey, Birkbeck college and STRC. It is funded by EPSRC

\section{References}

11 A. Shor, Y. Eisen L M a dar, Nuclear Instruments and Methods A 458 (2001)42 2) G. De Ceronima, P. OConnor V. Radeka, B. Yu, Nuclear Instruments and Methods in Physics Research A 471 (2001) 192.

B] G. De Ceronimo, P. OConnor, A. Kandasamy Instruments and Methods in Physics Research A 484 (2002) 533.

[4] P.N Luke, M. Amman jS. lee, PF. Manfredi, IEEE Transactions an Nuclear science NS.48 (3) (2001) 
CdZnTe Energy Resolving Array Detectors

Paul Seller

Rutherford Appleton Lab

Acknowledgements:-

Many thanks to Matt Wilson, Matt Veale and Lawrence Jones and others at RAL.

Also thanks for the work illustrated here from the Universities of Surrey, Manchester and Durham.

\section{Science \& Technology
Facilities council}

Material

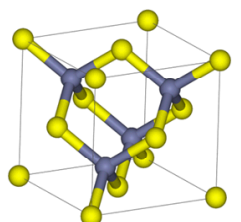

-CdTe Zinc-blend structure

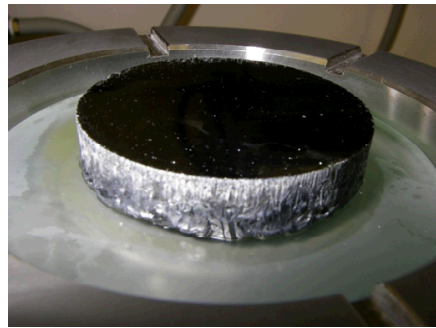

3 inch Durham University CZT
-CdTe is a black looking crystal

- CZT has the $\mathrm{Cd}$ sites substituted for $\mathrm{Zn}$. Mostly used as substrate for $\mathrm{HgCdTe}$ growth. (This substrate material is not detector grade.)

-Typically detectors are $\operatorname{TeCd}_{1-x} Z \mathrm{n}_{\mathrm{x}}$ (x from $3 \%$ to $10 \%$ )

-Piezo-electric crystal so inherently micro-phonic in parallel plate configuration.

-Also Birefringent so can look at internal strains and fields with polarisers.

- Hard and very brittle (handle with care)

-Carcinogenic and accumulative.

-Produced at $1100 \mathrm{C}$ by HP Bridgeman, Travelling Heater and Multi Tube Physical Vapour Transport (PVD).

-Thin Layers by CSS or HWE 550C growth substrate but need to lattice match substrate. 


\section{Scierce \& Technology
Facilties Councit}

Properties

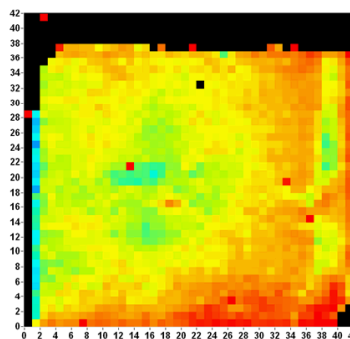

Photo luminescence map Band-gap and thus \%Zn
-Band-gap $\mathrm{CdTe}=1.5 \mathrm{eV}(\mathrm{Si}=1.12 \mathrm{eV})$ so room low leakage temperature semiconductor

-This is equivalent to $820 \mathrm{~nm}$ so transparent to IR light above this wavelength (can see defects with IR)

-Zn added solely to increase Band-gap

$$
\mathrm{Eg}=1.505+(0.631 \mathrm{x})+\left(0.128 \mathrm{x}^{2}\right)
$$

- Radiation conversion $(\mathrm{w})$ factor $=4.4 \mathrm{eV}$ per electron hole pair ( $40 \mathrm{keV}$ photon gives $10^{4}$ charge carriers)

$$
\begin{array}{c|c}
\text {-Fano Factor }=0.1 & \text { noise }[\#]=\sqrt{n} \sqrt{F} \\
F W H M[e V]=2.35 * w * \sqrt{n} \sqrt{F}
\end{array}
$$

\section{Science \& Rechnology
Facilties councit}

Radiation Absorption
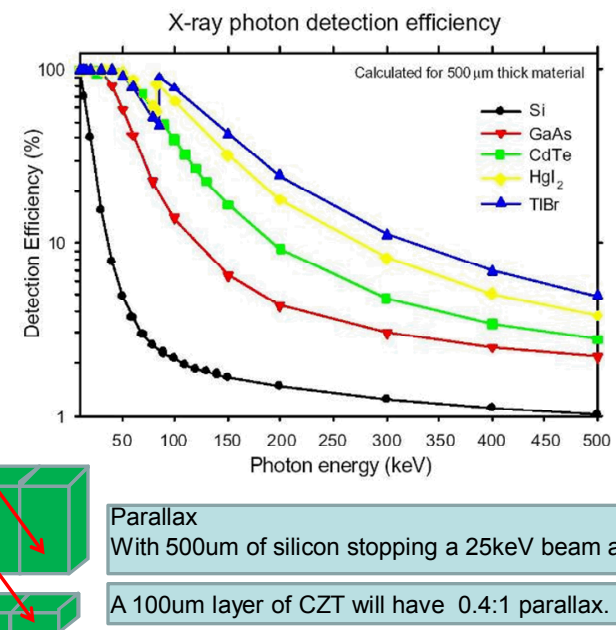

Filter Transmission

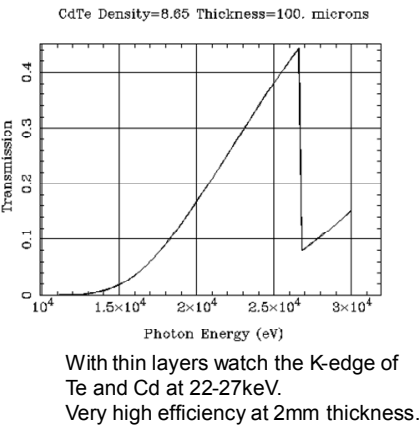

Parallax

With $500 \mathrm{um}$ of silicon stopping a $25 \mathrm{keV}$ beam a $250 \mathrm{um}$ voxel will have $2: 1$ parallax.

A 100um layer of CZT will have $0.4: 1$ parallax. 


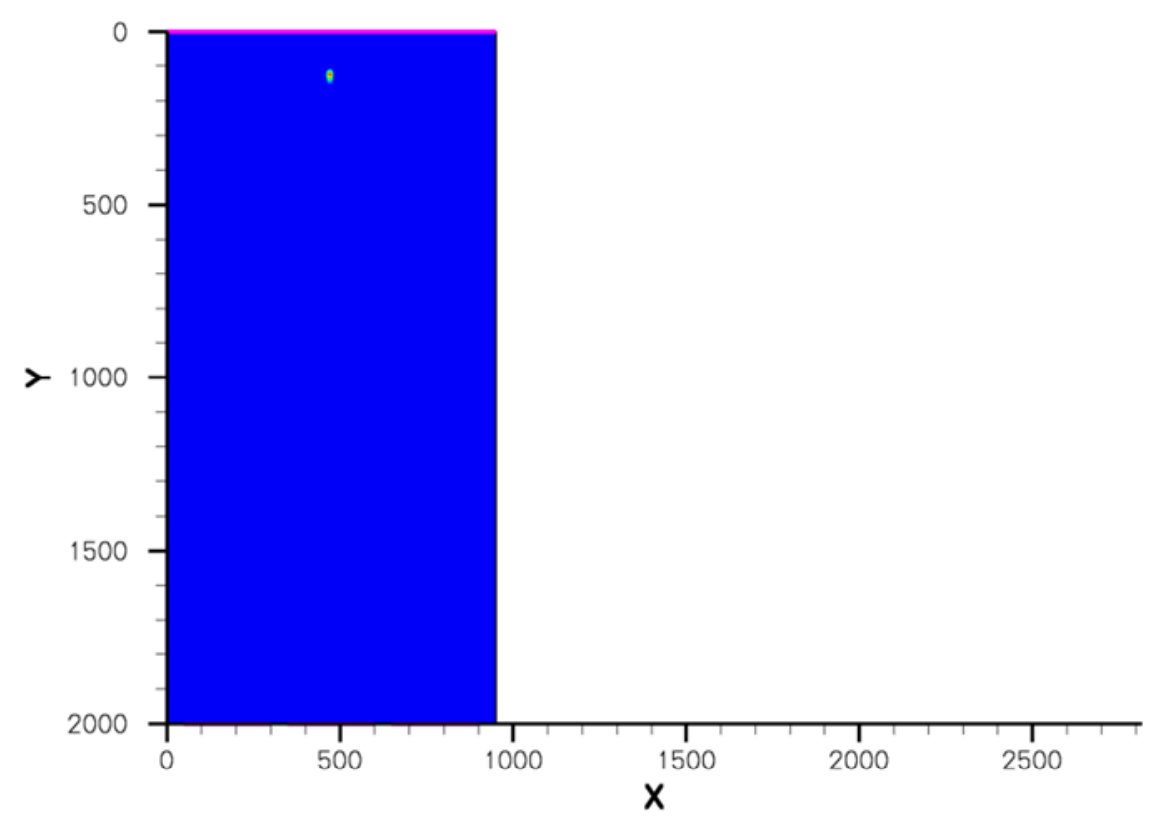

Science \& Technology

Charge transport
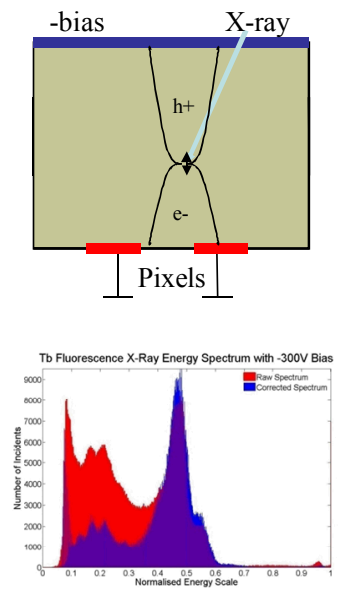

-Electron mobility $1000 \mathrm{~cm}^{2} / \mathrm{Vs}(\mathrm{Si}=1400)$

- Hole mobility

-Carrier lifetime $\quad$ 2us

$\bullet \mu \tau_{\mathrm{e}}$

$\cdot \mu \tau_{\mathrm{h}}$

$\sim 2 \times 10^{-3} \mathrm{~cm}^{2} \mathrm{~N}$

$\sim 2 \times 10^{-4} \mathrm{~cm}^{2} \mathrm{~N}$

-(Holes take 2 us to traverse $2 \mathrm{~mm}$ )

-Charge diffusion 100um typical for 2mm thick

-Bulk resistivity $\quad 3-9 \times 10^{10} \mathrm{Ohm}-\mathrm{cm}$ (CdTe less)

-Leakage current $1 \mathrm{nA} / \mathrm{mm}^{2}$ (due to mid band states, reduced by $\mathrm{Cl}$ doping in CdTe, $\mathrm{V}$ or $\mathrm{In}$ in CZT)

-Small pixel effect important to give single carrier output signal. (Improves speed and spectrum)

Shockley-Ramo theorem

$$
Q=q \varphi_{0}(x)
$$$$
i=q \bar{v} \bullet \bar{E}_{0}(x)
$$

Energy Resolving CZT arrays

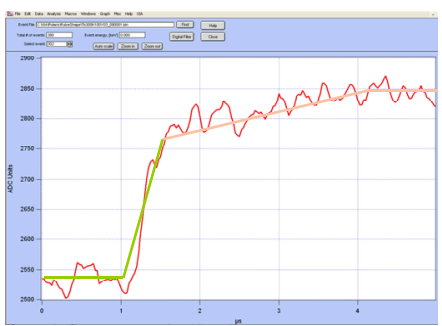

Paul Seller, RAL 


\section{Science 8 Technology
Facilities Councit}

Contacts
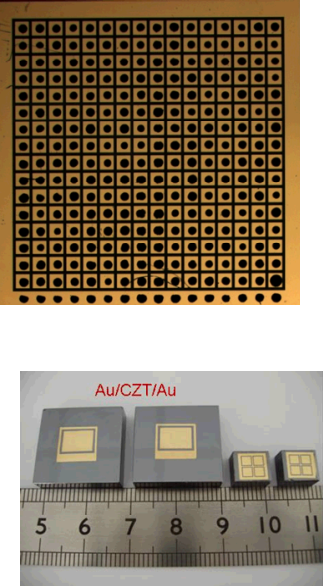

-CZT typically have Au or Pt contacts. Sputtered/evaporated pixels easy.

- $\mathrm{CdTe}: \mathrm{Cl}$ detectors now can have Indium rectifying anode contacts to reduce leakage and inter-pixel isolation.

-Important to passivate sides to reduce leakage.

- Need to remove surface damage (100-200um) and TeO layers before contacting. Etch with Br:Methanol.

-Contacts increase resistance (less leakage than bulk)

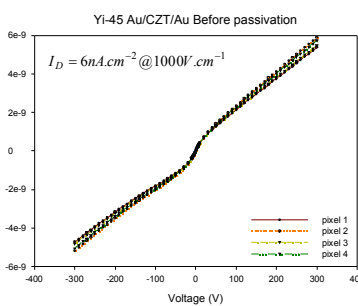

Energy Resolving CZT arrays

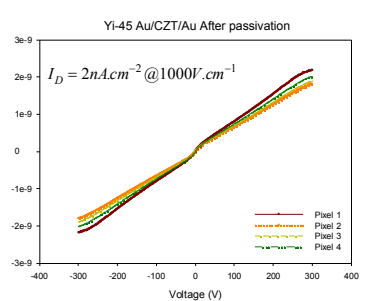

Paul Seller, RAL

\section{Science \& Rechnology
Facilties Councit}

\section{Manufacturers}

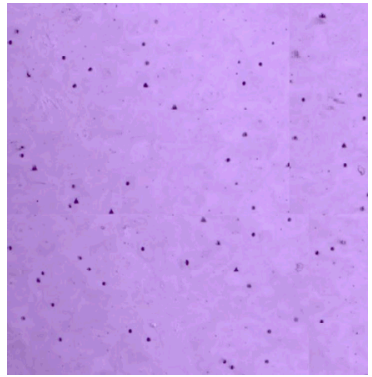

Te precipitates
-Te precipitates and inclusions distributed in bulk, decorate twins and grain boundaries

-These cause charge trapping and leakage.

-At high fluxes the trapping (space charge) can distort the internal field and even stop operation (so-called polarisation). Need good hole transport to reduce this $\left(\mu \tau_{\mathrm{h}}>10^{-4} \mathrm{~cm}^{2} / \mathrm{V}\right)$ to get to $>10^{-6}$ counts $/ \mathrm{s} / \mathrm{mm}^{2}$

-Usually anneal the crystal in Cd vapour to reduce inclusions but it might still have trapping sites.

-Watch operating temperature as low temperature increases trapping

-Can produce large CZT crystals with low trapping:

$\cdot e V$ Products

-Redlan

-Bruker Baltic (only processing)

- Orbotec

-Durham University (CZT from Hexitec)

-Acrorad (CdTe)

-Kromek (CdTe)

-Several Universities ???? 


\section{Science 8 Technology
Facilities Councit}

Interconnect

-Because CZT is very brittle and contacts are thin and fragile, difficult to use conventional ultrasonic wire bonding. - Most CZT devices do not like going above $150 \mathrm{C}$ or $120 \mathrm{C}$ for a long time. Probably due to redistribution of doping and diffusion of contacts.

-So need a low temperature bonding process.

-Other institutes use Indium bonding but in both cases have to watch diffusion.
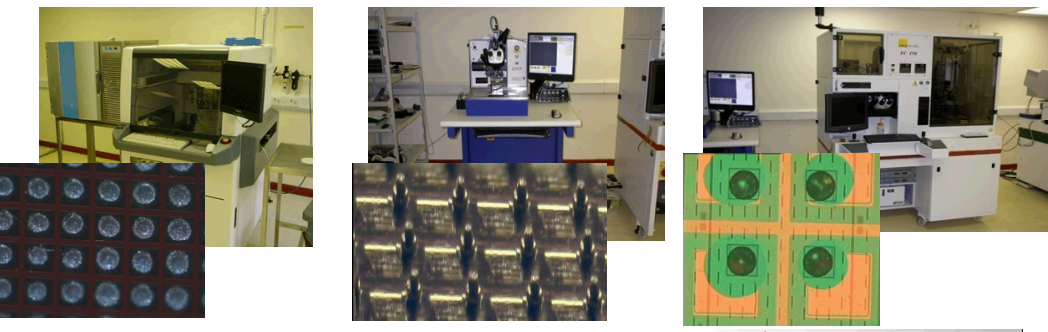

RAL low-temp Au-stud and Ag-epoxy method

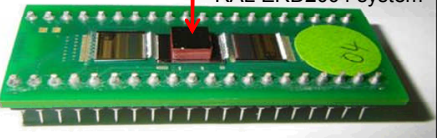

\section{Science 8 Technology
Facilities Council}

Spatial Resolution

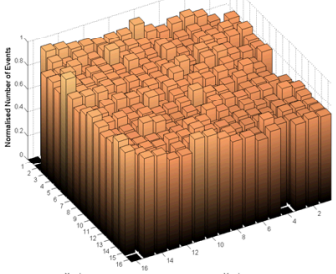

Silicon on ERD2004, uniformity almost at level of statistics.

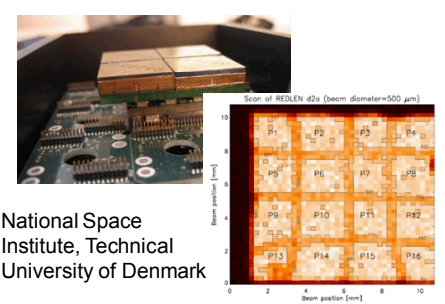

Energy Resolving CZT arrays
We believe this is due to

charge steering in the

array due to space

charge in the device.

Others suggest it is

actually the charge

trapping which causes

the non-uniformity.

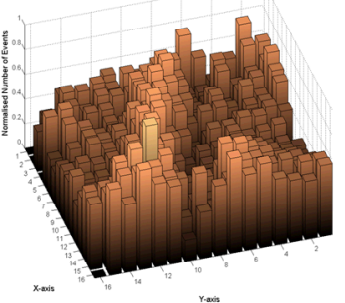

CZT on same ERD2004 device highly non-uniform

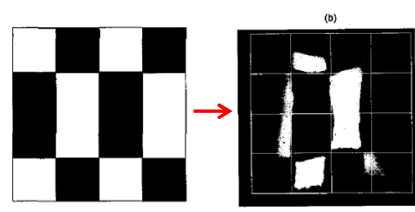

BNL. Bolotnikov et al. showing distorted internal fields in a thick detector.

Paul Seller, RAL 


\section{Science \& Technology
Facilities Councit}

Examples of imaging systems

-Si detectors readout holes, as high-resistivity Si wafers are usually n-type with $p+$ implanted pixels.

-Holes are slow and get trapped in CZT so not good for pixellated readout.

-...........Need different pixellated readout electronics for $\mathrm{CZT}$...........

•Existing systems which synchrotron and HEP users are well aware of:

-Medipix 1-2-3 CERN et. al.

-Pilatus PSI/Detris

-XPAD CPPM Marseille

-MPEC Bonn University

-CMS tracker, Atlas tracker, old LEP experiments

-Apart from CMS these are photon-counting with threshold not true energy resolving.

\section{Science 8 Technology
Facilities council}

\section{Examples of imaging systems:- Ciemat , Acrorad (CdTe)}

Ciemat CSTD 300um pixel Compton camera system for medical imaging
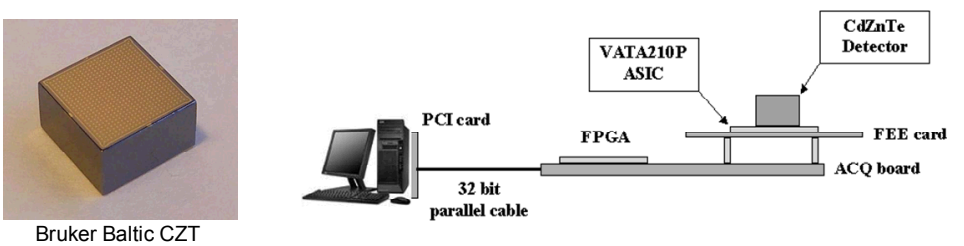

Acrorad CdTe 4-side buttable100um pixels 50fps FPD. (Uses TSV technology on ASIC)
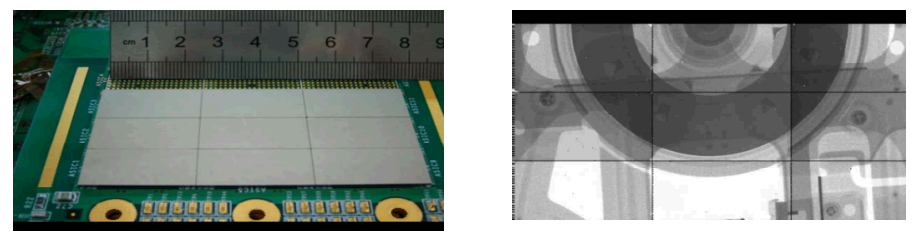

Energy Resolving CZT arrays

Paul Seller, RAL 


\section{Science \& Rechnology
Facilities Council}

Examples of imaging systems:- HEXITEC

-UK funded program to:

- make CZT material by MTPVT technique.

-make this into detectors.

-bond to an energy resolving imaging ASIC

- ASIC is $80^{*} 80$ pixels of 250 um with 12 bit resolution spectroscopy up to $150 \mathrm{keV}$ (or $1.5 \mathrm{MeV}$ )

-Maximum readout rate is $80 \mathrm{Meg}$ pixels/sec

-Data acquisition system will sparcify data on fly and sends to PC by Camera-link

-Durham, Surrey, Manchester, Birkbeck and STFC.
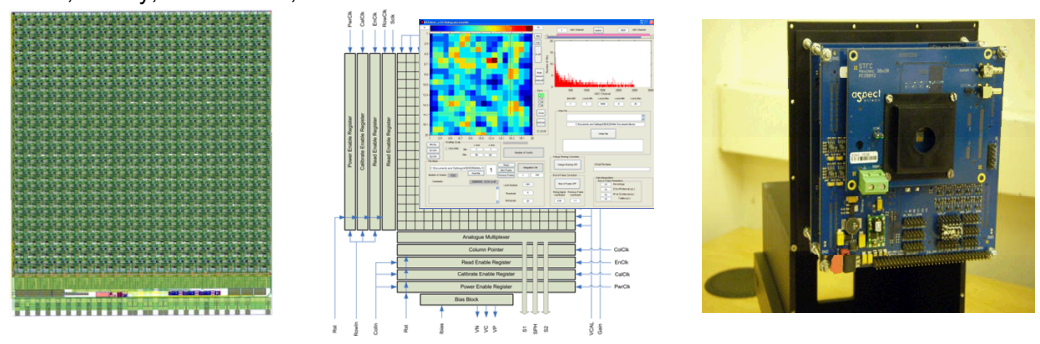

$20^{*} 20$ rolling shutter ASIC and camera-link based readout system $\left(80^{*} 80\right)$ by summer

\section{Science 8 Technology
Facilities Councit}

Example:- PORGAMRAYS Compton Gama camera for security applications

Portable Gamma Ray Spectrometer Compton Imaging and Spectroscopy

Partners:

STFC DL and RAL, Universities of Liverpool and Manchester, John Caunt Scientific, Centronic, Corus.

Funded by:

EPSRC and TSB
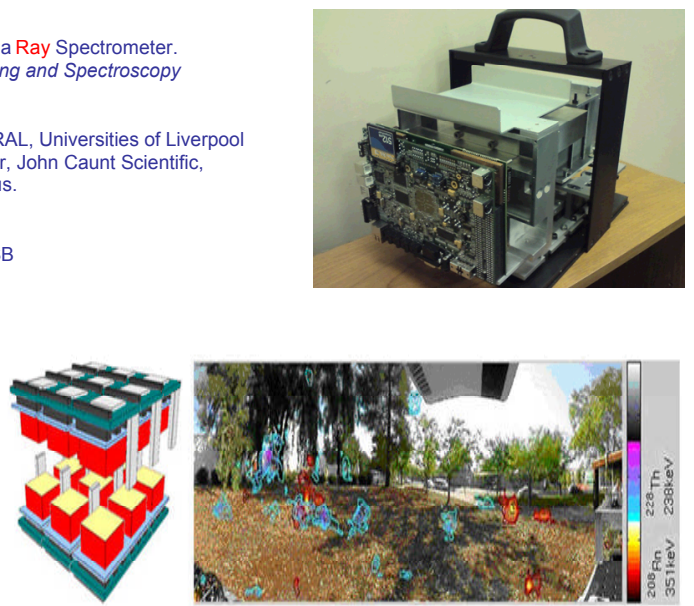

v Z. He et al, University of Michigan, IEEE NSS Conference Record, Hawaii 2007

Paul Seller, RAL 


\section{Science 8 Technology
Facilities councit}

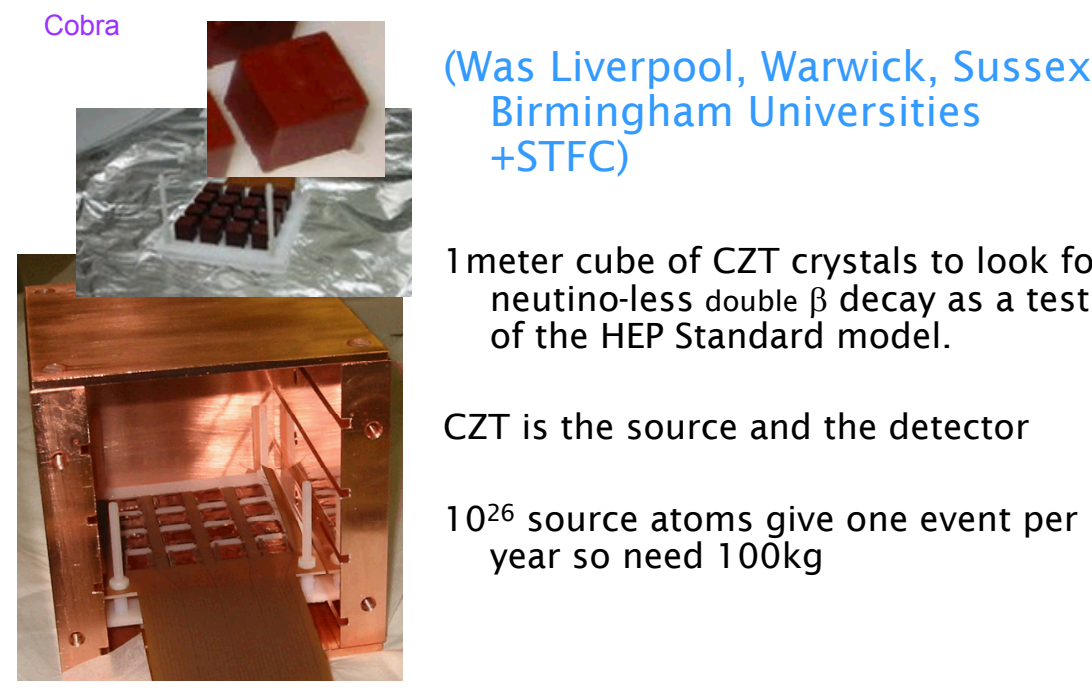

\section{Science 8 Technology
Facilities Council}

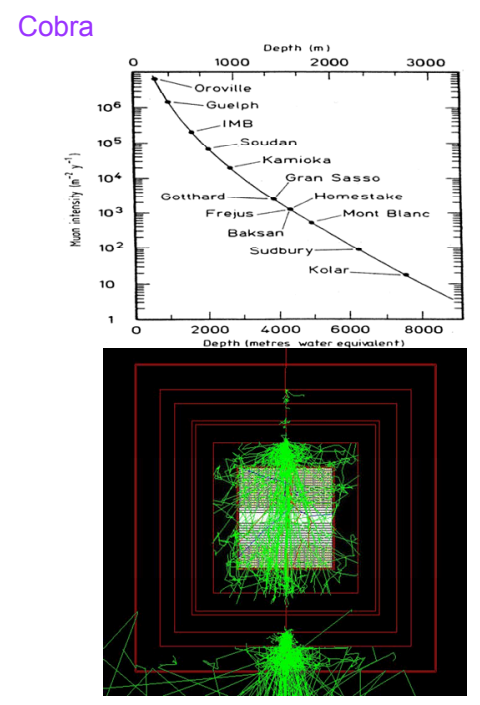

Energy Resolving CZT arrays
- Need to put the CZT in a mine to shield background cosmic rays

-Need to make CZT from isotopically enriched ${ }^{116} \mathrm{Cd}$

-Need to track interactions in the detector volume to get $1-2 \%$ accuracy of $2.8 \mathrm{MeV}$ decay. Need <200um voxel resolution.

-UK was proposing to use the PORGAMRAYS type technology.

-PPRP review in the UK decided not to follow this. There is an international collaboration with other physicists and CZT scientists 
Energy Resolution

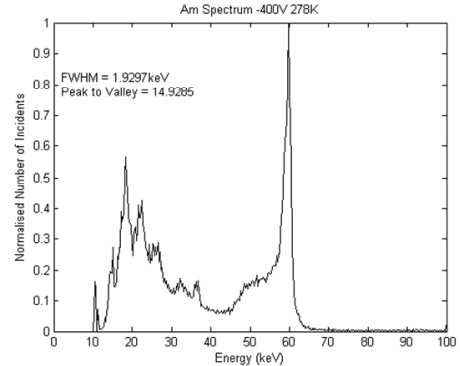

ERD2004 300um pixellated device. RAL. Am241 energy spectrum taken at $278 \mathrm{~K}$ and $-400 \mathrm{~V}$. Np peaks visible between 10 and $30 \mathrm{keV}$. The escape peaks of $\mathrm{Te}$ and $\mathrm{Cd}$ at 33 and $37 \mathrm{keV}$ respectively.
Best resolutions on Bulk detectors being

obtained are $0.8 \% \mathrm{FWHM} \mathrm{dE/E} \mathrm{with} \mathrm{signal}$

processing .(Zhong He below)

Typically used for $100-700 \mathrm{keV}$ with either

Coplanar-grid topology or double sided

readout. To get this resolution one has to

correct photopeaks for carrier trapping or use

small pixel effect to reject hole signal.

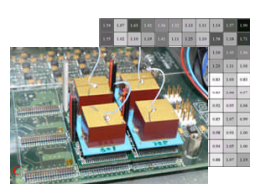

Three-Dimensional Position Sensitive CdZnTe Detector Array for PNNL.

Zhong $\mathrm{He}$, et. al. University of

Michigan wit h Gamma Medica

ASIC.

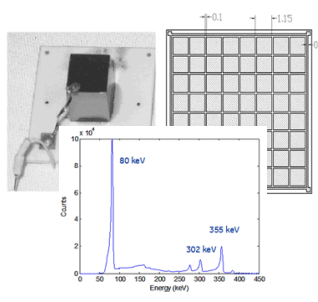

GE spectrometer with Rena-3 ASIC

Energy Resolving CZT arrays

Paul Seller, RAL 


\section{Appendix iii: Scintillators}

Robert G. Lanier

January 4, 2012

\section{Executive Summary}

\begin{tabular}{|c|c|c|c|c|c|c|c|c|c|c|}
\hline \multicolumn{11}{|c|}{ Critical Parameters for Selected Scintillators } \\
\hline & Nal:Tl & Csl:Tl & CaF2:Eu & $\mathrm{BaF}_{2}$ & YAG:Ce & YAP:Ce & GSO:Ce & BGO & LaBr:Ce & $\mathrm{CdWO}_{4}$ \\
\hline Density $[\mathrm{g} / \mathrm{cm} 3]$ & 3.67 & 4.51 & 3.18 & 4.89 & 4.57 & 5.37 & 6.71 & 7.13 & 5.03 & 7.89 \\
\hline Max Emmision $\lambda[\mathrm{nm}]$ & 415 & 550 & 435 & $325 / 220$ & 550 & 370 & 440 & 480 & 430 & $470 / 540$ \\
\hline Decay time [ns] & 230 & 900 & 940 & 630 & 70 & 25 & 45 & 300 & 25 & 12 \\
\hline Resolution @ 662kev [\%] $]^{(\mathrm{a})}$ & 8 & 5 & 6 & 12 & 5 & 7 & 10 & 14 & 3 & 10 \\
\hline Photon Yield [Photons/MeV] & 38,000 & 52,000 & 23,000 & 10,000 & 8,000 & 10,000 & 9,000 & 2,500 & 60,500 & 13,000 \\
\hline
\end{tabular}

The production of scintillator materials to service $\mathrm{x}$-ray detection applications by indirect methods remains a very active development area. This remains true even as there are concurrent and aggressive ongoing research programs to develop and investigate new scintillators or to improve the performance of existing and more popularly used materials. The table above collects together a number of critical parameters associated with

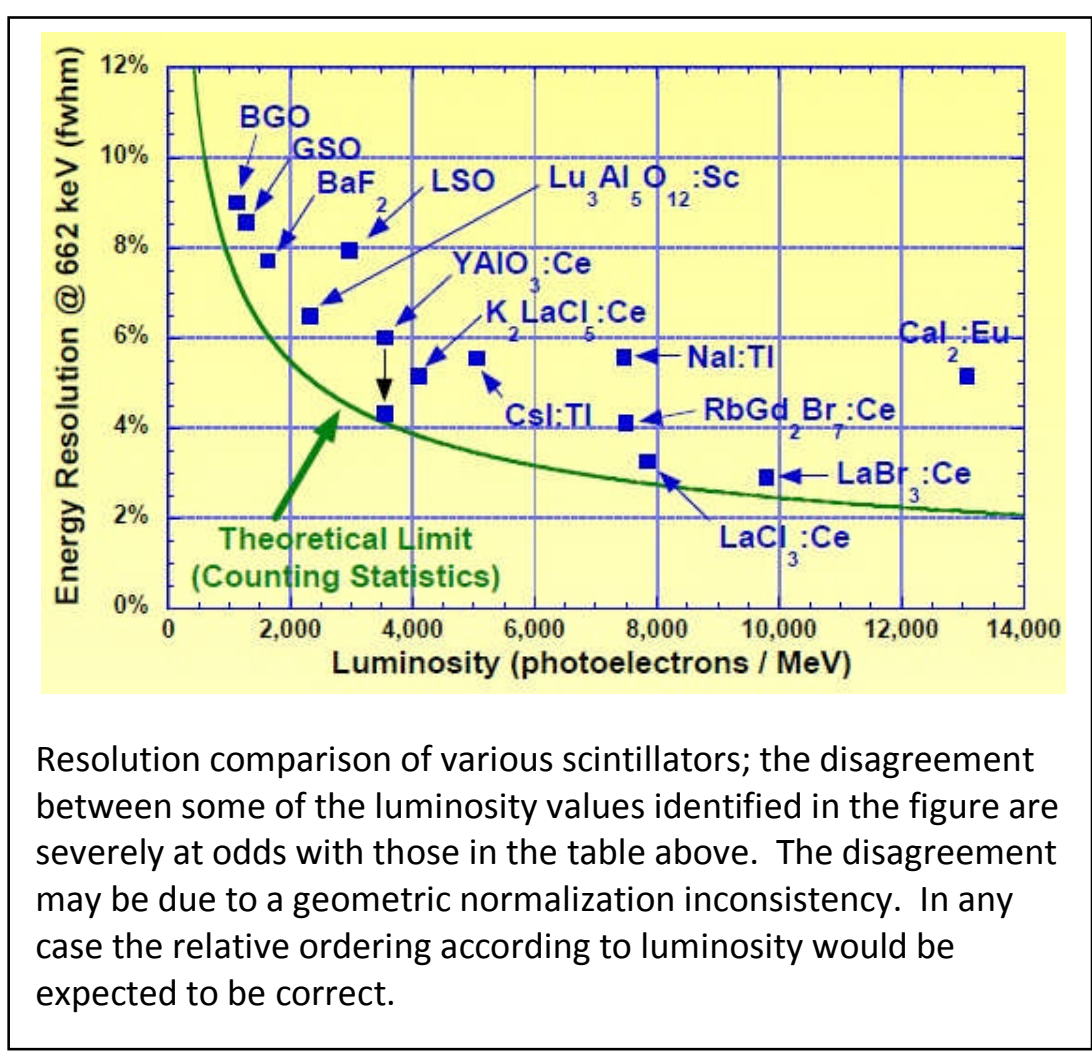
scintillators either widely used for various applications or among those under more focused development. The figure compares the resolutions of each crystal and plots the value vs luminosity. The medical community relies heavily on scintillator 
materials in their imaging applications and companies such as GE have their own in-house production facilities.

Three examples of the development of scintillator materials based on $\mathrm{Lu}$ and $\mathrm{Y}$ are described below. These include an example of research in the search for dopants that enhance certain desirable properties of these materials.

\begin{tabular}{|c|c|c|c|c|c|}
\hline \multicolumn{6}{|c|}{ Comparing the Properties of LU(Y)AP with Similar Crystals } \\
\hline \multirow[b]{2}{*}{ Property } & \multicolumn{5}{|c|}{ Material } \\
\hline & LSO & $\mathrm{BGO}$ & Lu(Y)AP & $\mathrm{LaBr}_{3}$ & LYSO \\
\hline Density $\left(\mathrm{g} / \mathrm{cm}^{3}\right)$ & 7.4 & 7.1 & $7.0-8.3$ & 5.3 & 7.1 \\
\hline Energy Resolution & $9 \%$ & $15 \%$ & $7 \%-9 \%$ & $3 \%$ & $10 \%$ \\
\hline Light Yield (relative to LSO) & 1 & $<0.2$ & $0.5-0.7$ & 2 & 1.2 \\
\hline Decay time $(\mathrm{ns})$ & 40 & 300 & 17 & 35 & 35 \\
\hline Physical robustness & Hard & Hard & Hard & Hygroscopic & Hard \\
\hline
\end{tabular}

Finally, the table in Appendix I catalogues the properties of a number of scintillator materials that have been developed for a variety of applications.

\section{$\operatorname{Lu}(Y) A P, \operatorname{LuAP}$}

LuYAP (lutetium yttrium aluminum perovskite) and LuAP (lutetium aluminum perovskite) crystals are a class of scintillators suitable for radiation detector modules for medical imaging and industrial applications, high energy physics, security scanning and research applications. These materials have very high density, fast decay times and provide competitive energy resolution.

Lu(Y)AP's good energy resolution, fast decay time and high stopping power makes it an alternative scintillation material for a number of advanced applications. Also, its robust high temperature performance is not typical of any other scintillating material.

In medical imaging Lu(Y)AP is essential in the phoswich design. It is an alternate choice for the next generation PET scanners and is expected to provide better image resolution, reduced scan time, reduced random noise and low scatter fraction.

In addition to medical imaging

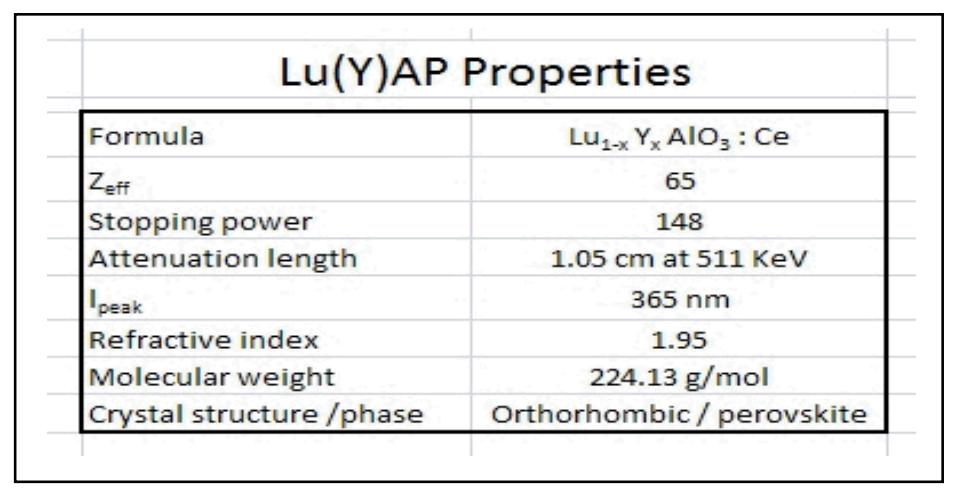


diagnostics, the crystal's good linearity response makes it an alternate candidate for all applications where precise gamma ray spectroscopy is required, such as industrial, homeland security equipment and high energy physics.

\begin{tabular}{|c|c|c|c|c|c|}
\hline \multicolumn{6}{|c|}{ YAG/YAP Comparison Table } \\
\hline \multicolumn{3}{|c|}{ Physical Properties } & \multicolumn{3}{|c|}{ Luminescence Properties } \\
\hline & YAG & YAP & & YAG & YAP \\
\hline Density $\left(\mathrm{g} / \mathrm{cm}^{3}\right)$ & 4.57 & 5.37 & $\begin{array}{l}\text { Integrated light } \\
\text { output (\%Nal: } \mathrm{Ti})\end{array}$ & 15 & 40 \\
\hline Hardness (Mho) & 8.5 & 8.6 & $\begin{array}{l}\text { Wavelength of } \\
\text { maximum emission } \\
(\mathrm{nm})\end{array}$ & 550 & 370 \\
\hline Index of refraction & 1.82 & 1.95 & Decay constant, ns & 70 & 25 \\
\hline Crystal structure & Cubic & Rhombic & $\begin{array}{l}\text { After glow (\% at } 6 \\
\text { ms) }\end{array}$ & $<0.005$ & $<0.005$ \\
\hline Melting point, ${ }^{\circ} \mathrm{C}$ & 1970 & 1875 & $\begin{array}{l}\text { Radiation length } \\
(\mathrm{cm})\end{array}$ & 3.5 & 2.7 \\
\hline Hygroscopic & No & No & $\begin{array}{l}\text { Photon yield at } 300 \\
{ }^{\circ} \mathrm{K}(103 \mathrm{Ph} / \mathrm{MeV})\end{array}$ & 8 & 10 \\
\hline $\begin{array}{l}\text { Linear coefficient of } \\
\text { thermal expansion, } \\
10-5 / K\end{array}$ & $0.8-0.9$ & $0.4-1.1$ & & & \\
\hline Cleavage & No & No & & & \\
\hline Chemical formula & $\mathrm{Y}_{3} \mathrm{Al}_{5} \mathrm{O}_{12}$ & $\mathrm{YAIO}_{3}$ & & & \\
\hline
\end{tabular}

Opto Materials ${ }^{34}$ is company that provides Lu(Y)AP crystals and identifies itself as a unique supplier worldwide of high-quality crystals which are offered in large boule formats. These can be supplied as finished pixels or assembled into customer specified array or module configurations.

In particular, the crystal expresses a scintillation emission peak is at $365 \mathrm{~nm}$, which matches well with the sensitivity spectrum of most PMTs with a light output that is twice that of BGO and a measured energy resolution at $662 \mathrm{keV}$ of $7 \%$ for $2 \times 2 \times 10$ $\mathrm{mm}$ crystals. The 1/e decay time of LuAP is $17 \mathrm{~ns}$, which is much shorter than the decay time of BGO. This allows high count rates and improved timing resolution.

\footnotetext{
${ }^{34}$ Opto Materials S.r.l., Localita' Baccasara, Zona Industriale, 08048 Tortoli'(OG), Italy
} http://www.optomaterials.com/Default.aspx 


\section{YAG/YAP Single Crystal Scintillators ${ }^{35}$}

Made of yttrium aluminum garnet activated with trivalent cerium, the $\underline{Y A G}$ exhibits ultrahigh light transmission $(\sim 97 \%)$ at $560 \mathrm{~nm}$. But the most important advantage is the high resistance of the single crystal scintillator to radiation damage. Other advantages include:

- Good signal-to-noise ratio.

- High temperature tolerance

- UHV "compatible"

- Refractive index: 1.84 at $550 \mathrm{~nm}$

- Self-absorption: $20 \%$ for $5 \mathrm{~mm}$ light path

Made of yttrium aluminum perovskite, the YAP single crystal is a breakthrough in the light output efficiency. Its emitted spectrum peaks at $378 \mathrm{~nm}$. The decay time of the YAP crystal is faster than the YAG crystal (40ns vs. 80ns). A list of additional features is noted below:

- Good signal-to-noise ratio.

\begin{tabular}{|c|c|c|c|c|}
\hline \multicolumn{5}{|c|}{ Properties of Rare-Earth (RE) Doped Ce:LSO Crystals } \\
\hline $\begin{array}{l}\text { Scintillator } \\
\text { Crystal }\end{array}$ & $\begin{array}{c}\text { Rare Earth } \\
\text { Concentration }\end{array}$ & $\begin{array}{c}\text { Crystal } \\
\text { Dimensions } \\
{\left[\mathrm{mm}^{3}\right]}\end{array}$ & $\begin{array}{c}\text { Energy } \\
\text { Resolution } \\
@ 511 \text { keV } \\
{[\mathrm{keV}]}\end{array}$ & $\begin{array}{c}\text { Photoelectron } \\
\text { Yield } \\
\text { [Photo- } \\
\text { electrons/MeV] }\end{array}$ \\
\hline ScLSO & 1 at $\% \mathrm{Sc}$ & $10 \times 10 \times 2$ & 15.9 & 4822 \\
\hline ScLSO & 1 at $\%$ Sc & $10 \times 10 \times 20$ & 16.1 & 4344 \\
\hline LaLSO & 1 at $\% \mathrm{La}$ & $10 \times 10 \times 2$ & 10.8 & 5474 \\
\hline LaLSO & 1 at $\%$ La & $10 \times 10 \times 20$ & 10.2 & 4696 \\
\hline GdLSO & 1 at $\%$ Gd & $10 \times 10 \times 2$ & 16.6 & 5500 \\
\hline LYSO & 4.47 at $\%$ Y & $10 \times 10 \times 20$ & 13.8 & 4840 \\
\hline LSO & & $10 \times 10 \times 2$ & 13.1 & 4470 \\
\hline
\end{tabular}

35 Available from SPI Supplies / Structure Probe, Inc., 569 East Gay Street, West Chester, PA 19380; spi3spi@2spi.com 
- High temperature tolerance

- Refractive index: 1.82

\section{Ce:LSO Scintillators}

Cerium doped lutetium oxyorthosilicate crystal, i.e., Ce: (LSO), is an efficient scintillator: It exhibits a very high light output (above 27000 photons/MeV), has high density $\left(7.4 \mathrm{gm} / \mathrm{cm}^{3}\right)$, exhibits a short decay time $(27 \mathrm{~ns})$ and has a suitable emission wavelength $(420 \mathrm{~nm})$.

Compared with LSO, both GSO and YSO have lower melting points and are easy to be doped into LSO crystals to essentially any percentage because of the similarity in crystal structure. Thus, the mixed scintillators LGSO and LYSO crystals are often presented as alternate choices. For example, LYSO presents similar scintillation properties and may be a good alternative to LSO. In addition, the addition of other rare earth (RE) ions may improve the distribution of $\mathrm{Ce}$ and the LSO photoelectron yield of LSO crystals. Recently, researchers ${ }^{36}$ have used several rare earth elements, such as Y, La, Sc and Gd ions, as dopants in LSO crystals to investigate these doping effects on crystal growth and scintillation properties. The tableabove shows some of the results of these doping effects on the scintillation properties of the Ce:LSO.

${ }^{36}$ Influence of Rare Earth (RE) Doping on the Scintillation Properties of LSO Crystals, Laishun Qin, Guohao Ren, Sheng Lu, Dongzhou Ding, and Huanying Li, IEEE Transactions on Nucl. Sci., 55, No 3, pp 1216-1220, June 2008 
Appendix I: Compilation of Scintillator Matrials and Their Properties

\begin{tabular}{|c|c|c|c|c|}
\hline $\begin{array}{c}\text { Scuntillator } \\
\text { Material }\end{array}$ & \begin{tabular}{|c|} 
Emission \\
Wavelength \\
\end{tabular} & Decay Time & Interfernce Index & Radiation Sensitivity \\
\hline $\mathrm{Gd}_{2} \mathrm{O}_{2} \mathrm{~S}: \mathrm{Tb}(\mathrm{P} 43)$ & \begin{tabular}{|l|} 
green (peak at \\
$545 \mathrm{~nm})$ \\
\end{tabular} & $\begin{array}{l}1.5 \mathrm{~ms} \text { decay } \\
\text { to } 10 \%\end{array}$ & low afterglow & $\begin{array}{l}\text { high X-ray absorption, for X-ray, neutrons and } \\
\text { gamma }\end{array}$ \\
\hline $\mathrm{Gd}_{2} \mathrm{O}_{2} \mathrm{~S}: \mathrm{Eu}$ & red $(627 \mathrm{~nm})$ & $850 \mu$ s decay & afterglow & $\begin{array}{l}\text { high X-ray absorption, for X-ray, neutrons and } \\
\text { gamma }\end{array}$ \\
\hline $\mathrm{Gd}_{2} \mathrm{O} 2 \mathrm{~S}: \mathrm{Pr}$ & green $(513 \mathrm{~nm})$ & $7 \mu$ s decay & no afterglow & $\begin{array}{l}\text { high X-ray absorption, for X-ray, neutrons and } \\
\text { gamma }\end{array}$ \\
\hline $\mathrm{Gd}_{2} \mathrm{O}_{2} \mathrm{~S}: \mathrm{Pr}, \mathrm{Ce}, \mathrm{F}$ & green $(513 \mathrm{~nm})$ & $4 \mu$ s decay & no afterglow & $\begin{array}{l}\text { high X-ray absorption, for X-ray, neutrons and } \\
\text { gamma }\end{array}$ \\
\hline $\mathrm{Y}_{2} \mathrm{O}_{2} \mathrm{~S}: \mathrm{Tb}(\mathrm{P} 45)$ & white $(545 \mathrm{~nm})$ & $1.5 \mathrm{~ms}$ decay & $\begin{array}{l}\text { low afterglow for low- } \\
\text { energy X-ray }\end{array}$ & \\
\hline $\mathrm{Y}_{2} \mathrm{O}_{2} \mathrm{~S}: \mathrm{Eu}(\mathrm{P} 22 \mathrm{R})$ & $\operatorname{red}(627 \mathrm{~nm})$ & $850 \mu$ s decay & $\begin{array}{l}\text { low afterglow for low- } \\
\text { energy X-ray }\end{array}$ & \\
\hline $\mathrm{Y}_{2} \mathrm{O}_{2} \mathrm{~S}: \mathrm{Pr}$ & white $(513 \mathrm{~nm})$ & $7 \mu$ decay & $\begin{array}{l}\text { low afterglow for low- } \\
\text { energy X-ray }\end{array}$ & \\
\hline $\begin{array}{l}\mathrm{Zn}(0.5) \mathrm{Cd}(0.4) \mathrm{S}: \mathrm{Ag} \\
\text { (HS) }\end{array}$ & green $(560 \mathrm{~nm})$ & $80 \mu$ s decay & afterglow & efficient but low-res X-ray \\
\hline $\begin{array}{l}\mathrm{Zn}(0.4) \mathrm{Cd}(0.6) \mathrm{S}: \mathrm{Ag} \\
(\mathrm{HSr})\end{array}$ & red $(630 \mathrm{~nm})$ & $80 \mu \mathrm{s}$ decay & afterglow & efficient but low-res X-ray \\
\hline $\mathrm{CdWO}_{4}$ & blue $(475 \mathrm{~nm})$ & $28 \mu \mathrm{s}$ decay & no afterglow & intensifying phosphor for X-ray and gamma \\
\hline $\mathrm{CaWO}_{4}$ & blue $(410 \mathrm{~nm})$ & $20 \mu \mathrm{s}$ decay & no afterglow & intensifying phosphor for X-ray \\
\hline $\mathrm{MgWO} 4$ & white $(500 \mathrm{~nm})$ & $80 \mu$ s decay & no afterglow & intensifying phosphor \\
\hline Y2SiO5:Ce (P47) & blue $(400 \mathrm{~nm})$ & 120 ns decay & no afterglow for electrons & suitable for photomultipliers \\
\hline YAlO3:Ce (YAP) & blue (370 nm) & 25 ns decay & afterglow for electrons & suitable for photomultipliers \\
\hline $\begin{array}{l}\text { Y3A15O12:Ce } \\
\text { (YAG) }\end{array}$ & green $(550 \mathrm{~nm})$ & 70 ns decay & no afterglow for electrons & suitable for photomultipliers \\
\hline $\begin{array}{l}\text { Y3(AlGa)5O12:Ce } \\
\text { (YGG) }\end{array}$ & green $(530 \mathrm{~nm})$ & 250 ns decay & low afterglow for electrons & suitable for photomultipliers \\
\hline CdS:In & green $(525 \mathrm{~nm})$ & $<1$ ns decay & no afterglow & ultrafast for electrons \\
\hline $\mathrm{ZnO}: \mathrm{Ga}$ & blue $(390 \mathrm{~nm})$ & $<5$ ns decay & no afterglow & ultrafast for electrons \\
\hline $\mathrm{ZnO}: \mathrm{Zn}(\mathrm{P} 15)$ & blue $(495 \mathrm{~nm})$ & $8 \mu$ s decay & $\begin{array}{l}\text { no afterglow for low-energy } \\
\text { electrons }\end{array}$ & \\
\hline $\begin{array}{l}(\mathrm{ZnCd}) \mathrm{S}: \mathrm{CuAl} \\
(\mathrm{P} 22 \mathrm{G})\end{array}$ & green $(565 \mathrm{~nm})$ & $35 \mu$ s decay & low afterglow for electrons & \\
\hline $\mathrm{ZnS}: \mathrm{CuAlAu}(\mathrm{P} 22 \mathrm{G})$ & green $(540 \mathrm{~nm})$ & $35 \mu$ s decay & low afterglow for electrons & \\
\hline $\mathrm{ZnCdS:AgCu(P20)}$ & green $(530 \mathrm{~nm})$ & $80 \mu$ s decay & low afterglow for electrons & \\
\hline $\mathrm{ZnS}: \mathrm{Ag}(\mathrm{P} 11)$ & blue $(455 \mathrm{~nm})$ & $80 \mu \mathrm{s}$ decay & $\begin{array}{l}\text { low afterglow for alpha } \\
\text { particles and electrons }\end{array}$ & \\
\hline anthracene & blue $(447 \mathrm{~nm})$ & 32 ns decay & no afterglow & \\
\hline plastic (EJ-212) & blue $(400 \mathrm{~nm})$ & 2.4 ns decay & $\begin{array}{l}\text { low afterglow for alpha } \\
\text { particles and electrons }\end{array}$ & \\
\hline $\mathrm{Zn} 2 \mathrm{SiO} 4: \mathrm{Mn}(\mathrm{P} 1)$ & green $(530 \mathrm{~nm})$ & $11 \mathrm{~ms}$ decay & low afterglow for electrons & \\
\hline $\mathrm{ZnS}: \mathrm{Cu}(\mathrm{GS})$ & green $(520 \mathrm{~nm})$ & $\begin{array}{l}\text { decay in } \\
\text { minutes }\end{array}$ & long afterglow for X-rays & \\
\hline NaI:Tl & for X-ray & alpha & and electrons & \\
\hline CsI:Tl & green $(545 \mathrm{~nm})$ & $5 \mu$ decay & $\begin{array}{l}\text { afterglow for X-ray, alpha } \\
\text { and electrons }\end{array}$ & \\
\hline 6LiF/ZnS:Ag (ND) & blue $(455 \mathrm{~nm})$ & $80 \mu$ s decay & for thermal neutrons & \\
\hline $\begin{array}{l}\text { 6LiF/ZnS:CuAlAu } \\
\text { (NDg) }\end{array}$ & green $(565 \mathrm{~nm})$ & $35 \mu$ s decay & for neutrons & \\
\hline
\end{tabular}




\title{
Appendix iv: Comparison of CMOS Detectors for Mamography
}

\author{
Robert G. Lanier \\ April 4, 2012
}

A PhD thesis ${ }^{37}$ submitted in 2011 to the University College London entitled Evaluation of Digital X-ray Detectors for Medical Imaging Applications contains a useful collection of data on the performance comparisons of several currently available digital x-ray systems. The primary focus of the thesis was to study the standard electro-optical performance evaluation of two novel CMOS (complementary metal oxide semiconductor) active pixel sensors against three commercial systems: (1) Remote RedEye HR, an active pixel sensor, (2) Hamamatsu C9732DK, a passive pixel sensor, and (3) an Anrad SMAM, an amorphous Se thin film transistor array. The novel systems were (1) a Large Area Sensor (LAS) built by a UK Consortium ${ }^{38}$ and (2) a Dexela CMOS $\mathrm{X}$-ray detector from Perkin Elmer. Figure 1below displays the relative performance of these systems through the comparisons of their respective presampling Modulation Transfer Functions (PMTF) and quantum detection efficiency (QDE).

The thesis also contains a table (reproduced below) that compares the x-ray performance of 13 detectors used in mammography.

\footnotetext{
${ }^{37}$ Evaluation of Digital X-ray Detectors for Medical Imaging Applications by Anastasios C. Konstantinidis, a Thesis Submitted to the University College Londin for the Degree of Doctor of Philosophy, Department of Medical Physics and Bioengineering University College London, England (2011)

${ }^{38}$ The RC-UK Basic Technology Programme which involves 11 research centers throughout the United Kingdom. The aim of this consortium is to develop CMOS APS for a broad range of scientific applications.
} 
Figure 2: Comparison of the $x$-ray Performance of Different Detectors Used in Mammography.

\begin{tabular}{|c|c|c|c|c|c|}
\hline Detector & $\begin{array}{l}\text { Detector } \\
\text { technology }\end{array}$ & $\begin{array}{c}\text { X-ray } \\
\text { absorber } \\
\text { material }\end{array}$ & $\begin{array}{l}\text { Radiation } \\
\text { quality }\end{array}$ & $\begin{array}{c}\text { pMTF } 50 \% \\
(x ; y-l p / m m)\end{array}$ & $\begin{array}{l}\text { DQE peak (x;y) at } \\
\text { specific DAK level }\end{array}$ \\
\hline $\begin{array}{c}\text { FUJIFILM } \\
\text { AMULET }\end{array}$ & a-Se TFT & $200 \mu \mathrm{m}$ a-Se & $\mathrm{W} / \mathrm{Rh}(28 \mathrm{kV})$ & 4.4 & 0.75 at $103 \mu \mathrm{Gy}$ \\
\hline $\begin{array}{c}\text { Sectra } \\
\text { MicroDose }\end{array}$ & $\begin{array}{l}\text { Direct photon } \\
\text { counting }\end{array}$ & $\begin{array}{l}\text { Crystalline } \mathrm{Si} \\
\text { wafer }\end{array}$ & $\mathrm{W} / \mathrm{Al}(28 \mathrm{kV})$ & $6.2 ; 3.3$ & $\begin{array}{c}0.63 ; 0.61 \\
\text { at } 113 \mu \mathrm{Gy}\end{array}$ \\
\hline $\begin{array}{l}\text { Fischer } \\
\text { Senoscan }\end{array}$ & $\mathrm{CCD}$ & $180 \mu \mathrm{m}$ CsI:T1 & $\mathrm{W} / \mathrm{Al}(28 \mathrm{kV})$ & 5.5 & 0.24 at $131 \mu \mathrm{Gy}$ \\
\hline $\begin{array}{c}\text { GE } \\
\text { Senographe } \\
2000 D\end{array}$ & a-Si:H TFT & $100 \mu \mathrm{m}$ CsI:T1 & $\begin{array}{c}\mathrm{Mo} / \mathrm{Mo}(28 \mathrm{kV}) \\
\text { (RQA-M 2) }\end{array}$ & 4 & 0.53 at $131 \mu \mathrm{Gy}$ \\
\hline $\begin{array}{c}\text { Hologic } \\
\text { Lorad } \\
\text { Selenia }\end{array}$ & a-Se TFT & $200 \mu \mathrm{m}$ a-Se & $\begin{array}{c}\mathrm{Mo} / \mathrm{Mo}(28 \mathrm{kV}) \\
\text { (RQA-M 2) }\end{array}$ & 5.8 & 0.59 at $92.5 \mu \mathrm{Gy}$ \\
\hline LAS & CMOS APS & $150 \mu \mathrm{m}$ CsI:T1 & $\mathrm{W} / \mathrm{Al}(28 \mathrm{kV})$ & 1.5 & 0.73 at $60.3 \mu \mathrm{Gy}$ \\
\hline $\begin{array}{c}\text { Hamamatsu } \\
C 9732 D K\end{array}$ & CMOS PPS & $160 \mu \mathrm{m}$ CsI:T1 & $\mathrm{W} / \mathrm{Al}(28 \mathrm{kV})$ & 3.3 & 0.48 at $120.5 \mu \mathrm{Gy}$ \\
\hline Dexela 2932 & CMOS APS & $150 \mu \mathrm{m}$ CsI:T1 & $\mathrm{W} / \mathrm{Rh}(25 \mathrm{kV})$ & 2.7 & $\begin{array}{c}0.59 \text { at } 105.7 \mu \mathrm{Gy} \\
\text { (HFW mode) }\end{array}$ \\
\hline Dexela 2932 & CMOS APS & $150 \mu \mathrm{m}$ CsI:T1 & $\mathrm{W} / \mathrm{Rh}(25 \mathrm{kV})$ & 2.7 & $\begin{array}{l}0.61 \text { at } 57.8 \mu \mathrm{Gy} \\
\text { (LFW mode) }\end{array}$ \\
\hline Dexela 2932 & CMOS APS & $150 \mu \mathrm{m}$ CsI:T1 & $\mathrm{W} / \mathrm{Al}(28 \mathrm{kV})$ & 3.3 & $\begin{array}{c}0.55 \text { at } 121.6 \mu \mathrm{Gy} \\
\text { (HFW mode) }\end{array}$ \\
\hline Dexela 2932 & CMOS APS & $150 \mu \mathrm{m}$ CsI:T1 & $\mathrm{W} / \mathrm{Al}(28 \mathrm{kV})$ & 3.3 & $\begin{array}{c}0.55 \text { at } 59.7 \mu \mathrm{Gy} \\
\text { (LFW mode) }\end{array}$ \\
\hline $\begin{array}{l}\text { Anrad } \\
S M A M\end{array}$ & a-Se TFT & $200 \mu \mathrm{m}$ a-Se & $\mathrm{W} / \mathrm{Al}(28 \mathrm{kV})$ & $6.1 ; 5.3$ & $\begin{array}{c}0.67 ; 0.66 \text { at } 108.6 \\
\mu \mathrm{Gy}\end{array}$ \\
\hline $\begin{array}{c}\text { Remote } \\
\text { RadEye } H R\end{array}$ & CMOS APS & $\begin{array}{c}85 \mu \mathrm{m} \\
\mathrm{Gd}_{2} \mathrm{O}_{2} \mathrm{~S}: \mathrm{Tb}\end{array}$ & $\mathrm{W} / \mathrm{Al}(28 \mathrm{kV})$ & 4.3 & 0.33 at $120.5 \mu \mathrm{Gy}$ \\
\hline
\end{tabular}




\section{Appendix v: A Collection of Recent Imaging Technology Developments}

Robert G. Lanier

January 3, 2012

May 15, 2012 (updated)

\section{Executive Summary}

A collection of encapsulated summaries of recent technology developments in the area of x-ray imaging is presented. The list presented is not exhaustive but it is representative of most of the major advances in this technological area.

Specifically, the excerpts highlight advances in scintillator development and highresolution detectors along with their associated electronic components. Generally, the examples presented focus on capturing $x$-ray information in the energy range associated with medical imaging applications (i.e. $\sim 30 \mathrm{keV}-160-\mathrm{kev}$ ).

However, a few items are mentioned from astronomical and space-borne research sources that cover energy ranges outside this domain. These have been included to cover the possibility that the electronics developed for these applications would overlap with general US Homeland Security interests.

The presentation format first presents a brief list of the technologies identified. This is followed by an expanded list where the technology is identified followed by the name of the institution, company or consortium responsible for its development. This is followed by a website references where more information may be found and a short descriptive text. Finally, a figure is included to provide a visual reference to the technology.

In one or two cases, the company offering to sell the technology also offers professional engineering services to provide an interested patron with the option of partnering with the company to develop a unique or "one of" application of the technology. These examples are noted as part of the exposition excerpts as well. 
1. Flash Pad - GE

2. PHOTON 100 - Bruker AXS

3. XinRay Systems - Siemens.

4. Digital Silicon Photomultipliers - Phillips

5. CdZnTe (CZT) Detectors- Redlen

6. Lensfree Optical Tomography - UCLA Research

$7 . \quad$ D-SPECT System - Spectrum Dynamics

8. XDAS detector boards V3 - Sens Tech

9. Ultrafast Ceramic Scintillator (UFC) - Siemens.

10. Advanced X-Ray Detectors-DxRay Inc

11. CCD Detector Development- MPI Halbleiterlabor,

12. DEPFET Detectors - MPI Halbleiterlabor

13. HICAM Gamma Camera - HICAM Collaboration

14. LuAG Scintillator Array - Japan Research

15. Strip Detectors - Baltic Scientific Instruments

16. The Solid-State X-Ray Image Intensifier (SSXII) - SUNY Researchers

17. RadEye ${ }^{\mathrm{TM}} \mathbf{X}$-ray Sensor Modules - Teledyne Rad-icon Imaging

18. The INTEGRAL Soft Gamma-Ray Imager (ISGRI) - ACRORAD

19. CCD 485 with Fiber Optic Faceplate - Fairchild Imaging

20. CMOS Linear Arrays- Fairchild Imaging

21. Selenium-based Flat panel X-ray Detector - Toshiba

22. SAPHIRE (scintillator avalanche photoconductor with highresolution emitter readout) Detector - .University-Industry Collaboration

23. (DEXI) diffraction-enhanced x-ray imaging instrument - Nesch, LLC

24. Linear scanning sensors with gas-based detector modules for X-ray imaging- Korean Collaboration

25. Security Detectors; High-energy X-ray Platforms - Varian 


\section{Flash Pad - GE}

http://www.gehealthcare.com/euen/radiography/radiography-flashpad.html http://www.newdesignworld.com/press/story/236923 http://www.wcet.us/wpcontent/uploads/201 $\underline{0 / 08 / 5 \text { GE Healthcare tour.pdf }}$

FlashPad is the first wireless detector to operate with Ultra- Wideband (UWB) connectivity. Rather than compete with other information on WI-FI networks, it communicates independently on a dedicated, high-priority channel - so data is transferred with speed and reliability. FlashPad can acquire multiple images in less than a second - so it can deliver advanced applications such as VolumeRAD* and Dual Energy Subtraction - helping enhance clinical confidence. As a digital detector, FlashPad enables you to image patients at less dose than $\mathrm{CR}$ and do it more quickly. The unit uses a CsI scintillators.

\section{PHOTON 100 - Bruker AXS}

http://www.bruker-

axs.com/photon100_cmos_sensor_single_crystal_crystallogr aphy.html

Diffracted X-ray photons are converted into visible light using high resolution phosphor screens and introduce charges on the sensor. These charges are readout from each pixel through a readout bus, similar to a random access

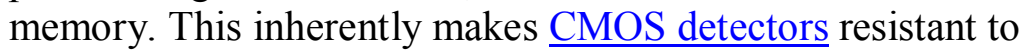
overexposure and charge overflows causing blooming and

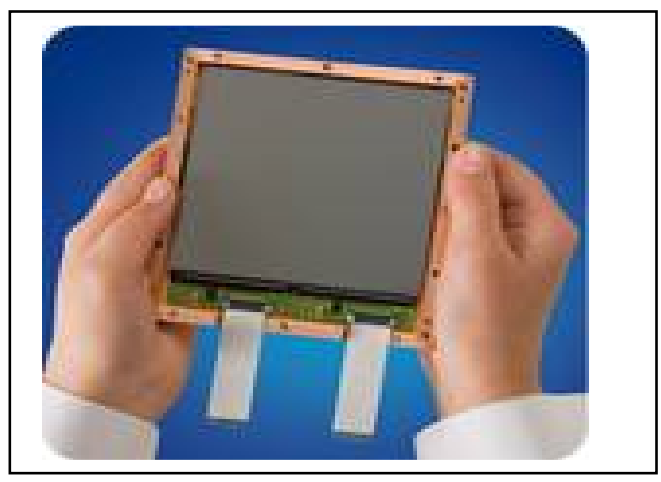
streaking.

Active area 100-cm2 CMOS Sensor

Cooling Air cooled

Sensor format $1024 * 1024$

Sensor Full well 4,000,000 (electrons, 10242)

Pixel size $96 \mu \mathrm{m}$

Demagnification 1:1 (no taper) 


\section{XinRay Systems - Siemens.}

http://nanopatentsandinnovations.blogspot.com/2010/01/siemens-unveils-fast-computertomograph.html

A fast computer tomograph (CT) system enabled by carbon nanotubes for airport $\mathrm{X}$-ray scans of people and baggage is being developed by Siemens and Xintek in a joint venture. Siemens Researchers are investigating the use of small, fast $\mathrm{X}$-ray sources based on nanotubes. In combination with a computer tomograph (CT) scanner, these could serve to generate high-quality images of rapid processes within the human body, such as the dispersion of a contrast medium. It will take several years before such X-ray sources can be used in practical applications.

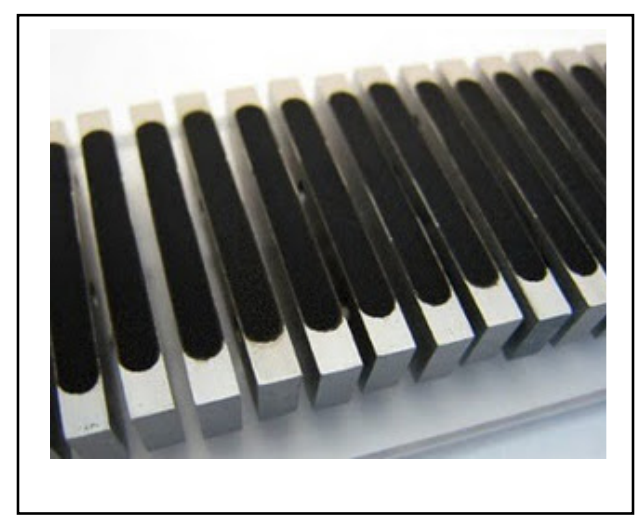

\section{Digital Silicon Photomultipliers - Phillips}

http://www.dicardiology.com/article/major-progress-made-fully-digital-light-detectiontechnology http://www.research.philips.com/initiatives/digitalphotoncounting/news/backgrounders/091008photon-counting.html

http://indico.cern.ch/getFile.py/access?contribId=11\&sessionId=7\&resId=0\&materialId=slides \& confld $=117424$

A new digital silicon photomultiplier (SiPM) technology has been developed with applications in both X-ray and nuclear imaging. The technology scales a single-pixel sensor to a fully integrated 64pixel sensor with a sensing surface of more than 10 square centimeters.

The unit is capable of counting single photons and detecting their arrival time with an accuracy of around 60 picoseconds and are scalable to large-area applications. Like photomultiplier tubes, SiPM's are capable of measuring extremely low light levels, to the point of being able to detect single photons.

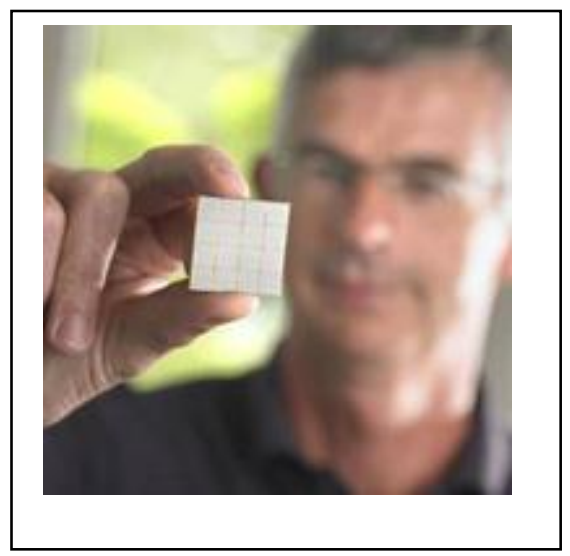

The company claims that the technology's scalability could have a major impact on the medical imaging field, particularly positron emission tomography. The technology offers a rugged, light weight, solid-state alternative to large-area sensors using photomultiplier tubes. Additionally, it consumes very little power. A prototype 8 by 8 pixel array consumes less than one $\mathrm{W}$, and it is insensitive to magnetic fields. 


\section{CdZnTe (CZT) Detectors- Redlen}

http://www.redlen.com/wp-content/uploads/2011/06/Redlen-Nuclear-Imaging-Module-ShortformDatasheet.pdf

Redlen Technologies claims to be "... leading the revolution in highperformance, CZT-based radiation detection and imaging technology" and is developing "... a new generation of high-performance equipment in ... "Nuclear Cardiology, CT Scanning, Airport Baggage Scanning and Dirty Bomb Detection". The company further claims that it is accomplishing this

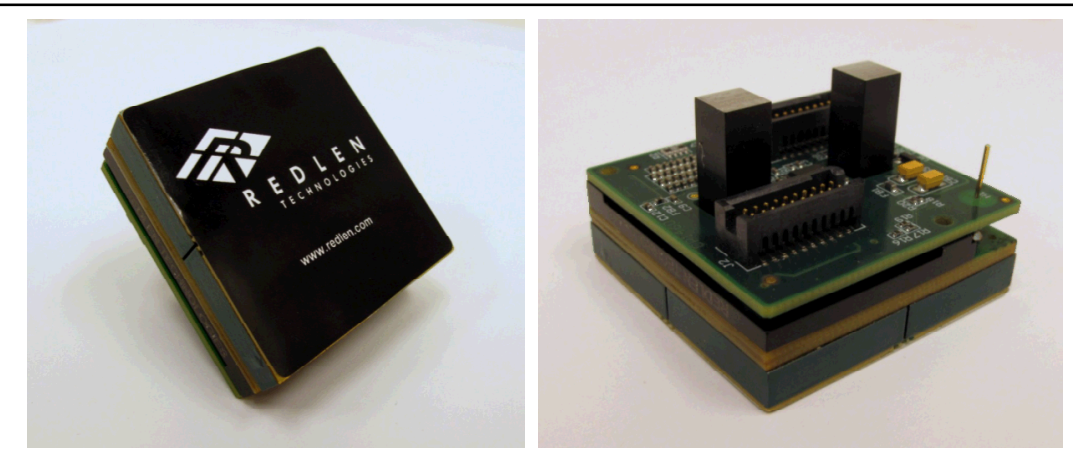

CZT detector module (left) mounted with electronic interface (right) by “... proprietary CZT semiconductor production technology....” which provides low-cost CZT radiation with "superior" resolution.

\section{Lensfree Optical Tomography - UCLA Research}

\section{$\underline{\text { http://spie.org/x84293.xml?highlight }=x 2416 \& \text { ArticleID }=x 84293}$}

A device capable of achieving tomographic microscopy of microobjects over large imaging volumes has been developed. Lensfree Optical Tomography (LOT) can provide a useful tool for lab-on-achip platforms and high-throughput imaging applications in lowresource settings. Using emerging sensor-array architectures,

researchers hope to extend the angular range of illumination to, for example, $\pm 80^{\circ}$. These may offer improved pixel-response at even higher incident angles and should allow the achievement of neaisotropic $3 \mathrm{D}$ resolution at the sub-micrometer scale.

A photograph (left) and schematic diagram (right) is shown of the field-portable lensfree tomographic microscope. Individual LEDs buttcoupled to multimode optical fibers provide multiple angles of illumination. Optical fibers are electromagnetically actuated to implement source-shifting based pixel super-resolution at each illumination angle. 


\section{D-SPECT System - Spectrum Dynamics}

http://www.itnonline.com/tech/spect-cardiac-imaging-system-incorporates-czt-modules http://www.spectrum-dynamics.com/

Spectrum Dynamics' D-SPECT (single photon emission computed tomography) system uses a cadmium zinc telluride (CZT) nuclear imaging detector, which enable high resolution, low-dose nuclear imaging. The design incorporates nine rotating columns of CZT detectors that are able to focus on specific anatomical points in the body, thereby improving the signal-to-noise-ratio. This also eliminates the need to rotate the gantry or the patient to sample the organ of interest.

Solid-state CZT based detectors, combined with advanced reconstruction algorithms, provide the foundation for rapid imaging and clinical applications not possible with conventional sodium iodide based detectors. They also enable dramatic reductions in radiation dose to the patient and significant improvements in image quality.

The Redlen M1762 nuclear imaging module provides a 40 x $40 \mathrm{~mm}$ CZT imaging array with 256 pixels. The module provides direct digital readout and averages less than 6 percent energy resolution for Tc-99 based imaging. The module is a key building block to enable a new generation of direct conversion low-dose, high-resolution nuclear imaging cameras.

\section{XDAS detector boards V3 - Sens Tech}

http://www.sens-tech.com/Products/XDAS/

The XDAS X-Ray Data Acquisition System provides a highly flexible means of creating an array of linear Xrays sensors, read out in digital format. The XDAS-V3 version has recently been launched to replace XDAS-V2 and provides many new features. The XDAS-V2 version remains available.

The system has a modular architecture, enabling system

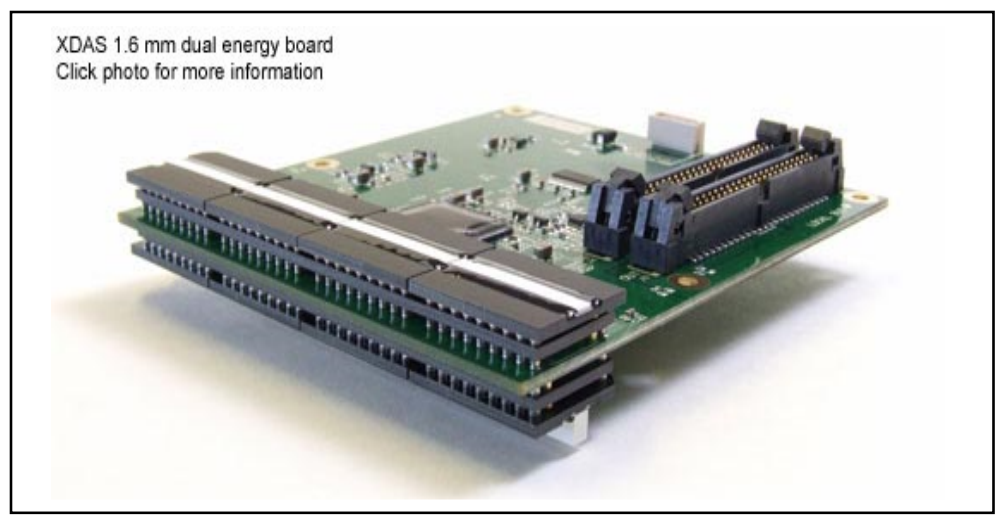
designers to build their own detectors with detector boards arranged as required. These may be in a linear or 'L' shaped format or with multiple rows for CT detector applications, where the detectors are arranged around a ring. Detectors can be supplied with $2.5 \mathrm{~mm}, 1.6 \mathrm{~mm}, 0.8 \mathrm{~mm}$ or $0.4 \mathrm{~mm}$ pitch. 


\section{Ultrafast Ceramic Scintillator (UFC) - Siemens.}

http://www.medical.siemens.com/webapp/wcs/stores/servlet/CategoryDisplay q q_atalogId e_$11 \sim$ a_categoryId e_1033570 a_catTree e_100010,1007660,12752,1033569,1033570 a_langId $\sim \mathrm{e}_{-}-\overline{1} 1 \sim \mathrm{a} \_$storeId $\mathrm{e}_{-} 10001 . \mathrm{htm}$

UFC or Ultra Fast Ceramic is a scintillator material which quickly and efficiently transforms radiation from the $\mathrm{X}$-ray tube into light signals. These signals in the visible spectrum are in turn picked up by photodiodes, transforming them into electric signals, which are computed to become visual 2D or 3D images.

Conventionally, other single crystalline substances are used in X-ray detectors

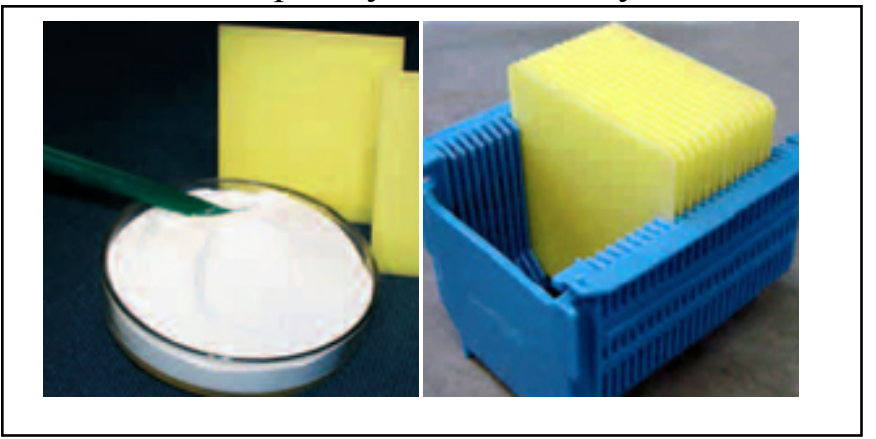
such as cadmium tungstate $\left(\mathrm{CdWO}_{4}\right)$, or cesium iodide (CsI). The Siemens Ultra Fast Ceramic uses instead a crystal lattice of the rare earth compound gadolinium oxysulfide (GOS) along with other dopants. The exact concentrations are proprietary. UFC has a large X-ray absorption coefficient and due to its fast decay, reacts very rapidly to changes in X-ray intensity. The vendor claims that UFC is superior to conventional detector materials in ways which include light output, decay time and drift. Competing products are also marketed by GE-Healthcare under the trade names Gemstone ${ }^{\mathrm{TM}}$ and HiLight $^{\mathrm{TM}}$.

\section{Advanced X-Ray Detectors- DxRay Inc}

http://www.dxray.com/

DxRay, Inc. claims that it researches, develops, markets and manufactures the next generation of detector technology for digital x-ray imaging. It further claims expertise in semiconductor detector materials such as silicon, mercuric iodide, cadmium zinc telluride, and cadmium telluride and in the most advanced high density ASICs (Application Specific Integrated Circuits) for solid state radiation sensor applications. The company's business model combines expertise and intellectual property, including patents and know-how related to semiconductor

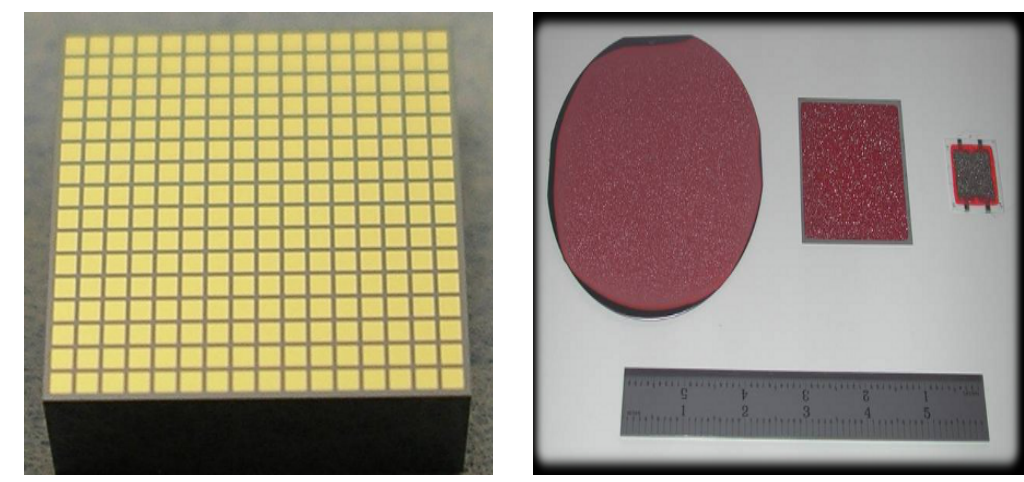

Left; CdTe Pixel Detector with Pitch of 0.5mm; Right; Examples of polycrystalline mercuric iodide $x$-ray detector films grown on various substrates.

sensor technologies with ASIC multichannel amplification and processing electronics. As such, the company claims to be able to carry out the most advanced x-ray imaging sensor developments. Examples of the company's products are shown in the figure. 


\section{CCD Detector Development- MPI Halbleiterlabor,}

http://ieeexplore.ieee.org/stamp/

stamp.jsp?tp $=$ \&arnumber $=5873$

$\underline{711}$

The German X-ray telescope eROSITA is the core instrument on the Russian satellite Spectrum-Roentgen-Gamma (SRG). Its scientific goal is the exploration of the X-ray Universe in the energy band from about $0.3 \mathrm{keV}$ up to 10 $\mathrm{keV}$ with excellent energy, time and spatial resolution and large effective telescope area. For high-resolution detection of Xray photons, frame transfer pnCCDs and their associated front-end electronics have been developed. The back-illuminated, $450 \mu \mathrm{m}$ thick and fully depleted pnCCDs with a $3 \mathrm{~cm} \mathrm{x} 3 \mathrm{~cm}$ large image area have been produced. By means of the concept of back-illumination and full depletion of the chip thickness, high quantum efficiency is obtained over the entire energy band of interest. An analog signal processor with 128 parallel channels was also developed for readout of the pnCCD signals. This ASIC permits fast and low noise signal filtering. For a detailed characterization of the CCD detectors an appropriate control, supply and data acquisition electronics system was developed.

\section{DEPFET Detectors - MPI Halbleiterlabor}

http://ieeexplore.ieee.org/stamp/stamp.jsp?tp $=$ \&arnumber $=5873713$

DEPFET detectors are silicon active pixel sensors for X-ray imaging spectroscopy. They will be used for the MIXS instrument of BepiColombo planetary mission and they are expected to be used for the Wide Field Imager of the International X-ray Observatory currently under study by ESA,

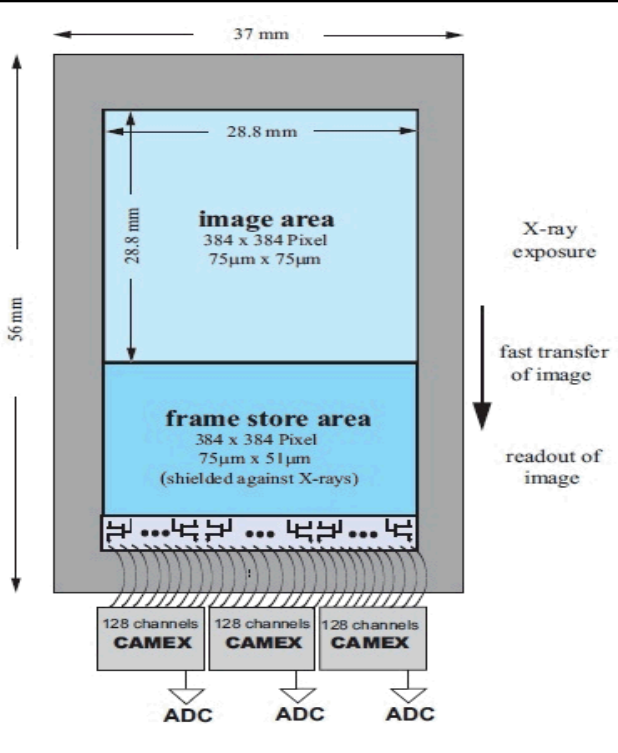

Left; CCD wafer produced for the eROSITA project. Four large-area flight CCDs can be seen in the centre of the 6 inch wafer. Right; Dimensions and structure of an eROSITA pnCCD detector. 
NASA and JAXA. New DEPFET matrixes with $256 \times 256$ pixels of $75 \mu \mathrm{m}$ pitch have been produced, mounted on ceramic boards with dedicated frontend electronics and integrated in a new set-up able to acquire large-format images and spectra.. Energy resolution as low as $129 \mathrm{eV}$ FWHM at $5.9 \mathrm{keV}$ has been obtained including all single events of the matrix back illuminated at $-40^{\circ} \mathrm{C}$ and read out at a 300 frames per second rate.

\section{HICAM Gamma Camera - HICAM Collaboration}

http://ieeexplore.ieee.org/stamp/stamp. jsp?tp $=$ \&arnumber $=5874116$

A new compact and high-resolution $(<1 \mathrm{~mm})$ Anger camera to be used in clinical and research environments where high overall spatial resolution and system compactness are required. The use of Silicon Drift Detectors (SDDs) as scintillator photodetectors, characterized by high quantum efficiency and low electronic noise, is the particular aspect of this camera. Two prototypes were produced during

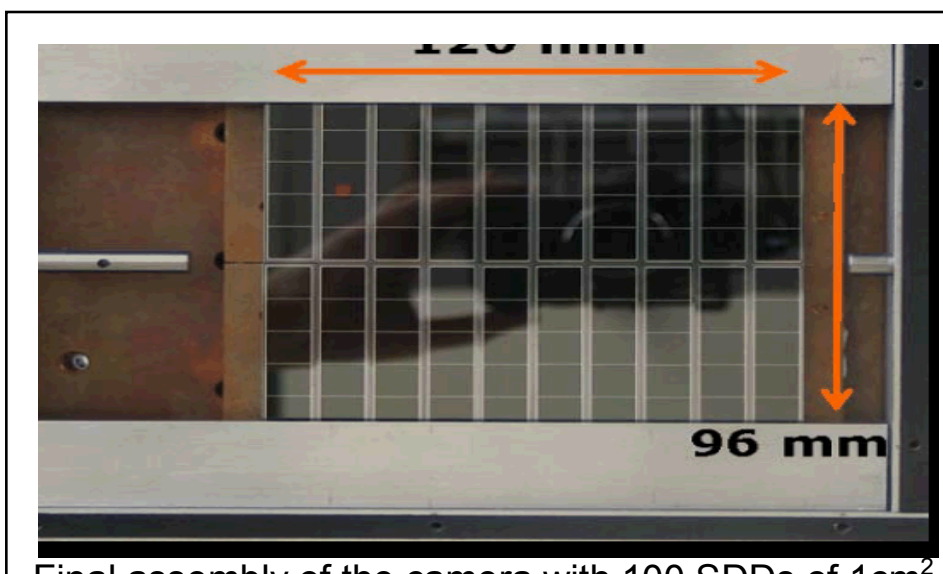

Final assembly of the camera with 100 SDDs of $1 \mathrm{~cm}^{2}$ active area each. the project. The smaller one, composed of 25 SDDs with a $5 \times 5 \mathrm{~cm} 2$ active area, has been used for a first assessment of the performances and first trials in small animal imaging. The larger prototype, developed following the same architecture, is composed of 100 SDDs of $1 \mathrm{~cm} 2$ active area each, in a $10 \times 10 \mathrm{~cm} 2$ array. We report on the results of imaging measurements carried out with the prototypes and on the analysis of the performances achieved.

\section{LuAG Scintillator Array - Japan Research}

http://ieeexplore.ieee.org/stamp/stamp.j $\mathrm{sp}$ ?tp=\&arnumber $=5485089$

A Pr:LuAG scintillator pixilated with $0.1 \mathrm{~mm} \mathrm{Ba} \mathrm{SO} 4$ was developed to be used for high-efficiency positron emission mammography (PEM). A one camera unit consisted of $20 \times 64$ pixels optically coupled with three H8500-03 multi anode PMTs. The PEM required four cameras on each side. Using eight cameras, a PEM was successfully fabricated. Spatial resolutions for a point source, a line-like source, and a

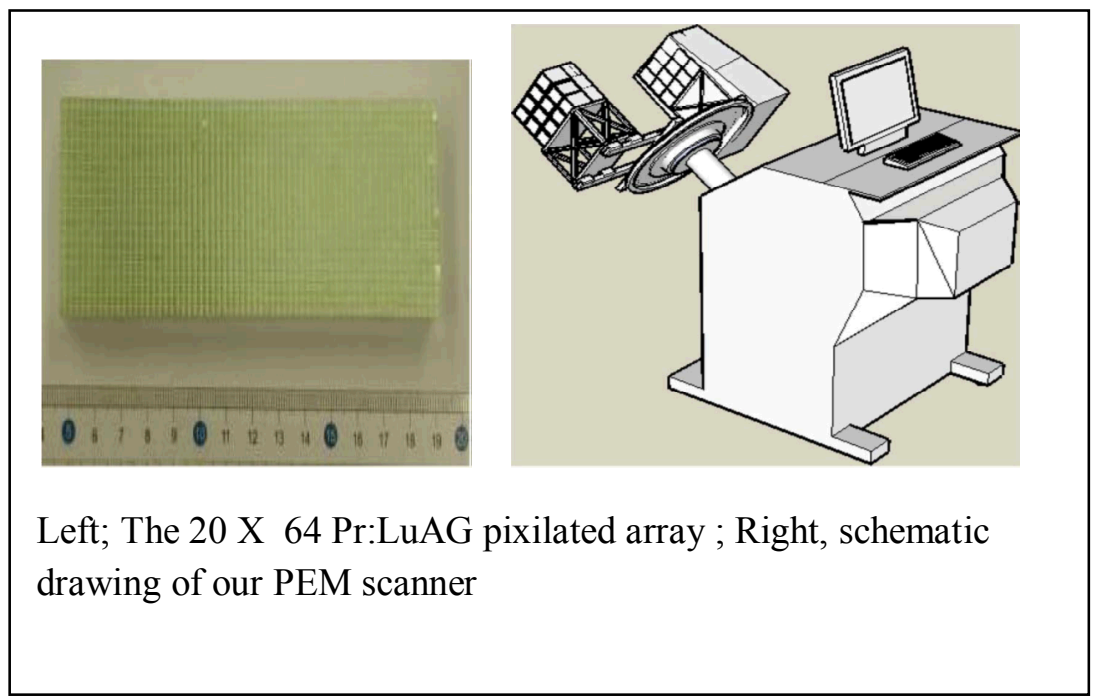


breast phantom were investigated. When the breast phantom was observed, $4 \mathrm{~mm}$ spatial resolution was achieved.

\section{Strip Detectors - Baltic Scientific Instruments}

http://www.bsi.lv/strip_detectors_eng.ht $\mathrm{ml}$

The company offers that it develops and fabricates $\mathrm{CdZnTe} / \mathrm{CdTe}$ type detectors along with the accompanying electronics based on general electronic components and ASICs. They claim that they manufactures detectors by request and further claim flexibility in their technological processes, engineering design services and custom fabrication of small and medium volumes of devices.

\section{The Solid-State X-Ray Image Intensifier (SSXII) - SUNY Researchers}

\section{http://www.ncbi.nlm.nih.gov/pmc/articles/PMC2557100/figure/F1/}

The solid-state $\mathrm{x}$-ray image intensifier (SSXII) is an EMCCD-based x-ray detector designed to satisfy an increasing need for high-resolution realtime images, while offering significant improvements over current flat panel detectors (FPDs) and x-ray image intensifiers (XIIs). FPDs are replacing XIIs because they reduce/ eliminate veiling glare, pincushion or s-shaped distortions and are physically flat. However, FPDs suffer from excessive lag and ghosting and their performance has been disappointing for lowexposure-per-frame procedures due to excessive instrumentation-noise. XIIs and FPDs both have limited resolution capabilities of $\sim 3$ cycles $/ \mathrm{mm}$. To overcome these limitations a prototype

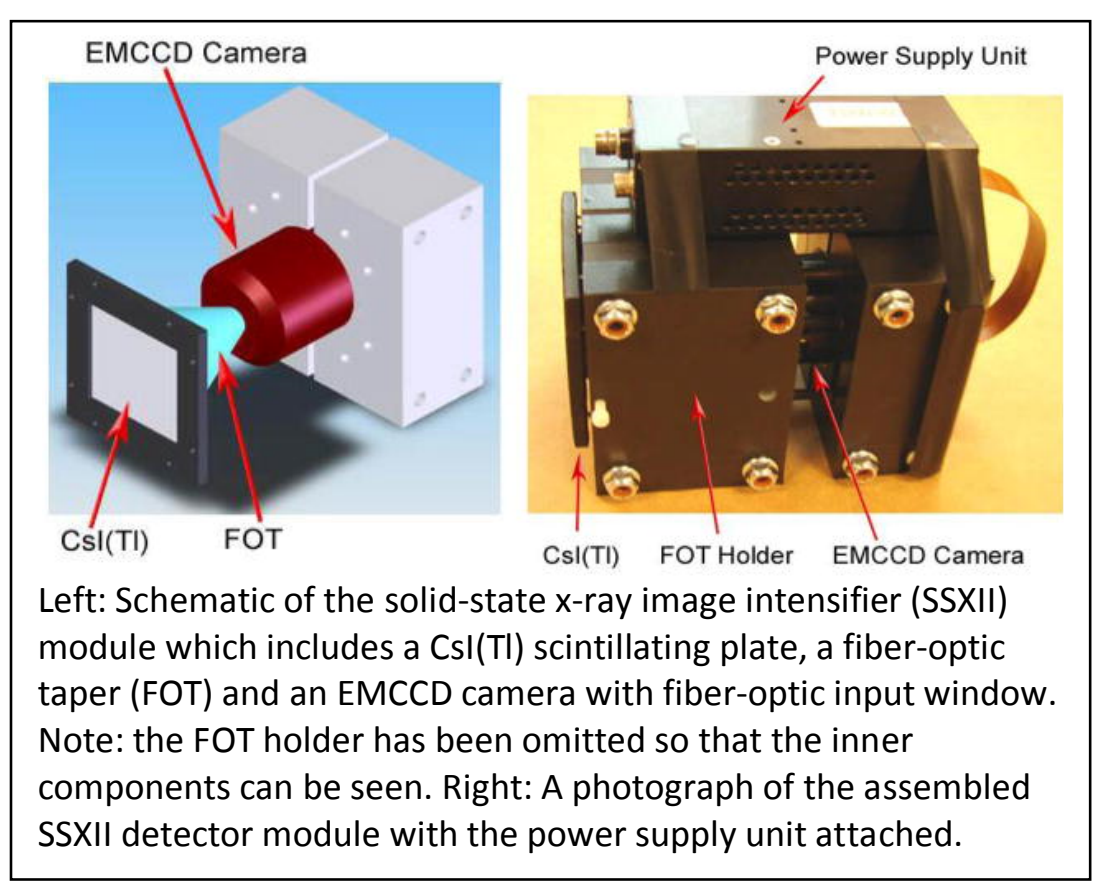


SSXII module has been developed, consisting of a $1 \mathrm{k} \times 1 \mathrm{k}, 8 \mu \mathrm{m}$ pixel EMCCD with a fiberoptic input window, which views a $350 \mu \mathrm{m}$ thick $\mathrm{CsI}(\mathrm{Tl})$ phosphor via a 4:1 magnifying fiberoptic-taper (FOT). Arrays of such modules will provide a larger field-of-view. Detector MTF, $\mathrm{DQE}$, and instrumentation-noise equivalent exposure (INEE) were measured to evaluate the SSXIIs performance using a standard x-ray spectrum (IEC RQA5), allowing for comparison with current state-of-the-art detectors. The highest-resolution mode has a $32 \mu \mathrm{m}$ effective pixel size. Comparison images between detector technologies qualitatively demonstrate these improved imaging capabilities provided by the SSXII.

\section{RadEye $^{\mathrm{TM}} \mathrm{X}$-ray Sensor Modules - Teledyne Rad-icon Imaging}

http://www.rad-icon.com/products-radeye.php

The RadEye series large-area x-ray sensor modules are packaged $\mathrm{x}$-ray image sensors that consist of several tiled RadEye sensors in a robust aluminum housing with scintillator and graphite entrance window. The standard product line features sensor modules with active areas ranging from $50 \times 50 \mathrm{~mm}$ (2" square) up to $100 \times 100 \mathrm{~mm}$ (4" square), although larger custom configurations are also possible. All modules are available either with direct-coupled GdOS (Gadox) scintillator for low-energy $(<50 \mathrm{kV})$ and low-dose applications, or with an integrated fiber-optic faceplate (FOP) for applications requiring higher $\mathrm{x}$-ray energies (up to $160 \mathrm{kV}$ ) and dose rates.

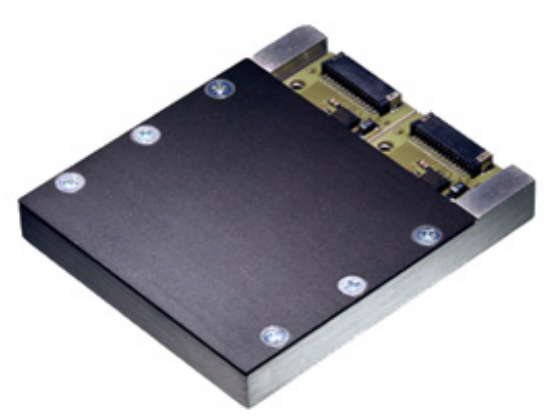

The RadEye sensor modules feature several parallel analog outputs, similar to a multitapped CCD sensor.

\section{The INTEGRAL Soft Gamma-Ray Imager (ISGRI) - ACRORAD}

http://www.aanda.org/index.php?option=com article\&a $\underline{\text { ccess }}=$ standard\&Itemid $=129 \&$ url=/articles/aa/full/2003/ 43/aaINTEGRAL62/aaINTEGRAL62.right.html

The figure shows a view of the detection plane of the ISGRI camera formed with 8 independent detector modules. Each pixel of the camera is a CdTe detector read out by a dedicated integrated electronic channel. Altogether, there are 16,384 detectors (128 x 128) and an equal number of electronic channels. Each detector is a $2 \mathrm{~mm}$ thick CdTe: $\mathrm{Cl}$ crystal of $2 \mathrm{~mm} \times 4$ $\mathrm{mm} \times 4 \mathrm{~mm}$ with platinum electrodes deposited with an electroless (chemical) process. The ACRORAD company provided 35000 detectors in total for the various models of ISGRI. All detectors have been screened for their spectroscopic performance and

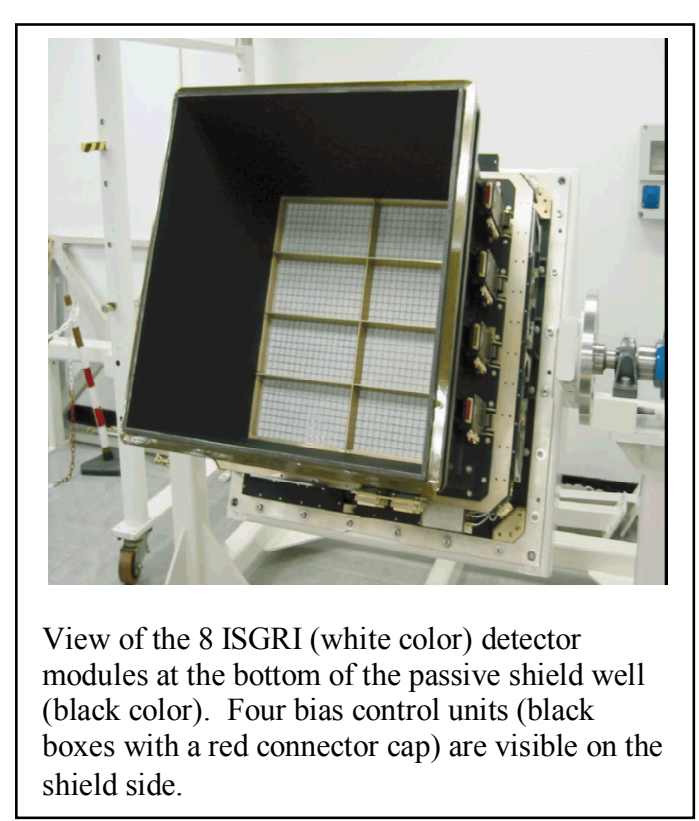


stability under a $100 \mathrm{~V}$ bias at $20 \mathrm{deg} \mathrm{C}$. The imager has demonstrated robust performance and shows absolutely no signs of degradation after 9 months in orbit.

\section{CCD 485 with Fiber Optic Faceplate - Fairchild Imaging}

http://www.fairchildimaging.com/products/fpa/custom/ccd_4 85 fiberoptic.htm

The CCD 485 is a sensor which consists of a charge coupled device (CCD), ceramic substrate, fiber optic faceplate and scintillator. The CCD chip was designed for high resolution scientific, medical and industrial applications. The unit is organized as a matrix array of 4096 horizontal by 4097 vertical imaging elements. The pixel pitch is $15 \mu \mathrm{m}$ and has $100 \%$ fill factor. The imaging area may be operated in either buried channel mode for high dynamic range or Multi-Pinned Phase (MPP) mode for low dark current. Three-phase clocking is employed in the imaging area. The imaging area is divided into four quadrants. Each quadrant may be clocked independently.. The CCD 485 may be clocked such that the full array is read out from any one of the four output amplifiers. The fiber optic faceplate and scintillator is attached to the top of the CCD for high resolution X-ray

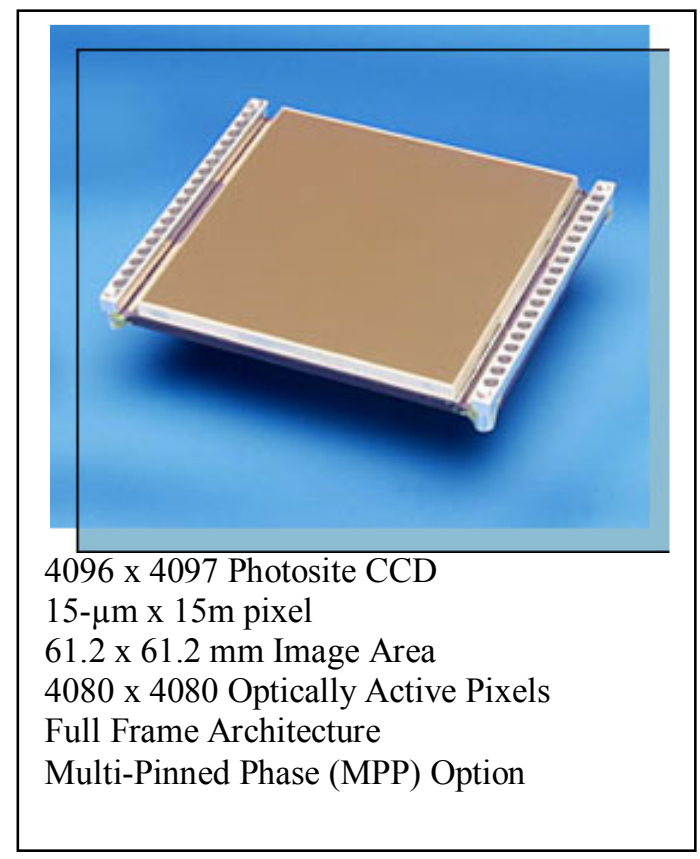
imaging. The CCD 485 is one of 6 CCD arrays offered by the vendor and described as "high performance charge coupled devices intended for use in advanced aerospace, industrial, medical and scientific imaging applications". The company further identifies these products as available in front illuminated as well as back illuminated configurations.

\section{CMOS Linear Arrays- Fairchild Imaging}

http://www.fairchildimaging.com/CMOS linear_arrays.asp

The Active Reset ${ }^{\mathrm{TM}}$ CMOS imager is designed for highsensitivity, high-conversion gain and low read noise applications. This device provides a data rate up to $80 \mathrm{MHz}$ and operates in three modes providing tailored choices for specific applications.

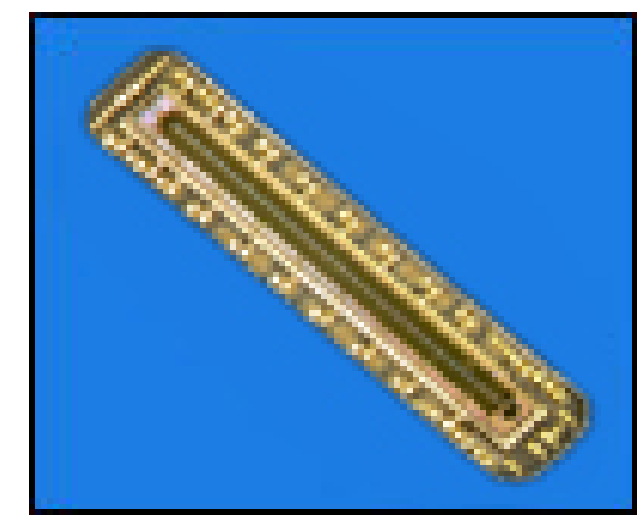

$2048 \times 1,7 \mu \mathrm{m}$ pixel pitch

\section{Selenium-based Flat panel X-ray Detector - Toshiba}

http://europeanhospital.com/media/article/2338/Selenium_Based_Flat_Panel_X ray 1_2001.pdf 
A selenium-based flat panel X-ray detector for digital fluoroscopy and radiography has been developed. This detector captures X-rays and converts them directly to digital dynamic and static images with high spatial resolution and contrast. The detector permits fluoroscopy at a rate of up to 30 images per second, making it possible to visualize medical conditions otherwise not easily observed. It is anticipated that a variety of detectors for a full range of digital X-ray applications from

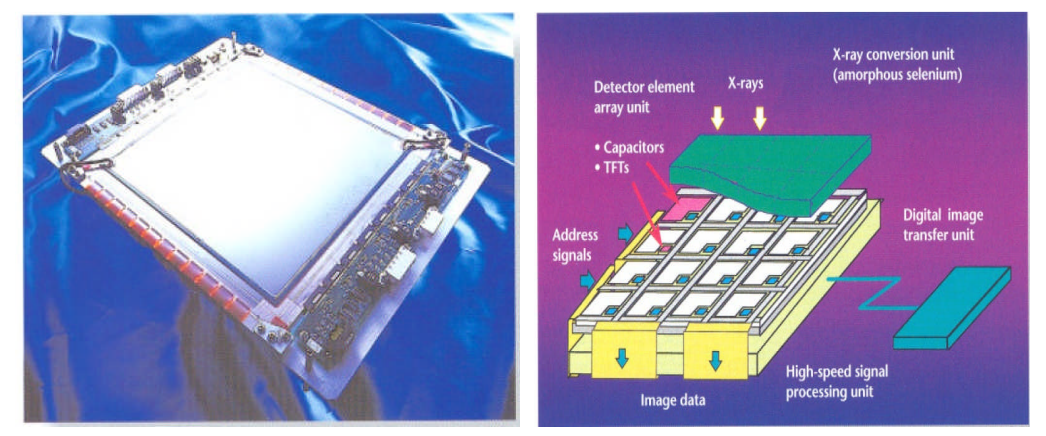

Left: External appearance of the flat panel detector for dynamic images; Right: Design of the direct conversion fluorescent panel detector for dynamic imaging general radiography to angiography will be developed. The detector specifications include an effective field of view: of $23 \times 23 \mathrm{~cm}, 150 \mu \mathrm{m}$ pixel pitch, and a selenium thickness: $1000 \mu \mathrm{m}$.

\section{SAPHIRE (scintillator avalanche photoconductor with high-resolution emitter readout) Detector - .University-Industry Collaboration}

http://spie.org/x23956.xml

Existing active-matrix flat-panel imagers (AMFPIs) use a two-dimensional array of thin-film transistors to read out a charge image generated by an x-ray image sensor. In 'direct conversion' this sensor is an x-ray photoconductor, while in 'indirect conversion' the sensor is a scintillator coupled with discrete photodiodes. These methods have two main limitations. First, in low-dose applications such as fluoroscopy (real-time x-ray medical imaging), electronic noise degrades the performance behind dense tissues. Second, the smallest pixel size currently used for digital mammography, $70 \mu \mathrm{m}$, may not be adequate in some cases.

The SAPHIRE concept (shown in Fig XX) is expected to overcome these limitations. The design consists of a needle-structured cesium iodide (CsI) scintillator, optically coupled (for example, through fiber optics) to a uniform thin layer of amorphous selenium (a-Se) photoconductor, with a Se thickness of $4-25 \mu \mathrm{m}$. The selenium layer is operated in avalanche multiplication mode, and is called HARP (high avalanche rushing amorphous photoconductor) ${ }^{39}$. The visible photons emitted from the scintillator pass through a transparent indium tin oxide

\footnotetext{
${ }^{39}$ K. Tanioka, J. Yamazaki, K. Shidara, et al., Avalanche-mode amorphous selenium photoconductive target for camera tube, Adv. Electron. Electron Phys. 74, pp. 379-387, 1988.
} 
(ITO) bias electrode to generate electron-hole pairs near the top of the HARP layer. Applying a positive voltage to the ITO causes holes to move toward the bottom (free) surface of the HARP. On the way, they experience avalanche multiplication under an electric field strength $E_{\mathrm{Se}}>$ $90 \mathrm{~V} / \mu \mathrm{m}$ which is an order of magnitude higher than is typically used in direct-conversion a-Se $\mathrm{x}-$ ray detectors. The holes form an amplified charge image at the bottom surface of the HARP layer, which is read out with electron beams generated by a two-dimensional field-emitter array (FEA), which is placed at a short distance $(\sim 1-2 \mathrm{~mm})$ below the scintillator-HARP structure. The FEA pixels are addressed by orthogonal gate and base lines.

\section{(DEXI) diffraction-enhanced $x$-ray imaging instrument - Nesch, LLC}

http://www.neschllc.com/products/additional_info.html

The diffraction-enhanced x-ray imaging (DEXI) instrument uses a conventional x-ray source to image the internal structure of an object. In laboratory tests, a human cadaveric thumb (see figure inset) was used as a test-sample to demonstrate the imaging capability of the instrument. A $22 \mathrm{keV}$ monochromatic $\mathrm{x}$-ray beam is prepared using a mismatched, two-crystal monochromator; a silicon analyzer crystal is placed in a parallel crystal geometry with the monochromator allowing both diffraction-enhanced imaging and multiple-imaging radiography to be performed. The DEXI instrument was found to have an experimentally determined spatial resolution of $160 \pm 7$ $\mu \mathrm{m}$ in the horizontal direction and $153 \pm 7$

A perspective schematic of the DEXI instrument: (a) $2.2 \mathrm{~kW} \mathrm{Ag}$ x-ray tube and multiaxis positioning cradle; (b) mismatched, two-crystal monochromator; (c) sample compartment; (d) analyzer crystal; (e) highresolution, digital x-ray detector; (f) inner-vibration-isolation platform; and $(\mathrm{g})$ outer-vibration-isolation platform.

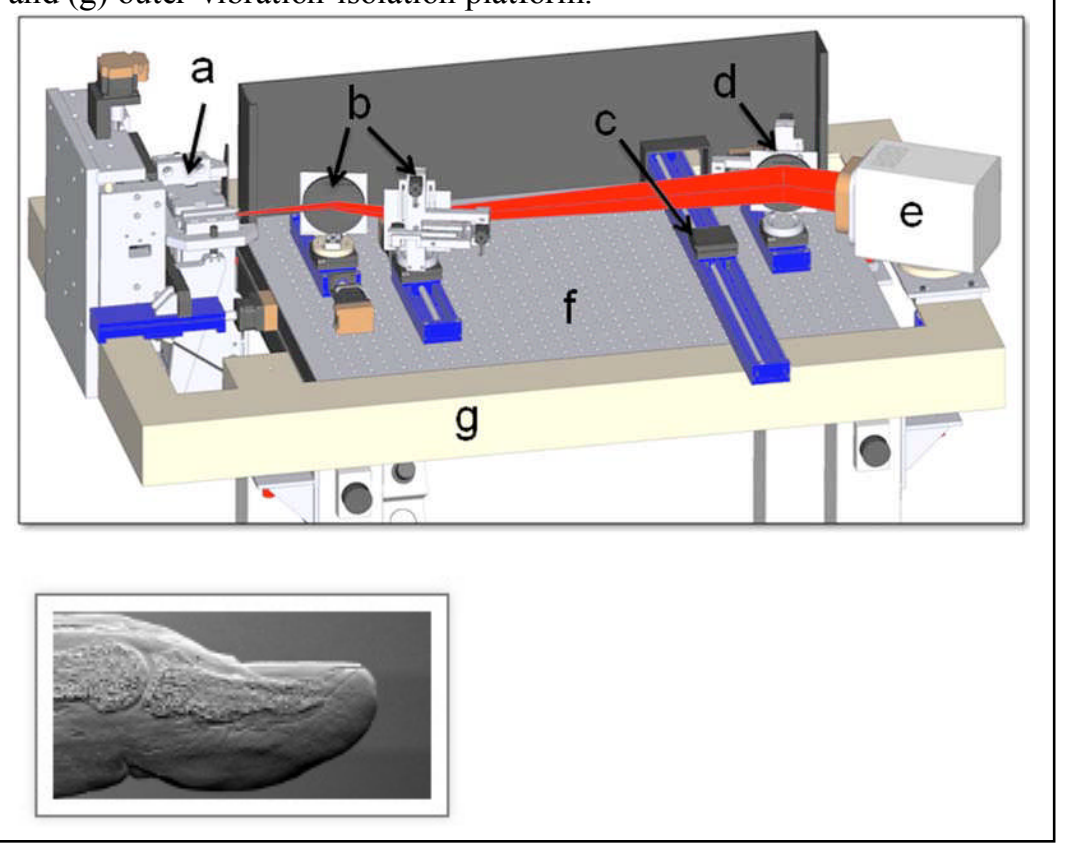




\section{Linear scanning sensors with gas-based detector modules for X-ray imaging- Korean Collaboration}

\section{http://iopscience.iop.org/1748- 0221/6/03/C03004/pdf/17480221 603 C03004.pdf}

Korean researchers have manufactured an x-ray image sensor by using a plasma display panel (PDP) fabrication process that can be used to obtain scanning images. The schematic of the linear scanning sensor is shown in the figure. The sensors are parallel-plate-type scanning detectors which consist of a sealed chamber with an electrode plane and data strip line. The electric signal generated by the ionization of electrons and positive ions in the sensor was evaluated for various gas mixtures - $\mathrm{Xe}(100), \mathrm{Xe} / \mathrm{CO} 2$ $(90 / 10)$, and $\mathrm{Xe} / \mathrm{CO} 2(80 / 20)$ - at atmospheric

Atmospheric pressure, gas filled imaging detector and the image of a phantom hand obtained with it.
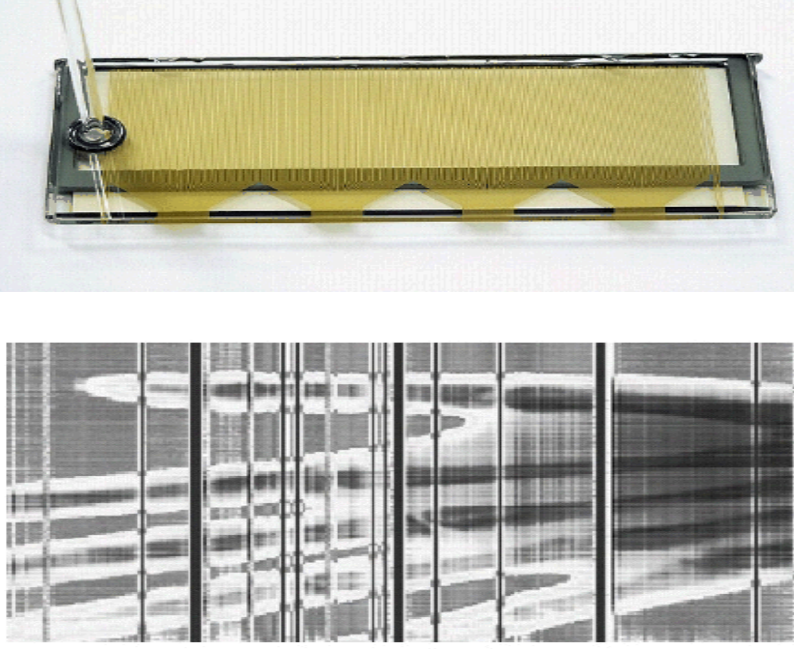

pressure. Normally gas typed sensors have used high pressure (above 3 atm.) gas fills A handphantom image acquired with the detection system is shown in the bottom portion of the figure.

\section{Security detectors; High-energy X-ray Platforms - Varian}

\section{http://www.varian.com/us/} security and inspection/products/detectors/

Varian claims that it is the premier supplier of high-energy X-ray platforms for cargo security systems. The vendor claims offering a modular design that allows the construction of units scalable to virtually any size application with modules that are easily field replaceable. The system uses the company's ACTIS software which is designed to integrate the X-ray source and detectors for seamless and optimized image processing. Detector arrays are constructed as individual modules that can be configured in arrays that meet custom size requirements. Shown in the figure is a schematic of a 32-channel module.
Varian's Vehicle Imaging Device. Schematic of individual detectors is shown below.
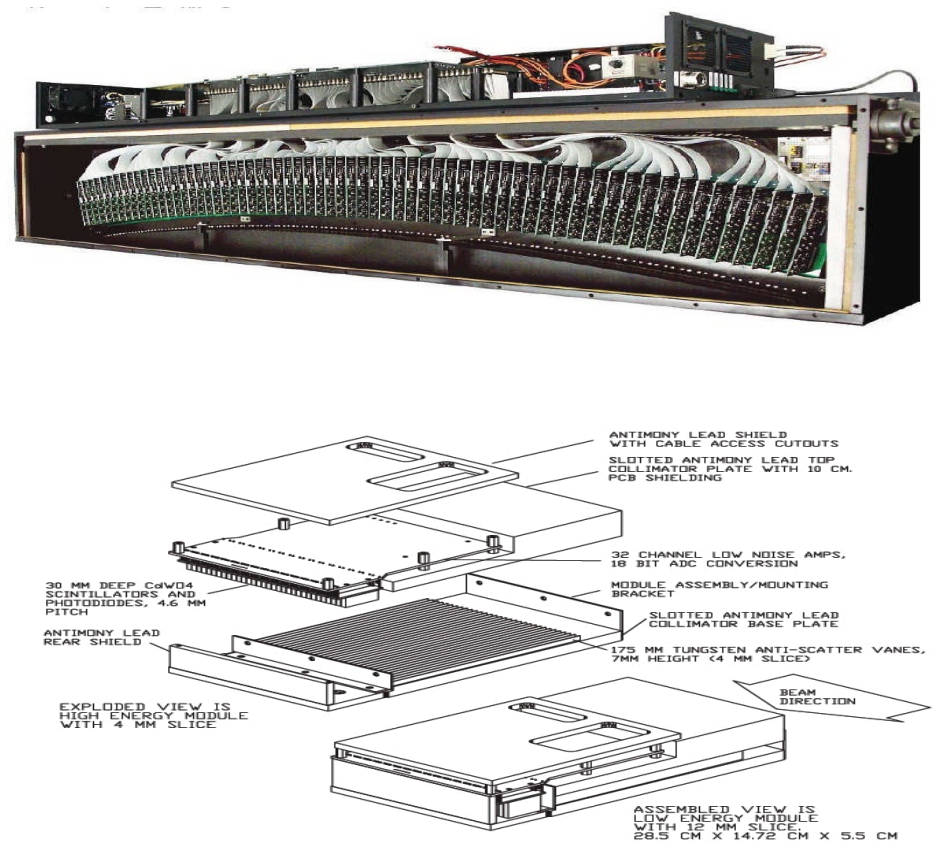


\section{Appendix vi: Data Sheets for Commercial Medical Imaging Devices $(2002-2008)$}

Robert G. Lanier

March 22, 2012

The data described here summarize various operating and cost parameters for all the medical imaging devices placed into service between 2002 and 2008. A magazine, Advance for Imaging \& Radiation Oncology, assembled and published these charts for a wide range of technologies used in medical imaging but ceased in 2009. Contact with the publisher suggests that it is unlikely that the magazine will

Table I: Summary of PDF images of vendor product fcomparisons.

\begin{tabular}{|c|c|c|c|c|}
\hline Digital Radiography & Computed Radiography & PET/CT/SPECT & Gamma Camera \\
\hline & & & \\
\hline CR-DR January 2008.pdf & CR-DR January 2008.pdf & PET-CT May 2007.pdf & Gamma Cameras January 2007.pdf \\
\hline CR-DR July 2006.pdf & CR-DR July 2006.pdf & CT January 2006.pdf & Gamma Cameras April 2005.pdf \\
\hline DR June 2005.pdf & CR June 2005.pdf & PET-CT February 2005.pdf & Gamma Cameras July 2003.pdf \\
\hline DR June 2004.pdf & CR June 2003.pdf & CT July 2004.pdf & \\
\hline DR July 2002.pdf & & CT March 2003.pdf & \\
\hline & & SPECT-CT May 2006.pdf & \\
\hline
\end{tabular}

begin these compilations in the foreseeable future.

In discussions with author of several of these charts, I was told that the process is quite labor intensive and each chart literally represents a man month or two of effort.

The charts are available electronically and are identified in Table 1 above:

A spread sheet has been prepared that identifies the units for which charts are available. An example of this summary spread sheet, Table II, is shown on the following page. The table lists the following information: (1) the class of systems represented, (2) the "pdf" image of the chart, and then in successive order (3) instrument vendor and (4) the various models for which more complete data are presented in the chart. Figure 1 shows the collection of pdf files representing vendor charts and Figures $2 \& 3$ is an example chart. 
Table II: Example table showing compilation structure of each tabulated data sheet

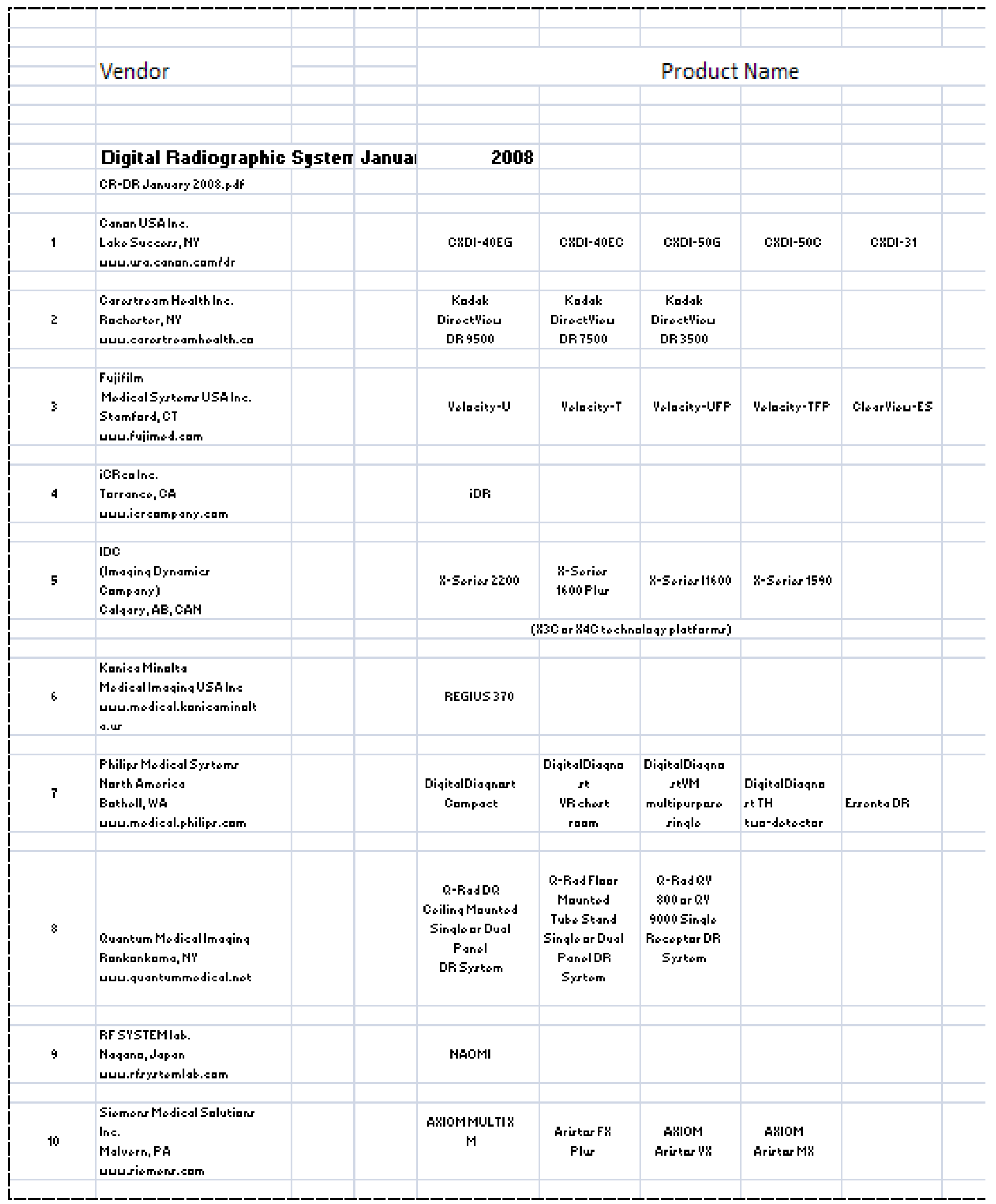


Figure 1: Collected pdf files containing information on vendor comparisons

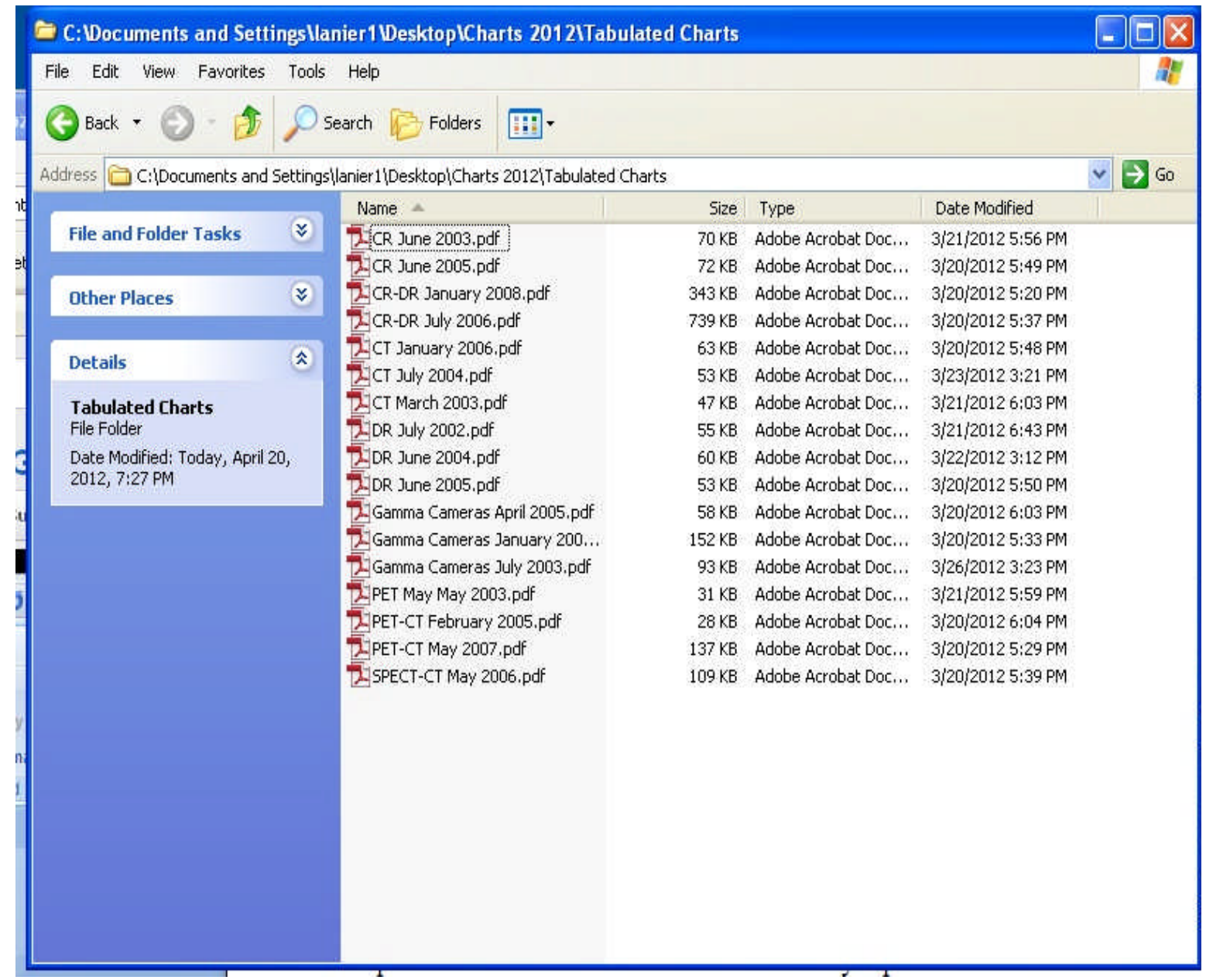


Figure 2: Example Chart for "Digital Radiography" Part 1

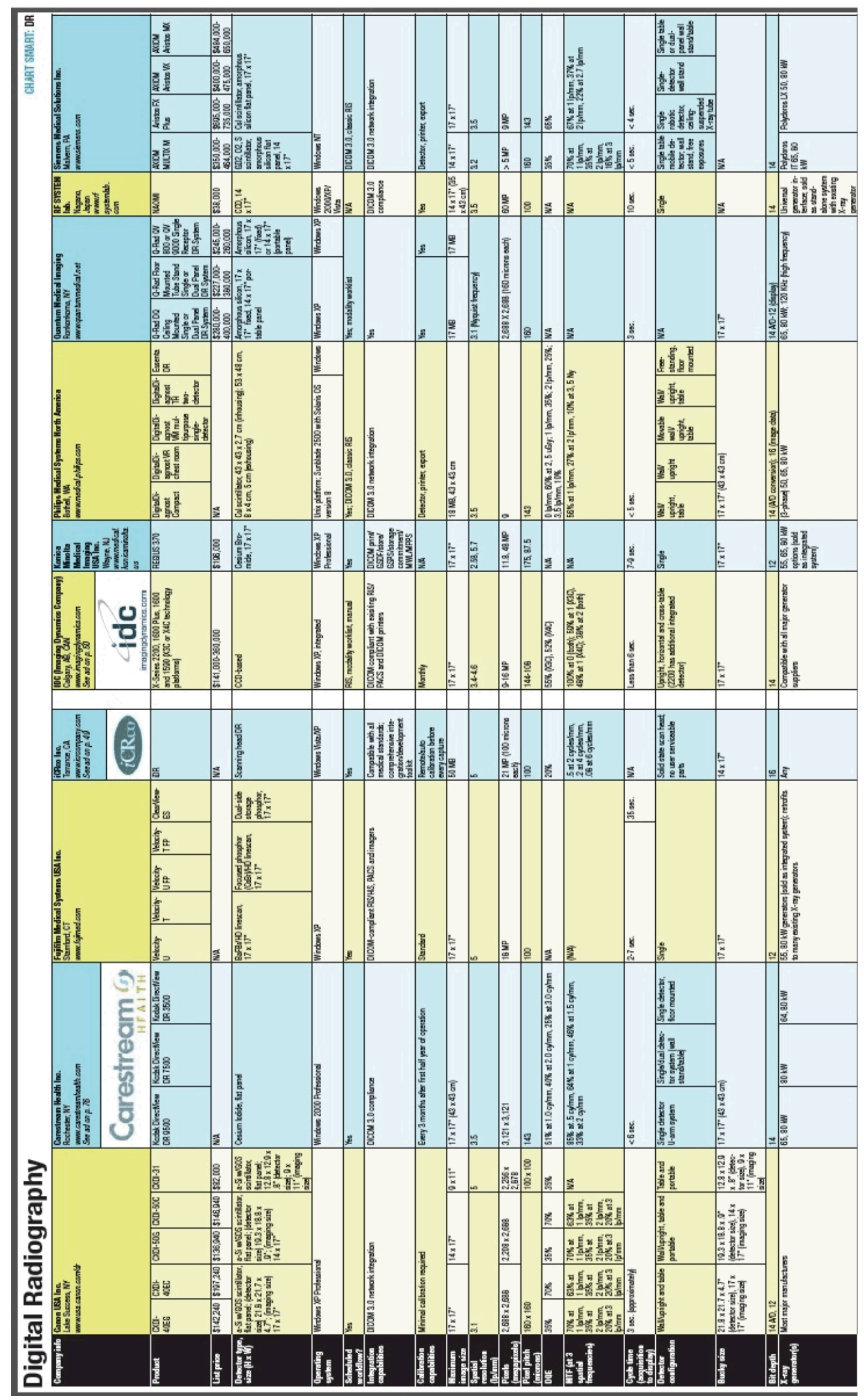


Figure 3: Example Chart for "Digital Radiography" Part 2

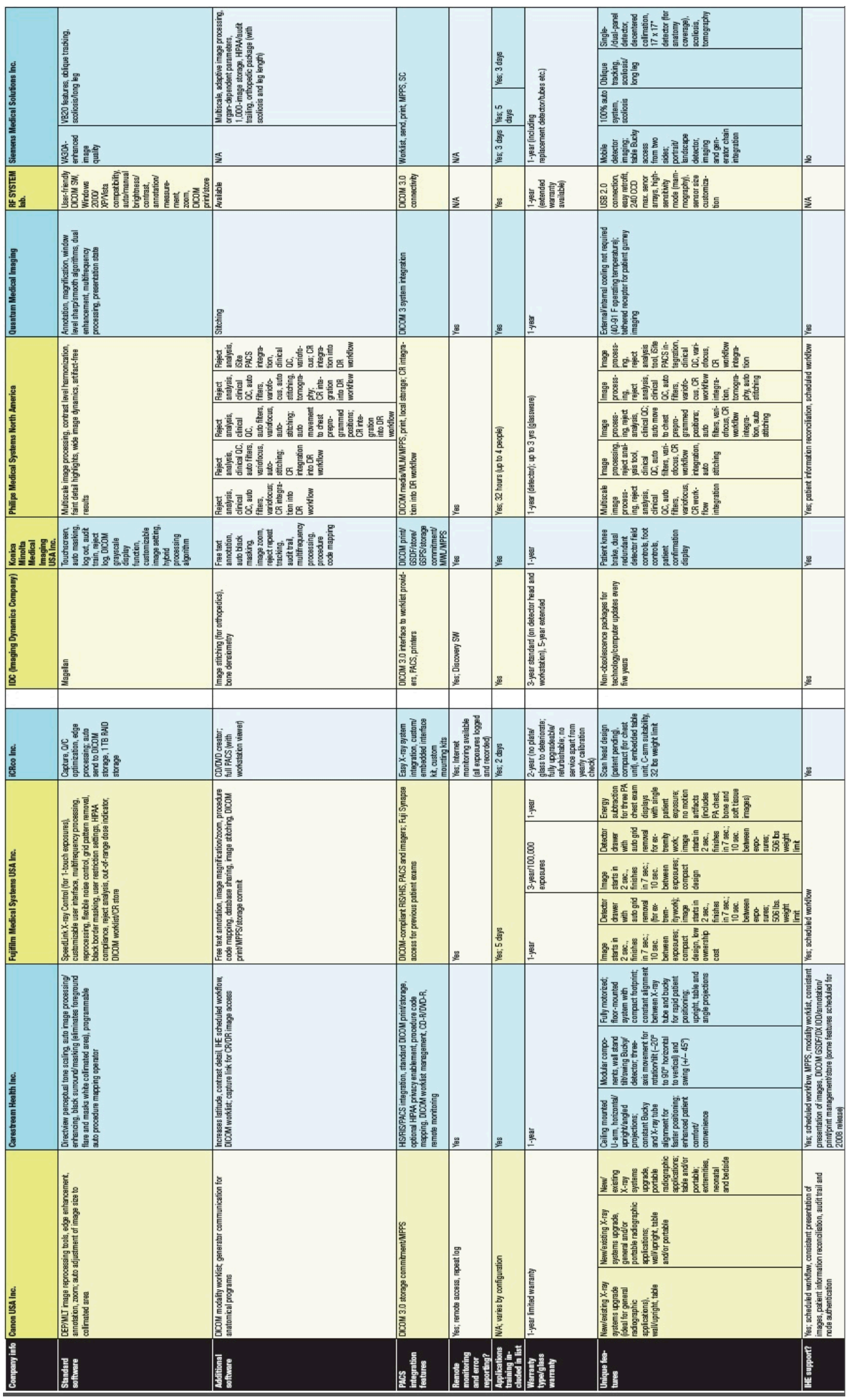




\section{Appendix vii: Detectors and Scintillator Materials; A Survey of Market Availability}

\section{Part I: Detectors (6 pages)}

The tables below present the results of a survey of $x$-ray imaging devices used in medicine and industry. The survey is not exhaustive but reasonably presents a cross section of what vendors currently offer. Each vendor provides a data sheet that contains information that it regards as useful to the consumer and may not publish other information because of proprietary concerns. As such, the technical specifications which are publicly available vary considerably. The table's intent was to highlight important operating parameters of each device. Unfortunately, because of the large variability in data sheet content, many entries are listed as "not available" (NA). 


\begin{tabular}{|c|c|c|c|c|c|c|c|c|c|c|c|}
\hline & & & & & & & & & & & \\
\hline 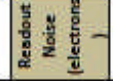 & 2 & $\frac{d}{2}$ & $\frac{s}{2}$ & $\frac{s}{2}$ & \pm & $\frac{5}{2}$ & 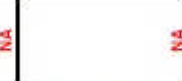 & 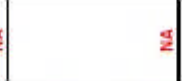 & 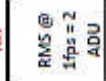 & 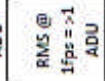 & 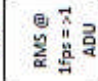 \\
\hline 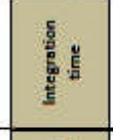 & 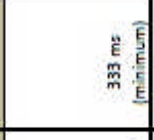 & 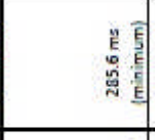 & $\frac{1}{2}$ & 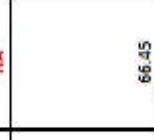 & 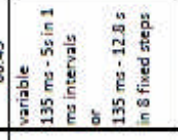 & & 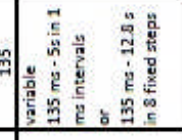 & 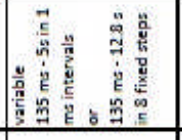 & 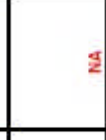 & $\frac{ \pm}{2}$ & \\
\hline 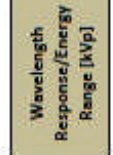 & 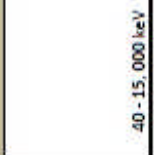 & $\begin{array}{l}3 \\
8 \\
0 \\
\vdots \\
\vdots \\
4\end{array}$ & 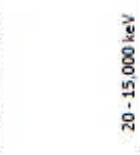 & 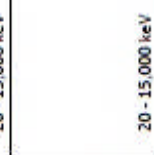 & & | & : & 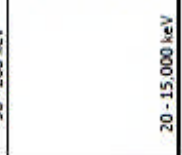 & 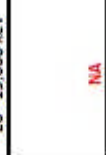 & $\Sigma$ & \\
\hline 童 & 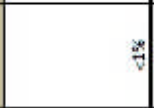 & 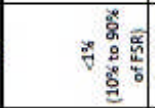 & $\frac{4}{2}$ & 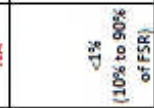 & 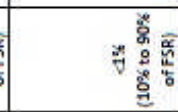 & 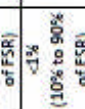 & 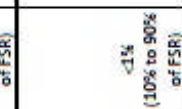 & 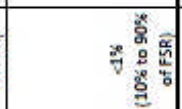 & $\frac{s}{2}$ & $\frac{s}{2}$ & 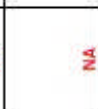 \\
\hline 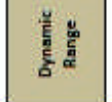 & 몀 & 昜 & 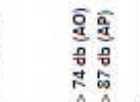 & 음 & : & : & 变 & 임 & \% & $\approx$ & \\
\hline 蒋 & 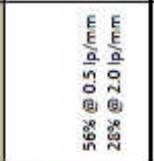 & 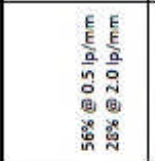 & 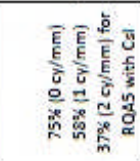 & 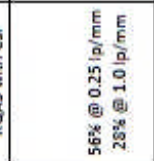 & 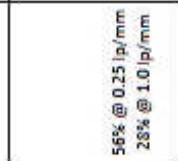 & 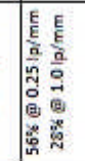 & 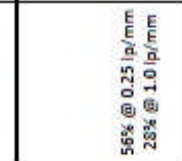 & 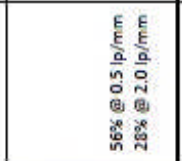 & $z$ & $\frac{d}{z}$ & \\
\hline 屴 & 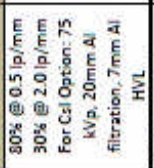 & 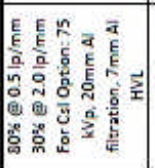 & 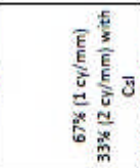 & 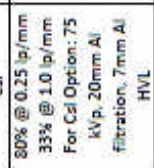 & 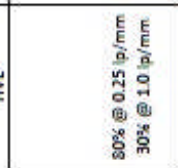 & 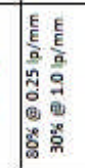 & 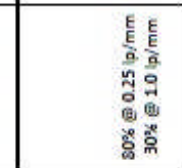 & 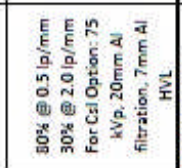 & \begin{tabular}{|l} 
\\
E
\end{tabular} & 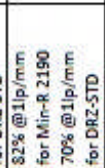 & 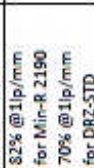 \\
\hline 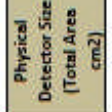 & 鹖 & : & t్ & : & $g$ & $\frac{9}{7}$ & $\stackrel{\circ}{q}$ & 구 & สี & 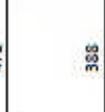 & \\
\hline 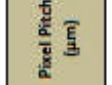 & ఫ్స & 워 & \& & ళ & 8 & 8 & 8 & \& & & ஃ & \\
\hline 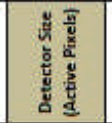 & 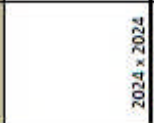 & :ี & $\stackrel{4}{z}$ & $\begin{array}{l}\text { : } \\
\text { : } \\
\text { : }\end{array}$ & 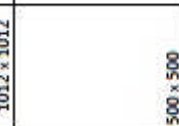 & : & 8 & : & $\ddot{z}$ & 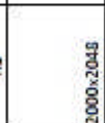 & \\
\hline 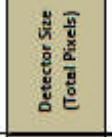 & 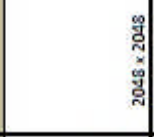 & 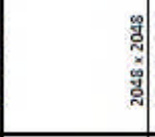 & 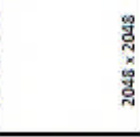 & 范 & 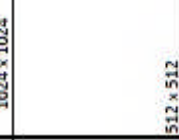 & 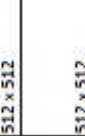 & in & 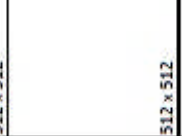 & 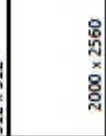 & 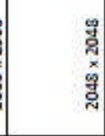 & \\
\hline 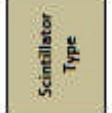 & 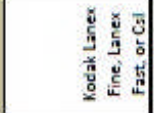 & 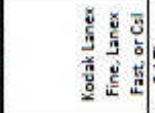 & 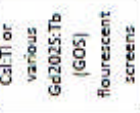 & 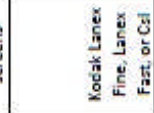 & 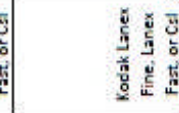 & 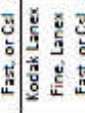 & 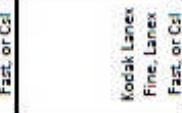 & 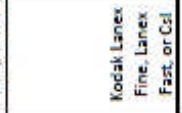 & 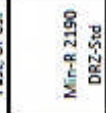 & 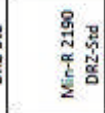 & 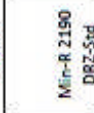 \\
\hline 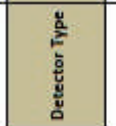 & & & 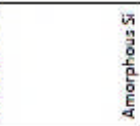 & & & 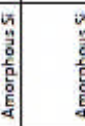 & 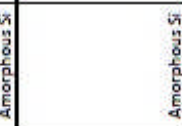 & & 仓ั้ & 읗 & \\
\hline 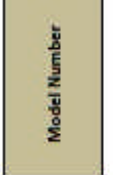 & & $\begin{array}{l}\text { ă } \\
\vdots \\
0 \\
\vdots \\
\vdots\end{array}$ & 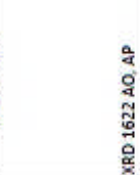 & 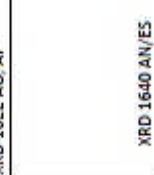 & 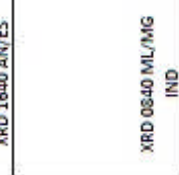 & 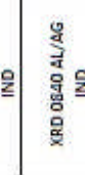 & 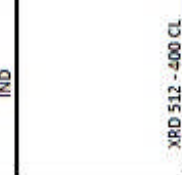 & & 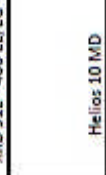 & $\begin{array}{l}\frac{1}{5} \\
\frac{5}{n} \\
\frac{5}{3}\end{array}$ & \\
\hline 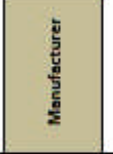 & 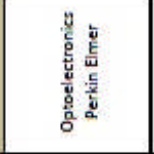 & 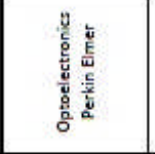 & 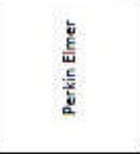 & 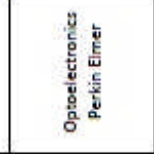 & 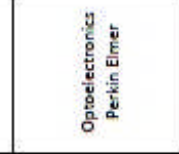 & 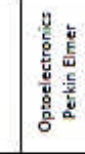 & 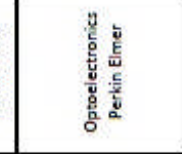 & 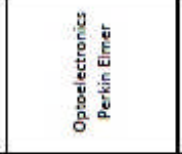 & 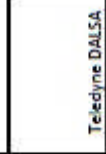 & 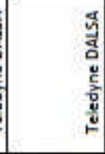 & 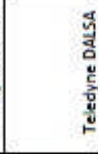 \\
\hline 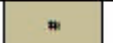 & - & $N$ & $\mathrm{~m}$ & $\triangle$ & in & $\infty$ & $r$ & $\infty$ & $a$ & : & $\Rightarrow$ \\
\hline & & & & & & & & & & & \\
\hline
\end{tabular}




\begin{tabular}{|c|c|c|c|c|c|c|c|c|c|c|c|c|}
\hline & & & & & & & & & & & & \\
\hline 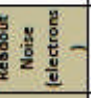 & 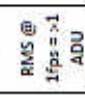 & 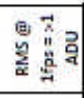 & 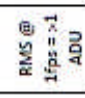 & 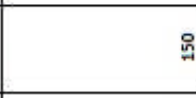 & 용 & $\stackrel{9}{9}$ & $\stackrel{g}{9}$ & $\stackrel{0}{0}$ & a & 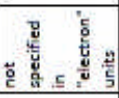 & & 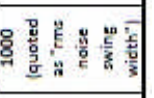 \\
\hline 造 & 2 & $\frac{1}{2}$ & $\frac{2}{2}$ & 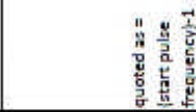 & 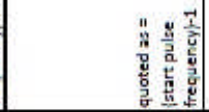 & 侣 & & 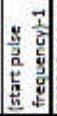 & 总 & $z$ & $\frac{s}{2}$ & \pm \\
\hline 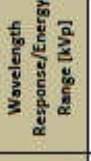 & 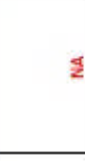 & $\underline{z}$ & $\frac{5}{2}$ & $\frac{s}{z}$ & 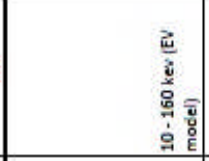 & 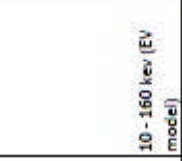 & 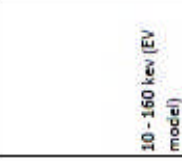 & $\frac{s}{2}$ & z & 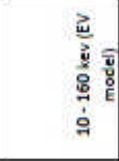 & & 웜 \\
\hline 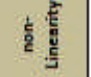 & $\frac{s}{2}$ & $\frac{1}{2}$ & $\frac{1}{2}$ & $\frac{1}{2}$ & $\frac{1}{2}$ & $\frac{1}{2}$ & $\frac{1}{z}$ & $\frac{\pi}{2}$ & $\frac{\pi}{2}$ & $\frac{\pi}{2}$ & & 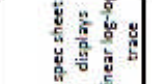 \\
\hline 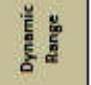 & F & $\approx$ & $\approx$ & 总 & 睘 & 品 & 品 & 吕 & . & & $e_{0}^{\frac{a}{5}}$ & 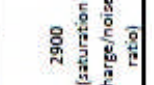 \\
\hline ̆ㅕㅁ & $\frac{z}{z}$ & $\frac{1}{2}$ & $\frac{1}{2}$ & $\frac{1}{z}$ & $\frac{d}{2}$ & $\frac{s}{z}$ & $\frac{\Delta}{2}$ & : & : & $\frac{4}{z}$ & $\frac{\pi}{2}$ & $\frac{1}{2}$ \\
\hline 点 & 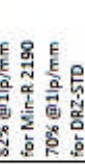 & 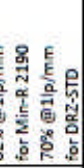 & 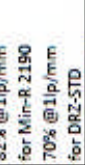 & 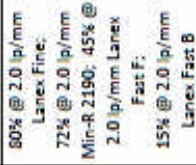 & 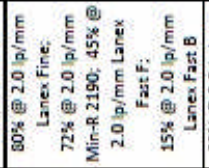 & 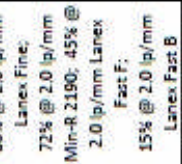 & 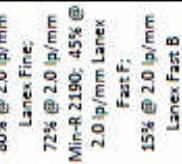 & $\frac{s}{2}$ & 2 & 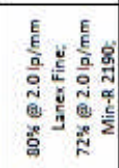 & $\frac{\mathrm{s}}{2}$ & 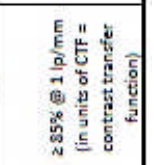 \\
\hline 跣 & 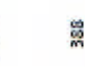 & 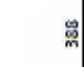 & 㗊 & $\underline{\tilde{E}}$ & g & $\stackrel{\circ}{\prime \prime}$ & च & $\Rightarrow$ & g & 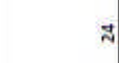 & $\bullet$ & $\therefore$ \\
\hline$\frac{5}{\frac{2}{2}} \overline{\frac{1}{3}}$ & ஃ & \% & ஃ & ะ & g) & \% & \& & of & $\because$ & & o & in \\
\hline 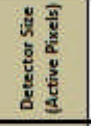 & 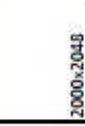 & : & : & $\frac{4}{z}$ & $\frac{4}{2}$ & $\frac{s}{2}$ & $\frac{\pi}{2}$ & : & : & $z$ & 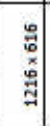 & : \\
\hline 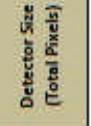 & $\begin{array}{l}\text { : } \\
\text { : } \\
\text { : } \\
\text { : }\end{array}$ & 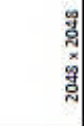 & 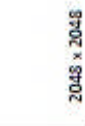 & & & & 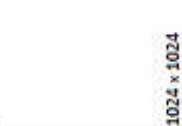 & $\approx$ & $\mathrm{a}$ & : & \begin{tabular}{l}
$:$ \\
\multirow{0}{0}{} \\
$\vdots$ \\
$\vdots$ \\
$\vdots$
\end{tabular} & 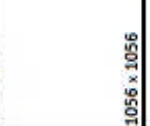 \\
\hline 鄫 & 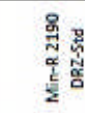 & 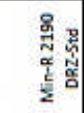 & 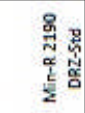 & 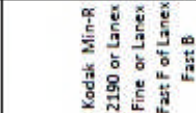 & 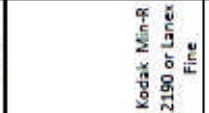 & 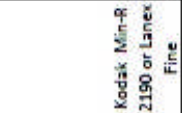 & 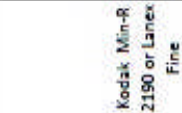 & 昜 & 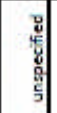 & 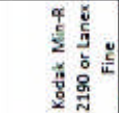 & $3^{3}$ & 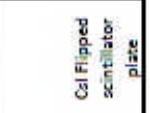 \\
\hline 递 & 잉 & 잏 & 。․ & है & | & 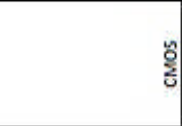 & 吠 & 웧 & 웧 & 气े & 8 & 영 \\
\hline $\begin{array}{l}\frac{5}{8} \\
\frac{5}{5} \\
\frac{5}{30} \\
\frac{5}{2}\end{array}$ & 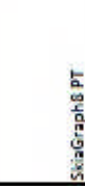 & $\begin{array}{l}3 \\
0\end{array}$ & 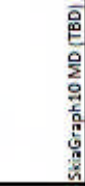 & 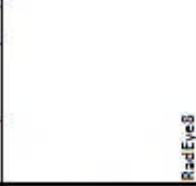 & $\begin{array}{r}\square \\
\vdots \\
\vdots\end{array}$ & 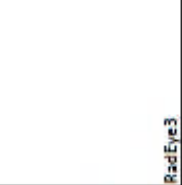 & 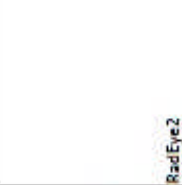 & 蓓 & : & $\begin{array}{l}0 \\
\vdots \\
\vdots\end{array}$ & 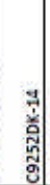 & 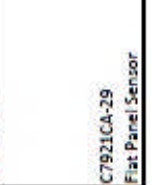 \\
\hline $\begin{array}{l}\frac{5}{2} \\
\frac{d}{2} \\
\frac{5}{2}\end{array}$ & 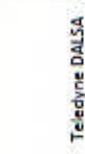 & 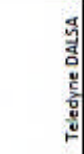 & 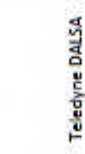 & 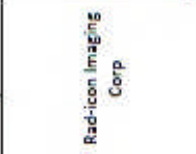 & 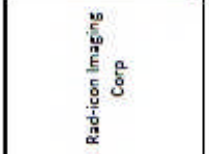 & 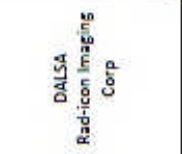 & 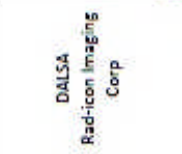 & 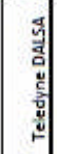 & $\begin{array}{l}\text { : } \\
\text { : } \\
\text { : } \\
\text { v. }\end{array}$ & 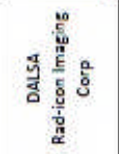 & 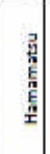 & 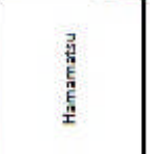 \\
\hline "* & $\approx$ & $m$ & $\exists$ & 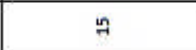 & 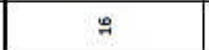 & $\Rightarrow$ & 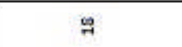 & $g$ & \& & $\vec{A}$ & $\approx$ & 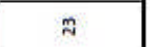 \\
\hline
\end{tabular}




\begin{tabular}{|c|c|c|c|c|c|c|c|c|c|c|c|c|c|c|c|}
\hline & & & & & & & & & & & & & & & \\
\hline 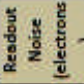 & 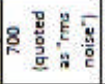 & $\begin{array}{l}8 \\
0\end{array}$ & 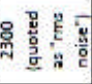 & $\mid$ & 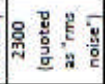 & 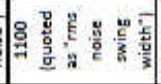 & $\begin{array}{ll}0 \\
8\end{array}$ & 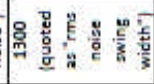 & 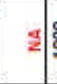 & 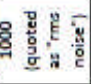 & 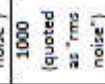 & 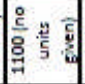 & क & 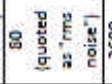 & 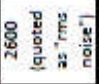 \\
\hline है & $\frac{ \pm}{2}$ & \pm & \pm & 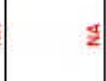 & 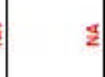 & $\frac{1}{2}$ & $\frac{1}{2}$ & 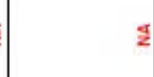 & $z$ & $\frac{ \pm}{2}$ & $\frac{1}{2}$ & & $\frac{\pi}{2}$ & $\frac{\pi}{2}$ & \pm \\
\hline 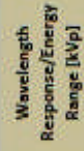 & $\begin{array}{l}\stackrel{0}{a} \\
\dot{a}\end{array}$ & $\frac{\pi}{2}$ & 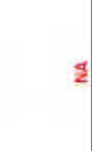 & $z$ & $\frac{y}{2}$ & & & 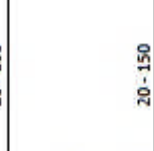 & 2 & & 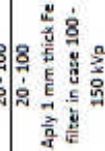 & 号 & 8 & 辛 & : \\
\hline 它 & $\frac{1}{2}$ & $\frac{1}{2}$ & $\frac{1}{z}$ & $\frac{1}{2}$ & $z$ & 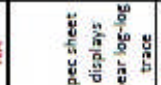 & $\frac{1}{z}$ & 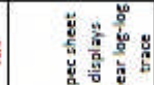 & $\frac{s}{2}$ & $\frac{1}{z}$ & $\frac{1}{2}$ & $\frac{a}{2}$ & $\frac{\pi}{2}$ & $\frac{4}{2}$ & $\frac{1}{2}$ \\
\hline 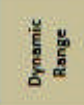 & 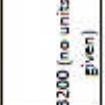 & 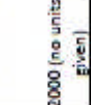 & 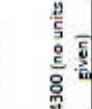 & 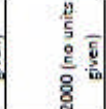 & 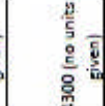 & 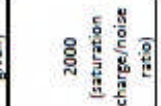 & 然商 & 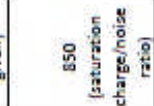 & $\frac{s}{2}$ & 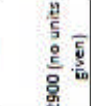 & 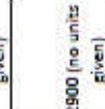 & 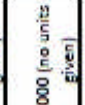 & 8 & 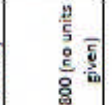 & 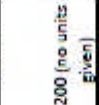 \\
\hline ̆ & $\frac{4}{2}$ & $\frac{4}{2}$ & $\frac{\pi}{2}$ & $\frac{4}{2}$ & $\frac{\pi}{2}$ & $\frac{s}{2}$ & $\frac{d}{z}$ & $\frac{\pi}{2}$ & $\frac{d}{2}$ & $\frac{d}{z}$ & $\frac{s}{z}$ & $\frac{\pi}{2}$ & $\frac{z}{2}$ & $\frac{4}{2}$ & $\frac{4}{2}$ \\
\hline 芝 & 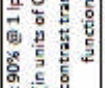 & $z$ & $\frac{1}{z}$ & $\frac{z}{2}$ & $\frac{z}{2}$ & 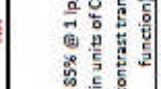 & 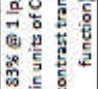 & $\frac{s}{z}$ & $\frac{d}{2}$ & $\frac{\Delta}{z}$ & $\frac{s}{z}$ & 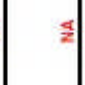 & $\stackrel{s}{z}$ & $\frac{4}{2}$ & $\frac{\pi}{2}$ \\
\hline 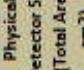 & $\exists$ & $\exists$ & 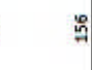 & $\ddagger$ & : & ปี & $\stackrel{:}{\circ}$ & J & 或 & ๘ & g & : & $\circ$ & (a) & 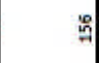 \\
\hline$\frac{5}{3} \bar{g}$ & in & in & 8 & in & \&్ల & in & \&్ల & in & in & in & in & 品 & (9) & in & 8 \\
\hline 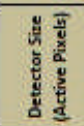 & 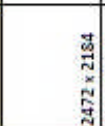 & 哭 & 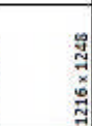 & 䒺 & 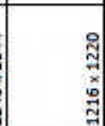 & & 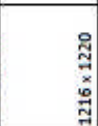 & 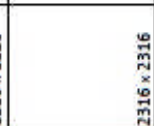 & $\frac{5}{2}$ & : & 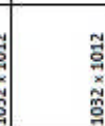 & 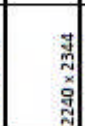 & $\begin{array}{l}0 \\
\vdots \\
\vdots \\
\vdots\end{array}$ & 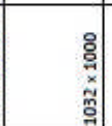 & : \\
\hline 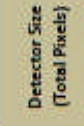 & 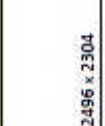 & 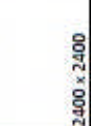 & تّٕ & : & : & $\begin{array}{l}: \\
\vdots \\
\vdots \\
\vdots\end{array}$ & 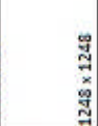 & 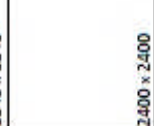 & 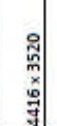 & $\begin{array}{l}0.0 \\
:\end{array}$ & 惫 & $\begin{array}{l}\text { : } \\
\vdots \\
\vdots\end{array}$ & $z$ & 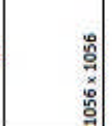 & : \\
\hline$\frac{2}{\frac{2}{2}}$ & ڤั & $\overline{3}$ & $\bar{s}$ & $\bar{s}$ & $\overline{3}$ & 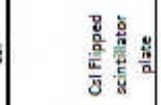 & 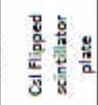 & 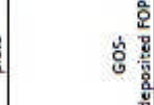 & $\bar{s}$ & $\bar{s}$ & $\bar{s}$ & $\overline{5}$ & 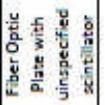 & $\bar{s}$ & $\overline{3}$ \\
\hline 递 & 这 & है & 气ू & : & 气ू & 웧 & 잏 & क्षे & ํ. & بू. & 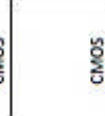 & 웧 & 影 & : & 혛 \\
\hline $\begin{array}{l}\frac{5}{5} \\
\frac{5}{4} \\
\frac{5}{2} \\
\frac{1}{2}\end{array}$ & 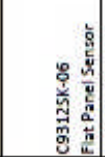 & 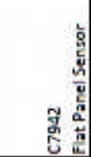 & 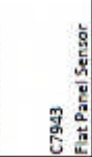 & 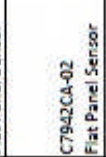 & 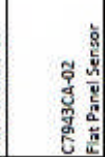 & 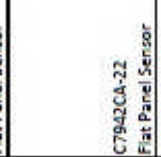 & 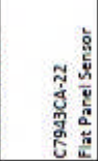 & 党 & | & 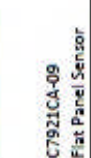 & 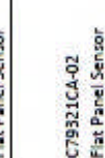 & 竎 & : & 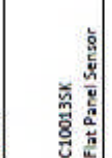 & 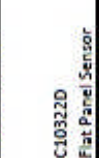 \\
\hline 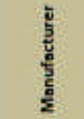 & 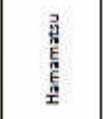 & 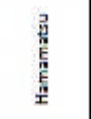 & 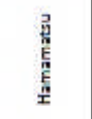 & 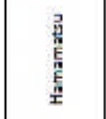 & 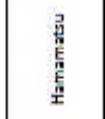 & 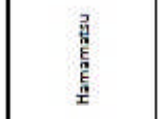 & 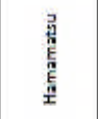 & 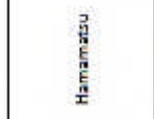 & 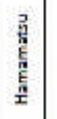 & 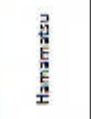 & 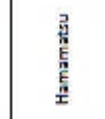 & 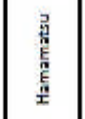 & 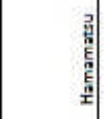 & 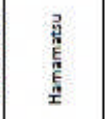 & 正 \\
\hline " & $\not$ & $\not 2$ & $\not 2$ & 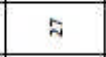 & मี & शి & 이 & $\vec{m}$ & $\tilde{m}$ & $\stackrel{m}{m}$ & 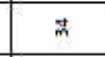 & $\stackrel{m}{m}$ & $\stackrel{\circ}{m}$ & w & 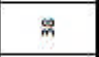 \\
\hline & & & & & & & & & & & & & & & \\
\hline
\end{tabular}




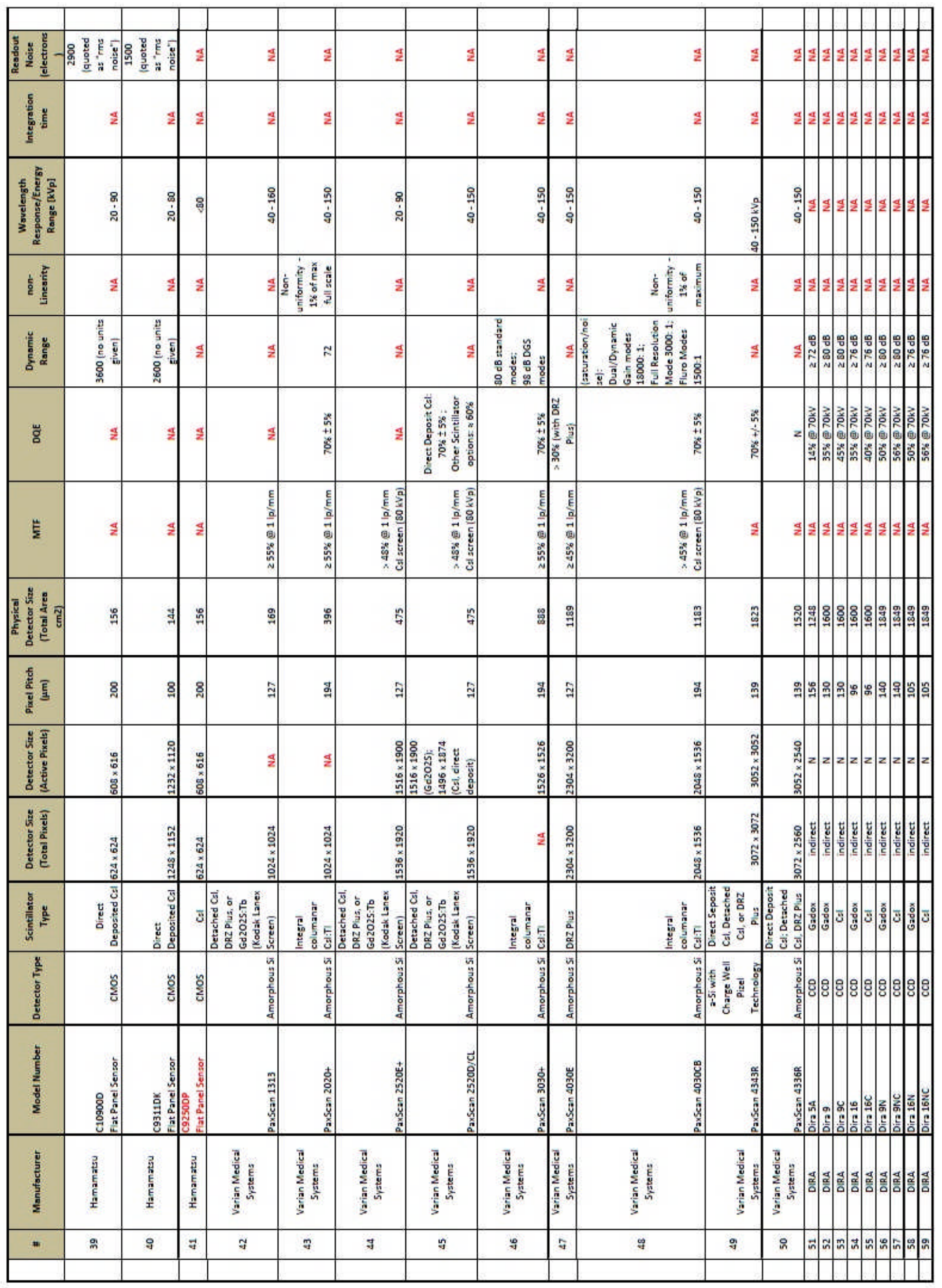




\begin{tabular}{|c|c|c|c|c|c|c|c|c|c|c|c|c|c|c|c|c|c|c|c|c|c|}
\hline & & & & & & & & & & & & & & & & & & & & & \\
\hline 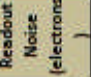 & 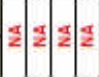 & 용 & $\frac{\pi}{2}$ & $\frac{\pi}{2}$ & $\Rightarrow$ & में & ง & 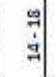 & $=2=2$ & $\Rightarrow$ & $\frac{\pi}{2}$ & 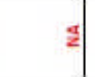 & $\frac{2}{2}$ & $=$ & $\Rightarrow$ & $\frac{\pi}{2}$ & $\frac{\pi}{2}$ & $\frac{s}{2}$ & $\frac{z}{z}$ & 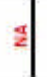 & $\frac{\pi}{2}$ \\
\hline 郎 & $\frac{2}{2}=2=\frac{1}{2}$ & 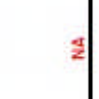 & $\frac{4}{2}$ & $\frac{4}{2}$ & $\frac{1}{2}$ & 2 & $\frac{4}{2}$ & $\frac{\pi}{2}$ & $\frac{\pi}{2} \geq \frac{\pi}{2}$ & 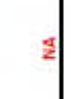 & $\frac{4}{2}$ & 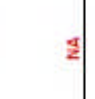 & $\frac{2}{2}$ & 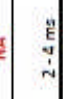 & 常 & $\begin{array}{c}: \\
\vdots \\
\vdots \\
\vdots \\
\vdots\end{array}$ & 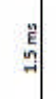 & 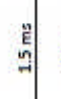 & $\begin{array}{l}\text { : } \\
\vdots \\
7\end{array}$ & 朐 & : \\
\hline 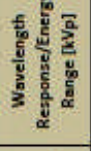 & 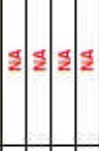 & 站 & 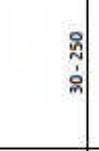 & $\begin{array}{c}\stackrel{0}{0} \\
\vdots \\
\vdots\end{array}$ & $\approx$ & 2 & 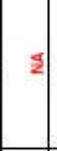 & $z$ & 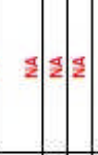 & 2 & 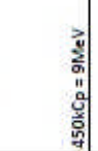 & 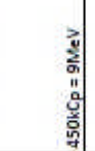 & 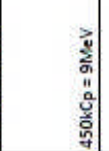 & & $\begin{array}{l}0 \\
\text { : } \\
\vdots \\
\vdots \\
0\end{array}$ & $\begin{array}{l}0 \\
\vdots \\
\vdots \\
\vdots \\
\vdots \\
\vdots\end{array}$ & 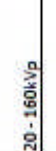 & 商 & 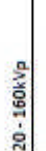 & 章 & : \\
\hline 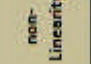 & $\frac{1}{2}=\frac{1}{2}=\frac{1}{2}$ & $\frac{4}{2}$ & $\frac{4}{2}$ & $\frac{4}{2}$ & $\frac{4}{2}$ & $\frac{4}{2}$ & $\frac{4}{2}$ & $\frac{\pi}{2}$ & $z=\frac{1}{2}=\frac{d}{2}$ & $\frac{4}{2}$ & $\frac{4}{2}$ & $\frac{4}{2}$ & $\frac{\pi}{2}$ & $\stackrel{*}{7}$ & $\stackrel{0}{7}$ & $\stackrel{\circ}{\vee}$ & $\stackrel{2}{v}$ & $\stackrel{\circ}{\vee}$ & $\stackrel{\circ}{\square}$ & 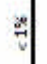 & $\because$ \\
\hline 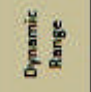 & $\frac{A}{2} \leq \mathrm{a}=\frac{\mathrm{s}}{2}$ & 哭 & : & $\begin{array}{l}0 \\
\vdots \\
\vdots \\
N\end{array}$ & $\frac{s}{2}$ & $\frac{a}{2}$ & $\frac{4}{2}$ & $\frac{\pi}{2}$ & & 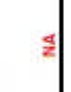 & : & 椈 & & 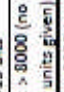 & : & 量司: & & 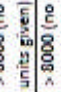 & & 包 & : \\
\hline 형 & $\frac{1}{2} \frac{\pi}{2}=\frac{1}{2}$ & $\approx$ & $\frac{2}{2}$ & $=$ & $\frac{z}{2}$ & $\frac{1}{2}$ & $\frac{\pi}{2}$ & $\frac{\pi}{2}$ & $\frac{1}{z}=\frac{A}{2}=\frac{1}{2}$ & $\approx$ & $\frac{4}{2}$ & $\frac{4}{2}$ & $\frac{z}{2}$ & $\frac{1}{2}$ & $\frac{1}{2}$ & $\frac{\pi}{2}$ & $\frac{1}{2}$ & $\frac{\pi}{z}$ & $\frac{s}{2}$ & $=1$ & $z$ \\
\hline$\frac{\mathrm{E}}{2}$ & $\frac{1}{2}=\frac{\pi}{2}=\frac{5}{2}$ & 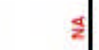 & $\frac{s}{2}$ & $\frac{\pi}{2}$ & $\frac{a}{z}$ & $\approx$ & $\frac{s}{2}$ & $\frac{a}{2}$ & $\frac{1}{2}=\frac{\pi}{2}=\frac{5}{2}$ & $\frac{s}{2}$ & 웜 & 웟 & 恕 & $\frac{ \pm}{2}$ & $\frac{ \pm}{2}$ & $\frac{s}{2}$ & $\frac{s}{2}$ & $\frac{4}{2}$ & $\frac{s}{2}$ & $\frac{s}{2}$ & z \\
\hline 语 & $\frac{1}{2} \frac{4}{2}$ & : & : & 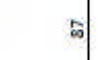 & $\frac{4}{2}$ & $\frac{4}{2}$ & $\frac{4}{2}$ & $\frac{4}{2}$ & $\frac{x}{2}=\frac{x}{2}$ & $\frac{a}{2}$ & $\frac{a}{2}$ & $\frac{a}{2}$ & $\frac{4}{2}$ & 2 & 2 & $\frac{4}{2}$ & $\frac{4}{2}$ & $\frac{4}{2}$ & $\frac{1}{2}$ & $\frac{1}{2}$ & $\frac{1}{2}$ \\
\hline$\frac{5}{\frac{5}{2}} \overline{\frac{5}{2}}$ & & & $\stackrel{2}{7}$ & 8 & $\div$ & 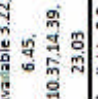 & 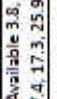 & : & & 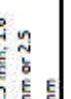 & $\stackrel{\mathrm{E}}{\mathrm{E}}$ & 占 & \begin{tabular}{c|}
$\mathrm{E}$ \\
$\mathrm{E}$ \\
G \\
\end{tabular} & ⿷ & ह & 气 & है & : & $\begin{array}{l}\mathrm{E} \\
\mathrm{E} \\
\mathrm{a}\end{array}$ & 舅 & 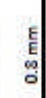 \\
\hline 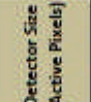 & & 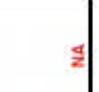 & $\frac{4}{2}$ & $z$ & $\frac{q}{2}$ & $\frac{\pi}{2}$ & $\frac{4}{2}$ & $\frac{4}{2}$ & $\frac{x}{2} \leq \frac{x}{2}$ & $\approx$ & $\frac{s}{2}$ & $z$ & $\frac{a}{z}$ & $\approx$ & 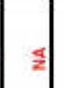 & $\frac{s}{z}$ & $\frac{\pi}{z}$ & $\frac{4}{2}$ & $\frac{\pi}{2}$ & $z$ & $z$ \\
\hline 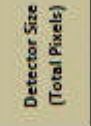 & $\frac{0}{0}$ & 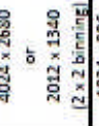 & 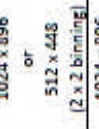 & 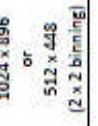 & 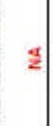 & 웜 & 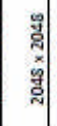 & $\begin{array}{l}\text { : } \\
\vdots \\
\vdots \\
\vdots\end{array}$ & 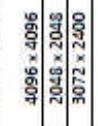 & 2 & $\frac{ \pm}{2}$ & 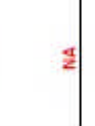 & $\frac{\pi}{2}$ & $\frac{\pi}{2}$ & $z$ & $\frac{2}{2}$ & $z$ & $\frac{\pi}{2}$ & $\frac{\pi}{2}$ & $\frac{ \pm}{2}$ & $\frac{ \pm}{2}$ \\
\hline 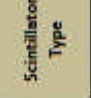 & 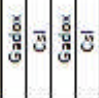 & g & : ํํㅇ & a & & 㻤 & & 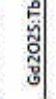 & 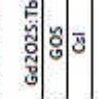 & $\frac{4}{2}$ & 高 & 产 & $\begin{array}{ll}0 \\
\vdots \\
0\end{array}$ & & t & : & & & ô & 高 & : \\
\hline 造 & 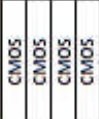 & : & 8 & 8 & 8 & e & & & & & & & & & & 费 & $\frac{\pi}{2}$ & $\frac{\pi}{2}$ & $\frac{1}{2}$ & $\frac{1}{2}$ & $\frac{4}{2}$ \\
\hline 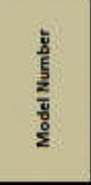 & 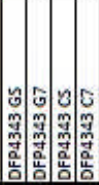 & 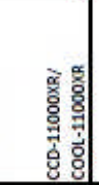 & : & 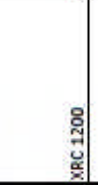 & 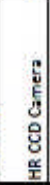 & 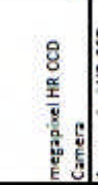 & 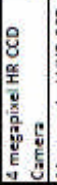 & 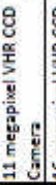 & 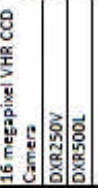 & 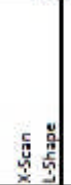 & 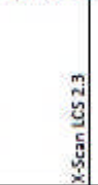 & 递 & 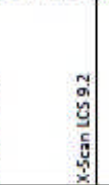 & & $\begin{array}{l}\text { 뽐 } \\
\text { a } \\
\text { : }\end{array}$ & $\begin{array}{l}\text { w. } \\
\vdots \\
\vdots \\
\vdots \\
\vdots \\
\vdots\end{array}$ & 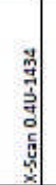 & 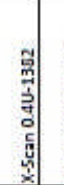 & 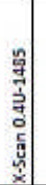 & 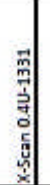 & 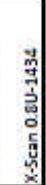 \\
\hline $\begin{array}{l}\frac{\hbar}{2} \\
\frac{d}{2} \\
\frac{d}{2} \\
\frac{5}{2}\end{array}$ & $\frac{5}{4}$ & 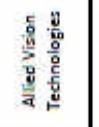 & 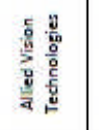 & 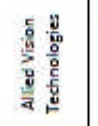 & 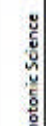 & & & : & : & 它 & & & & & & & & & & & . \\
\hline " & $|:|: \mid$ & t & : & $\stackrel{\circ}{\circ}$ & 6 & ஜ & : & 8 & $\therefore \approx \pi$ & \pm & in & 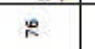 & $\approx$ & 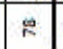 & 2 & ळ & $\vec{\omega}$ & ซ & 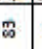 & \$ & 苟 \\
\hline & & & & & & & & & & & & & & & & & & & & & \\
\hline
\end{tabular}




\begin{tabular}{|c|c|c|c|c|c|c|c|c|c|c|c|c|c|c|}
\hline & & & & & & & & & & & & & & \\
\hline$\frac{5}{2}$ & $\frac{\pi}{2}$ & 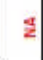 & $\mathrm{s}$ & 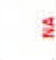 & 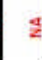 & 2 & $\Xi$ & $z=$ & & 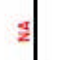 & $=$ & & 2 & 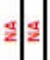 \\
\hline 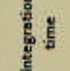 & 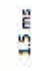 & $\approx$ & 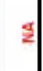 & 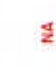 & 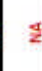 & 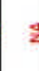 & 2 & $z=$ & & 2 & $z$ & & $\frac{y}{2}$ & 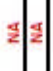 \\
\hline 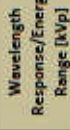 & 咅 & & 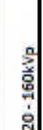 & 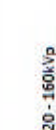 & 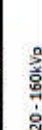 & 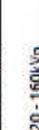 & & 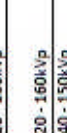 & & $\frac{1}{2}$ & 2 & & 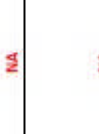 & $\geq \approx$ \\
\hline 表旁 & $\stackrel{3}{3}$ & $\stackrel{\circ}{*}$ & 북 & $\stackrel{*}{*}$ & $\stackrel{\circ}{*}$ & $\div$ & & $\because \frac{2}{2}$ & & $\frac{1}{2}$ & $\frac{s}{2}$ & & $\frac{4}{2}$ & $\frac{4}{2}=\frac{1}{2}$ \\
\hline & & $\bar{g}$ & & $\begin{array}{l}8 \\
\frac{8}{8} \\
\frac{2}{2}\end{array}$ & & 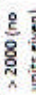 & $\frac{0}{5} \overline{5}$ & 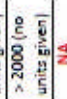 & & $\begin{array}{l}\text { : } \\
\vdots \\
\vdots \\
\text { : }\end{array}$ & 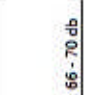 & & \begin{tabular}{l|l}
0 \\
0 \\
0 \\
0 \\
0
\end{tabular} & \begin{tabular}{l|l}
0 \\
$\vdots$ \\
0 \\
0
\end{tabular} \\
\hline ๕̆ & $\frac{s}{z}$ & $\frac{d}{z}$ & $\frac{1}{2}$ & $\frac{4}{2}$ & $\frac{\varepsilon}{2}$ & 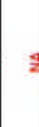 & $\frac{s}{2}$ & $\frac{\mathrm{d}}{\mathrm{z}}$ & & 煦 & $\begin{array}{l}\text { : } \\
\vdots \\
\vdots \\
\vdots \\
\vdots \\
\vdots \\
\vdots\end{array}$ & & 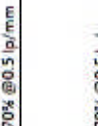 & 悬 \\
\hline$\underline{E}$ & $\frac{s}{2}$ & $\frac{\mathrm{s}}{z}$ & $\frac{1}{2}$ & $\frac{4}{2}$ & $z$ & 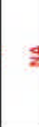 & & $=$ & & : & $\begin{array}{l}\text { ह } \\
\vdots \\
\vdots \\
\vdots \\
\vdots\end{array}$ & & : & 悬 \\
\hline 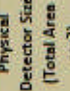 & $\frac{4}{2}$ & $\frac{ \pm}{2}$ & $\frac{s}{2}$ & $\frac{4}{2}$ & $\frac{4}{2}$ & $\frac{s}{2}$ & $\frac{4}{2}$ & $\frac{4}{2}$ & & $\approx$ & 5 & & 禺 & 8 \\
\hline 营 & 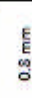 & E. & 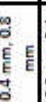 & 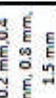 & 㚖 & 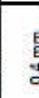 & 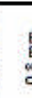 & 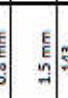 & & 원 & $\stackrel{p}{q}$ & & ? & 9 \\
\hline 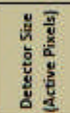 & $\frac{4}{z}$ & $\frac{ \pm}{z}$ & $\frac{s}{2}$ & $\frac{d}{z}$ & $\frac{s}{2}$ & $\approx$ & & $=\frac{2}{2}$ & & $\begin{array}{l}\text { : } \\
\text { : } \\
0 \\
0\end{array}$ & 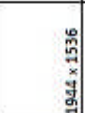 & & 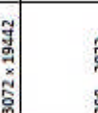 & 孃 \\
\hline 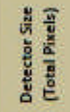 & 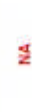 & $z$ & $\frac{ \pm}{2}$ & $\frac{4}{2}$ & 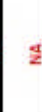 & $\frac{ \pm}{2}$ & & 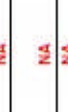 & & 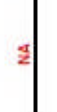 & $z$ & & $\frac{1}{2}$ & 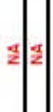 \\
\hline 总 & "ै & $\frac{1}{2}$ & $\frac{1}{2}$ & $\frac{1}{2}$ & ̆ & : & & 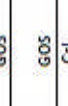 & 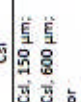 & & 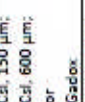 & 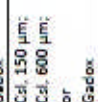 & 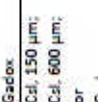 & \\
\hline 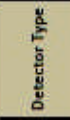 & $\frac{4}{2}$ & $\frac{d}{z}$ & $\frac{1}{2}$ & $\frac{4}{2}$ & 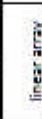 & 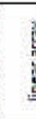 & 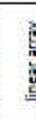 & $=$ & & 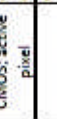 & 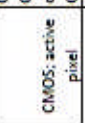 & 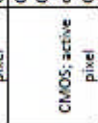 & 产 & 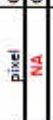 \\
\hline$\frac{\bar{y}}{\frac{\pi}{2}}$ & & & 조 & 商 & $\begin{array}{c}\frac{\pi}{3} \\
0 \\
0 \\
3\end{array}$ & $\frac{\pi}{2}$ & & 罗 & & 氮 & :ี & $\stackrel{2}{2}$ & : & 国邆 \\
\hline & 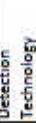 & 5 & 8 & 8 & 5 & 5 & & & & 焉 & 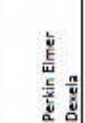 & 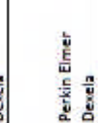 & 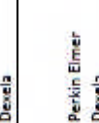 & 啇 \\
\hline * & $\stackrel{\circ}{\circ}$ & ธ & 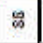 & ஜூ & \& & व & $\approx$ & \% & 品 & & ஃ & aे & ๘ & क \\
\hline
\end{tabular}




\section{Part II: Scintillators (2 pages)}

The tables below present the results of a survey of scintillators used in x-ray imaging devices. The survey is not exhaustive but reasonably presents a collection of the more common items used. Each vendor provides a data sheet that contains information that it regards as useful to the consumer and may not publish other information because of proprietary concerns. As such, the technical specifications which are publicly available vary considerably. The table's intent was to highlight important operating parameters of each device. Unfortunately, because of the large variability in data sheet content, many entries are listed as "not available" (NA). 


\begin{tabular}{|c|c|c|c|c|c|c|c|c|c|c|c|c|c|c|c|c|c|c|c|c|}
\hline & & & & & & & & & & & & & & & & & & & & \\
\hline $\begin{array}{l}\text { : } \\
\frac{\mathrm{E}}{8}\end{array}$ & & & & 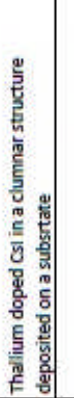 & 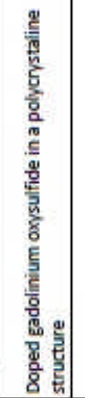 & & 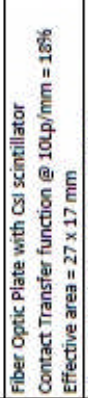 & 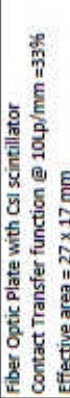 & 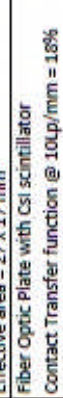 & 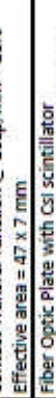 & 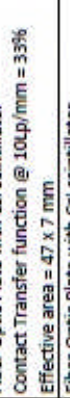 & 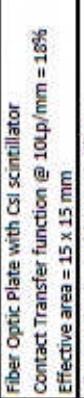 & 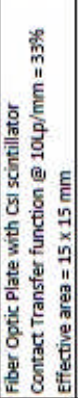 & 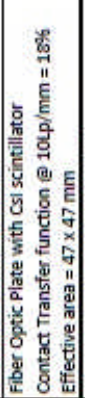 & 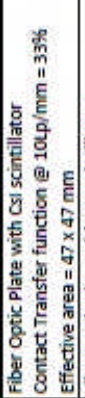 & 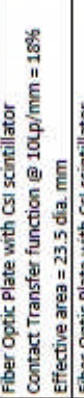 & 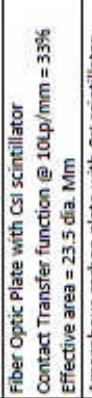 & 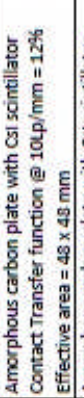 & 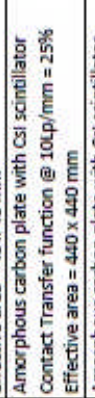 & 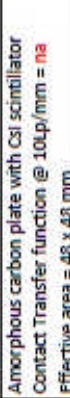 \\
\hline 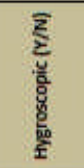 & 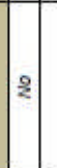 & & & $\frac{1}{2}$ & $\frac{1}{z}$ & $\frac{1}{2}$ & $\frac{d}{2}$ & $\frac{1}{2}$ & & $\approx$ & 2 & $\frac{1}{2}$ & $z$ & 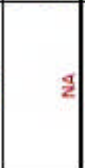 & $\frac{\pi}{2}$ & $\frac{4}{2}$ & $\frac{1}{2}$ & $\frac{1}{2}$ & $\frac{\pi}{2}$ & $\frac{1}{2}$ \\
\hline 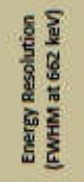 & $\frac{\pi}{2}$ & & & $\frac{s}{2}$ & $\frac{\pi}{2}$ & $\frac{1}{2}$ & 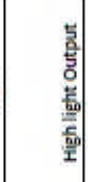 & 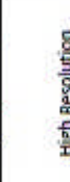 & & 言 & 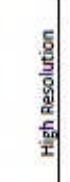 & 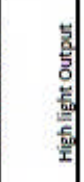 & 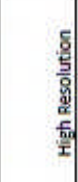 & 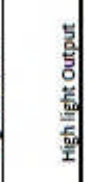 & 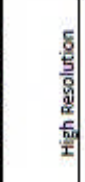 & 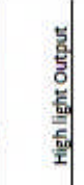 & 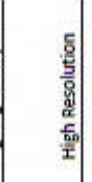 & 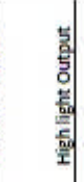 & 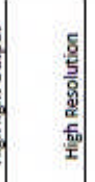 & . \\
\hline 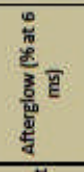 & $\rightarrow$ & & & 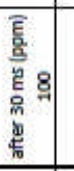 & 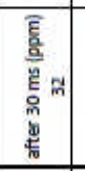 & 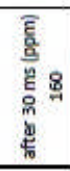 & $\frac{s}{2}$ & $\frac{1}{2}$ & a) & 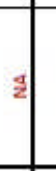 & $z$ & $\frac{s}{2}$ & $\frac{s}{2}$ & $z$ & $\frac{s}{2}$ & $\frac{\mathrm{s}}{2}$ & $\frac{s}{2}$ & $\frac{s}{2}$ & $\frac{s}{2}$ & $z$ \\
\hline 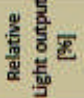 & & & & 욤 & 8 & q & 요 & q & & 인 & q & 인 & q & 요 & 의 & 인 & \& & 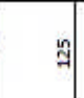 & 응 & ந \\
\hline 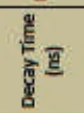 & 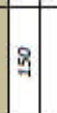 & & & : & 8 & 8 & 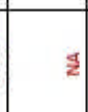 & $z$ & & $\frac{1}{2}$ & $z$ & $\frac{\pi}{2}$ & $\mathrm{z}$ & $z$ & $z$ & $z$ & $\frac{\xi}{2}$ & $z$ & $\frac{s}{2}$ & 2 \\
\hline 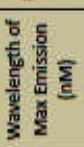 & : & & & $\mathrm{z}$ & $\mathrm{z}$ & $\underline{z}$ & $z$ & z & & 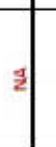 & $\mathrm{z}$ & $z$ & $z$ & $z$ & $\mathrm{z}$ & $\mathrm{z}$ & $\mathrm{s}$ & $\mathrm{z}$ & 2 & 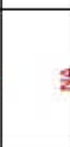 \\
\hline 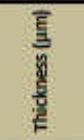 & ఫ्वे & & & $\begin{array}{l}8 \\
\vdots \\
\vdots \\
\vdots\end{array}$ & $\begin{array}{l}8 \\
\vdots \\
\vdots \\
\vdots\end{array}$ & $\begin{array}{l}\text { ष्ष } \\
\dot{8}\end{array}$ & 욤 & I & & 号 & : & 영 & 용 & : & : & 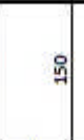 & : & : & : & 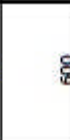 \\
\hline 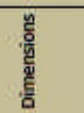 & & & & 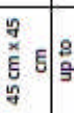 & 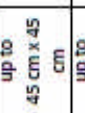 & 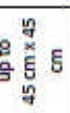 & 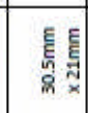 & 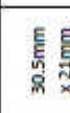 & & 㝕 & 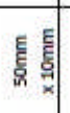 & 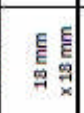 & 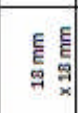 & 点总 & 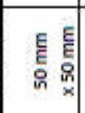 & 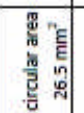 & 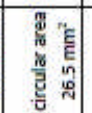 & 舆 & 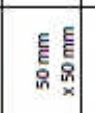 & 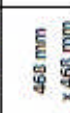 \\
\hline 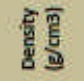 & 7 & & & aे & 苞 & $\stackrel{9}{\sim}$ & $\frac{d}{2}$ & & $\frac{\pi}{2}$ & $\frac{1}{2}$ & $z$ & $\frac{1}{2}$ & $\frac{s}{2}$ & $\approx$ & $\frac{\mathrm{s}}{2}$ & $\frac{s}{2}$ & $\frac{s}{2}$ & $\frac{s}{2}$ & $\frac{s}{2}$ & $\frac{S}{2}$ \\
\hline 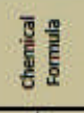 & 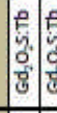 & : & 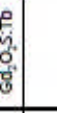 & $\bar{y}$ & $\frac{0}{5}$ & हैं & 立 & $\frac{\bar{E}}{\overline{8}}$ & 㖣 & 目 & 氞 & 氧 & 島 & 氞 & 氞 & E & 㖣 & 氞 & 흫 & 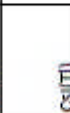 \\
\hline 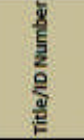 & 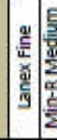 & 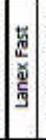 & 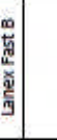 & $\frac{4}{2}$ & $\frac{\mathrm{z}}{\mathrm{z}}$ & $\frac{1}{2}$ & 音 & & 章 & 思 & : & : & 蒿 & 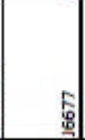 & : & : & $\begin{array}{l}\mathbf{b} \\
\vdots \\
0 \\
0\end{array}$ & 蔓 & t: & 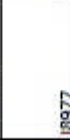 \\
\hline 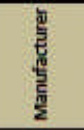 & 善 & & 善 & 薏 & 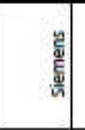 & 遶 & 离 & & & & 离 & 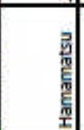 & 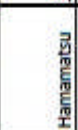 & 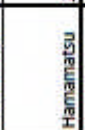 & 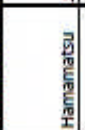 & 리 & 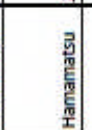 & & 蹵 & \\
\hline " & $\rightarrow$ & $m$ & व & in & • & n & $\infty$ & a & ? & 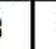 & F & $\approx$ & $m$ & $\nexists$ & $\Rightarrow$ & : & $A$ & 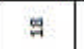 & 9 & ㅇ \\
\hline & & & & & & & & & & & & & & & & & & & & \\
\hline
\end{tabular}




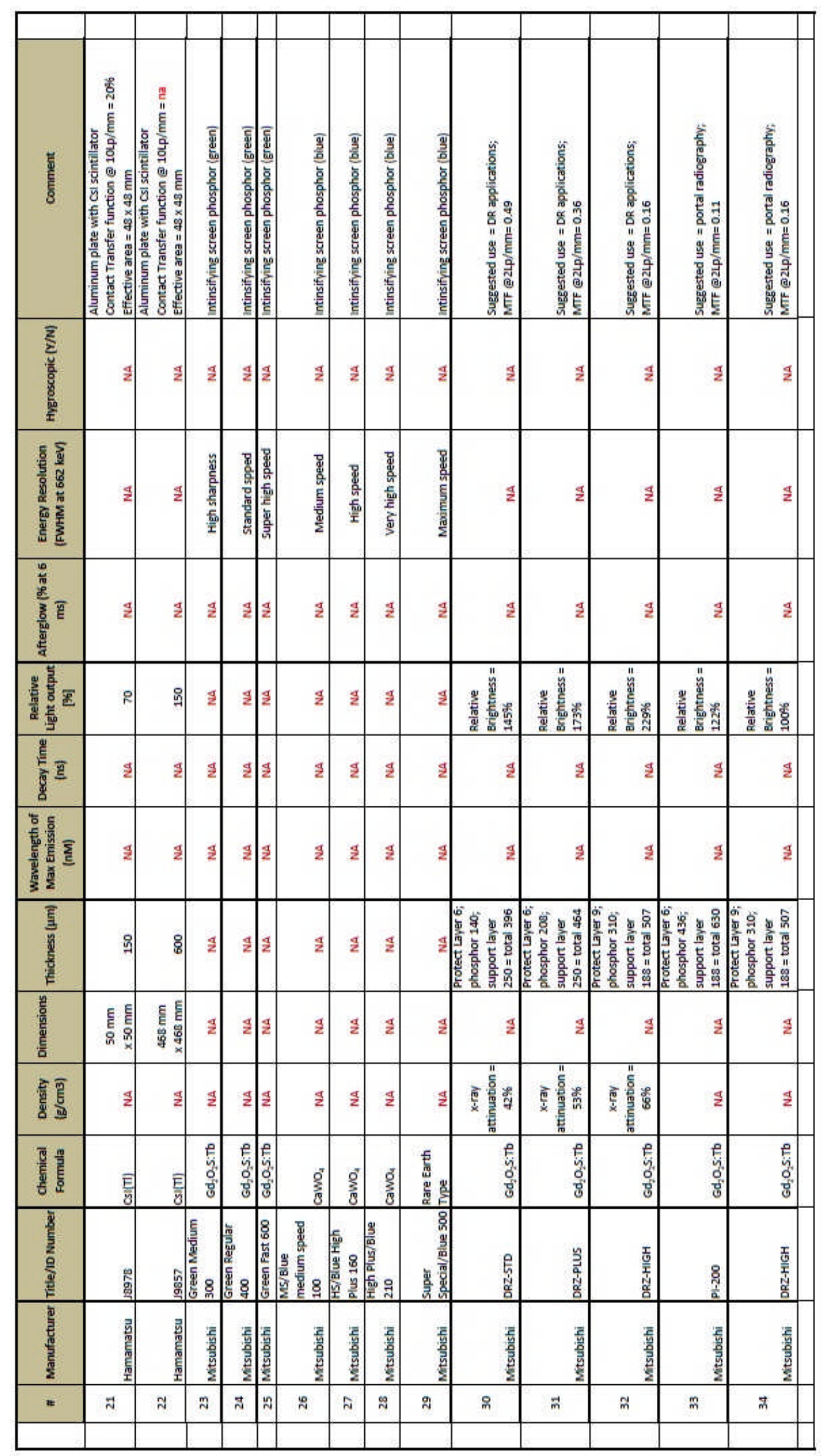




\section{Appendix viii: Titles}

Robert G. Lanier

January 13, 2012

In researching imaging technologies, a number of articles were uncovered that might be appropriate for individuals interested in pursuing additional information on technologies that are either in the process of maturing or undergoing investigation because of their future promise to imaging applications. The list represents only a handful of articles encountered during this literature search and no particular criteria were applied in their selection except that they appeared to speak to aspects of imaging technology.

The list identifies the title of the article, the author list and the web address where the text of the article may be found. 


\section{Development of an LYSO based gamma camera for positron and scinti-mammography}

H-C Liang ${ }^{\mathrm{a}, \mathrm{b}}$, M-L Jan ${ }^{\mathrm{a}}, \mathrm{W}-\mathrm{C} \operatorname{Lin}^{\mathrm{a}}, \mathrm{S}-\mathrm{F} \mathrm{Yu}^{\mathrm{a}}, \mathrm{J}-\mathrm{L} \mathrm{Su}^{\mathrm{b}}$ and L-H Shen ${ }^{\mathrm{a}}$

http://iopscience.iop.org/1748-0221/4/08/P08009/pdf/1748-0221 408 P08009.pdf

\section{Comparative evaluation of single crystal scintillators under $\mathrm{x}$-ray imaging conditions}

OPEN ACCESS 4th International Conference on Imaging Technologies in Biomedical Sciences

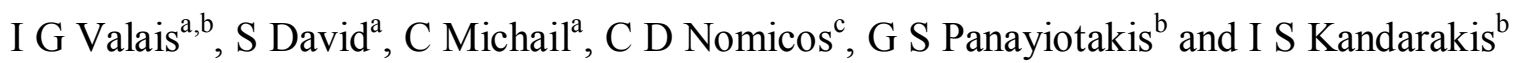

http://iopscience.iop.org/1748-0221/4/06/P06013/pdf/1748-0221 406 P06013.pdf

\section{A new x-ray imaging technique for radiography mode of flat-panel imager}

Proc. SPIE 6510, 651047 (2007); doi:10.1117/12.709079

Jiang Hsieh, Michael J. Flynn K. Suzuki, S. Ikeda, and K. Ueda ; Hitachi Medical Corp. (Japan)

R. Baba Hitachi Ltd. (Japan)

http://scitation.aip.org/getpdf/servlet/GetPDFServlet?filetype=pdf\&id=PSISDG0065100000016

$\underline{51047000001 \& \text { idtype }=\text { cvips \&doi=10.1117/12.709079\&prog=normal }}$

\section{On the Development of Digital Radiography Detectors : A Review}

Ho Kyung Kim, Ian Alexander Cunningham, Zhye Yin and Gyuseong Cho

http://www.imaging.robarts.ca/ icunning/SiteResources/publications/2008\%20ijpem\%200986\%20Kim\%20Review.pdf

\section{Inorganic Scintillators in Positron Emission Tomography}

Carel W.E. van Eijk* 
http://www.springerlink.com/content/4227881124t1x170/fulltext.pdf

\section{Development of High-image Quality and High Durability Direct Conversion Digital Radiography System "FDR AcSelerate"}

Hirotaka Watano, Fumito Nariyuki, Shiniji Imai, Toshiyuki Nabeta, Uyichi Hosoi, Tetsuya Tsuji, Keita Watanabe, Jun Enomoto and Masaru Sato.

http://www.fujifilm.com/about/research/report/055/pdf/index/ff_rd055_002_en.pdf

\section{Proposal of New Organic CMOS Image Sensor for Reduction in Piel Size}

Mikio Ihama, Tetsurou Mitsui, Kamiatsu Nomura, Yoshiki Maehara, Hiroshi Inimata, Takashi Gotou and Yutaka Takeuchi

http://www.fujifilm.com/about/research/report/055/pdf/index/ff_rd055 004_en.pdf

\section{Advantages and Use of CdZnTe Detectors in Safeguards Measurements}

Rolf Arlt, Victor Ivanov and Kevin Parnham

http://www.evmicroelectronics.com/pdf/Applications/Advantages\%20and\%20use\%20of\%20Cd $\underline{\text { ZnTe.pdf }}$

\section{Performance evaluation of D-SPECT: a novel SPECT system for nuclear cardiology}

Kjell Erlandsson1, Krzysztof Kacperski, Dean van Gramberg and Brian F Hutton

http://iopscience.iop.org/0031-9155/54/9/003/pdf/0031-9155 549 003.pdf

\section{Quantum Dot Composite Radiation Detectors}

Mario Urdaneta, Pavel Stepanov, Irving Weinberg, Irina Pala and Stephanie Brock2 
http://www.intechopen.com/source/pdfs/17231/InTech

Quantum dot composite radiation detectors.pdf

\title{
CZT detector in multienergy $x$-ray imaging with different pixel sizes and pitches: Monte Carlo simulation studies
}

Yu-Na Choi, Hee-Joung Kim*, Hyo-Min Cho, Chang-Lae Lee, Hye-Suk Park, Dae-Hong Kim, Seung-Wan Lee, Hyun-Ju Ryu

http://scitation.aip.org/getpdf/servlet/GetPDFServlet?filetype=pdf\&id=PSISDG0079610000017 $\underline{9614 \text { H000001\&idtype }=\text { cvips } \& \text { doi }=10.1117 / 12.878357 \& \text { prog }=\text { normal }}$

\section{Large-area mercuric iodide $x$-ray imager}

G. Zentai, L. Partain, R. Pavlyuchkova, G. Virshup, A. Zuck, L. Melekhov, O.Dahen, A.Vilensky and H. Gilboa

http://independent.academia.edu/GeorgeZentai/Papers/665079/Large area mercuric iodide $\underline{\text { X-ray imager }}$

\section{Comparison of Mercuric Iodide and Lead Iodide X-Ray Detectors for X-Ray Imaging Applications}

G. Zentai, Member, L. Partain, R. Pavlyuchkova, C. Proano, M. Schieber, K. Shah, P. Bennett, L. Melekhov, and H. Gilboa

http://ieeexplore.ieee.org/stamp/stamp.jsp?arnumber=01710230

\section{X-ray detection using bulk GaAs}

\author{
A.D. Holland, A.D.T. Short, and T. Cross \\ http://pdn.sciencedirect.com/science? ob=MiamilmageURL\& cid=271580\& user=8139564\& \\ pii $=0168900294907242 \&$ check=y\& origin=article \& zone=relatedPdfPopup\& coverDate $=1994$ \\ -07-15\&piiSuggestedFrom $=$ S0168900296003464\&wchp=dGLzVIV- \\ zSkzS\&md5=39cd119877d6a983fa11423020acde28/1-s2.0-0168900294907242-main.pdf
}




\section{Review of X-ray Detectors for Medical Imaging}

Martin Hoheisel

http://www.esrf.eu/events/conferences/IWORID7/FinalProgramme/hoheisel_1.pdf

\section{Comparison of HgI, CdTe and Si (p-i-n) X-ray detectors}

J.S. Iwanczyk, B.E. Patt, Y.J. Wang, A. Kh. Khusainov

http://pdn.sciencedirect.com/science? ob=MiamilmageURL\& cid=271580\& user $=8139564 \&$ pii=S0168900296004949\& check=y\& origin=article\& zone=toolbar \& coverDate=01-Oct$1996 \&$ view=c\&originContentFamily=serial \&wchp=dGLbVIVzSkWb\&md5=1ea23beb72501f529ea5395acad969fa/1-s2.0-S0168900296004949-main.pdf

\section{Amorphous and Polycrystalline Photoconductors for Direct Conversion Flat Panel X-Ray Image Sensors}

Safa Kasap, Joel B. Frey, George Belev, Olivier Tousignant, Habib Mani, Jonathan Greenspan, $\underline{\text { Luc Laperriere, }}$ Oleksandr Bubon, Alla Reznik, Giovanni DeCrescenzo, Karim S. Karim and John A. Rowlands

http://www.mdpi.com/1424-8220/11/5/5112/ 